\title{
Effect of Passive Flow Control on the Aerodynamic Performance, Entropy Generation and Aeroacoustic Noise of Axial Turbines for Wave Energy Extractor
}

\author{
Ahmed S. Shehata ${ }^{1,2 *}$, Qing Xiao ${ }^{1}$, Mohamed A. Kotb ${ }^{2}$, Mohamed M. Selim ${ }^{2,3}$, A.H. \\ Elbatran$^{2}$, Day Alexander ${ }^{1}$ \\ 1) Department of Naval Architecture, Ocean and Marine Engineering, University of Strathclyde, Glasgow G4 OLZ, \\ U.K \\ 2) College of Engineering and Technology, Arab Academy for Science Technology and Maritime Transport, P.O. \\ 1029 AbuQir, Alexandria, Egypt \\ 3) Material Science and Engineering, University of Alabama at Birmingham, Birmingham, AL, U.S.A \\ *Corresponding Author: Ahmed S. Shehata E-mail address: a_samir@aast.edu
}

\section{ABSTRACT}

Wells turbine is the simplest type of an axial flow self-rectifying air turbine that can be used in conjunction with Oscillating Water Column (OWC) system in the extraction of ocean wave energy. It has been noticed that this turbine is subjected to early stall. As a consequence, several attempts for improving the energy extraction performance of Wells turbine within the stall regime have been investigated. One of these attempts was using an inclined slot as a passive flow control to obtain a delayed stall. In the following study, the impact of varying the angle for the slot on the performance of Wells turbine in the stall regime was investigated. Furthermore, the first law of thermodynamics and the entropy analysis has been used to examine the effect of the slot angle on the entropy generation features around the turbine blade. Moreover, Investigation of slot angle effect on the aerodynamics noise emission from Wells turbine airfoil during the normal operation and the stall regime is covered in this study. The blade of turbine with optimum angle of slot was investigated using the OWC based on actual data from the Egyptian Northern Coast. It was found that the optimum slot angle is 10 degrees clockwise which results in $3 \%$ improvement in the torque coefficient before the stall and $15 \%$ after the stall as compared to the 0 degree slot. Otherwise, it gives a lower global entropy generation rate than the 0 degree slot by $4 \%$ before the stall and $3 \%$ after the stall. Furthermore, using airfoil of blade turbine with a slot resulted in a reduction of aeroacoustic noise by $-21.2 \%$ at the stall regime under oscillating flow conditions. 
1 Keywords: Oscillating flow; Wave turbine; Passive Flow Control; Entropy generation;

2 Aeroacoustic Noise; Egyptian Coasts.

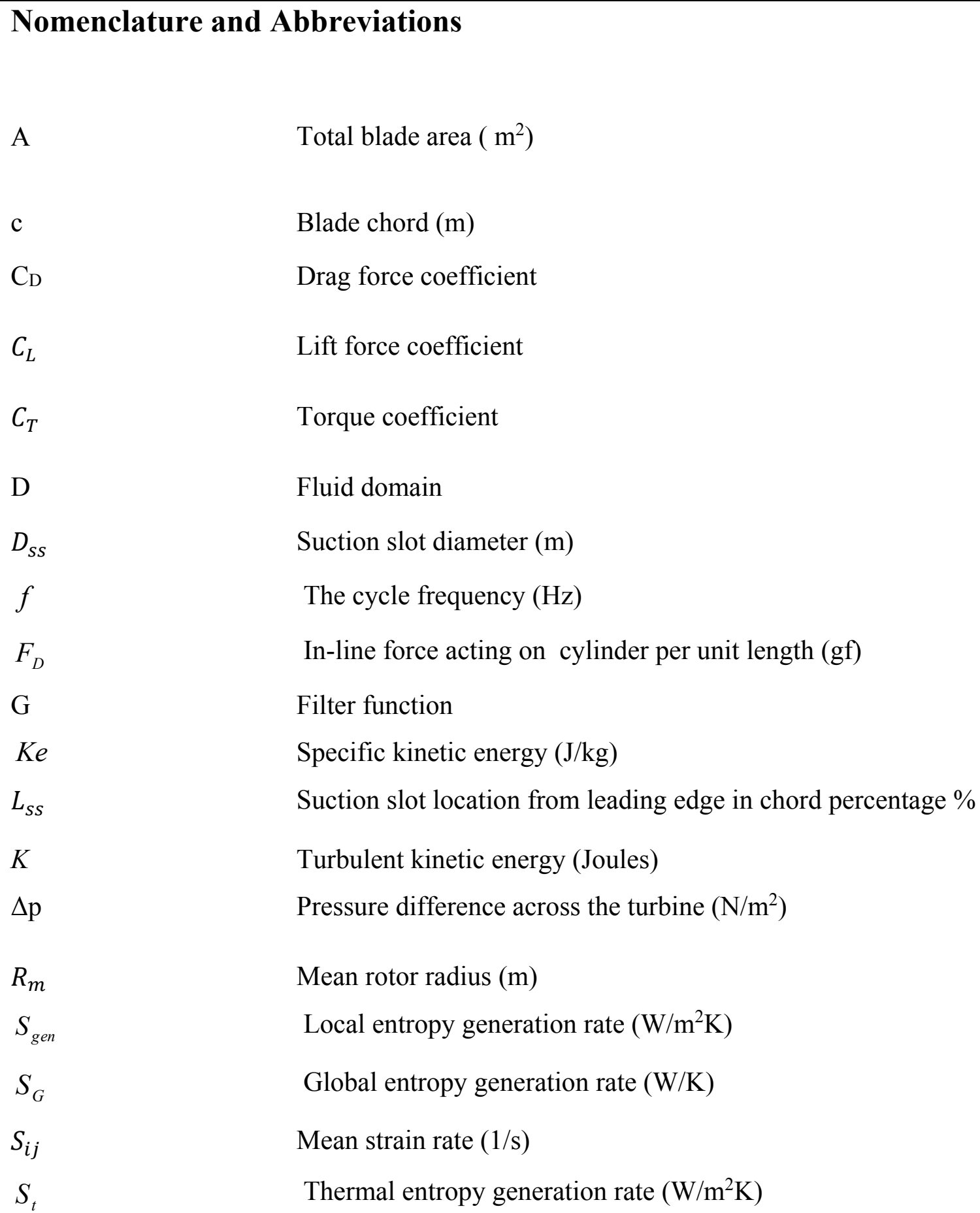




\begin{tabular}{|c|c|}
\hline$S_{V}$ & Viscous entropy generation rate $\left(\mathrm{W} / \mathrm{m}^{2} \mathrm{~K}\right)$ \\
\hline$T_{o}$ & Reservoir temperature $(\mathrm{K})$ \\
\hline$t_{\sin }$ & Time period for sinusoidal wave $=1 / f$ (second) \\
\hline $\bar{u}_{i}$ & Reynolds Averaged velocity component in i direction $(\mathrm{m} / \mathrm{s})$ \\
\hline$V$ & Volume of a computation cell $\left(\mathrm{m}^{3}\right)$ \\
\hline$V_{a}$ & Instantaneous Velocity $(\mathrm{m} / \mathrm{s})$ \\
\hline$V_{a m}$ & highest speed of axial direction $(\mathrm{m} / \mathrm{s})$ \\
\hline$V_{o}$ & Initial velocity for computation $(\mathrm{m} / \mathrm{s})$ \\
\hline$\dot{W}$ & Net-work transfer rate $(\mathrm{W})$ \\
\hline$\dot{W}_{r e v}$ & Reversible work (W) \\
\hline$\alpha_{S S}$ & Angle of suction slot (Degree) \\
\hline$\eta_{F}$ & Efficiency in first law of thermodynamics \\
\hline$\eta_{S}$ & Second law efficiency \\
\hline$\mu$ & Viscosity $(\mathrm{Kg} / \mathrm{m} . \mathrm{s})$ \\
\hline$\mu_{t}$ & Turbulent viscosity (N.s/ $\left.\mathrm{m}^{2}\right)$ \\
\hline$\rho$ & Density $\left(\mathrm{Kg} / \mathrm{m}^{3}\right)$ \\
\hline $\bar{\emptyset}$ & Flow coefficient \\
\hline$\omega$ & Rotor angular speed $(\mathrm{rad} / \mathrm{sec})$ \\
\hline$\left(-\overline{\rho u_{i}^{\prime} u_{j}^{\prime}}\right)$ & Reynolds stress tensor \\
\hline CFD & Computational Fluid Dynamics \\
\hline NACA & National Advisory Committee for Aeronautics \\
\hline OWC & Oscillating Water Column \\
\hline
\end{tabular}




\section{Introduction}

The main challenge facing the wave energy extraction devices with oscillating water 3 column system is to find an economical and efficient means of converting bidirectional flow from the waves motion to unidirectional rotary motion for driving electrical generators [1-3], as seen in

Figure 1 A. A self-rectifying air turbine such as Wells turbine, see Figure 1 B, [4-9] can be used 6 to extract the energy from the oscillating air column [10-15]. Wells turbine suffers low 7 performance problem at stall condition [10,16-21] which is a remarkable subject that needs to be explored and improved. In case of large angles of attack and that means large flow rates, the separation area will be increased on the blade due to the separate boundary layers, which decrease

10 the value of torque coefficient and thus the efficiency. The reason behind that, is the decrease in 11 the lift value and also a big increase in the drag value. From references $[10,22,23]$ it can be 12 concluded that Wells turbine can produce energy at relatively low air flow rate, when other types 13 of turbines con not [22, 24, 25]. Furthermore, the aerodynamic efficiency increases with the 14 increase of the angle of attack or the flow coefficient up to an appointed value, after that it 15 decreases. Thus, most of the previous studies $[10,26]$ aimed to improve the torque coefficient (the 16 turbine output) and improve the turbine performance during the stall condition.

The following references [27-29] noted that the delay of stall beginning contributes to improved Wells turbine performance. Employing guide vanes on the rotor's hub can achieve this 19 delay [27, 30, 31]. It was found that adding guide vanes to a multi-plane turbine increases the efficiency by approximately $20 \%$ compared to the one without guide vanes. Setoguchi et al., [32] carried out a comparison between Wells turbines having two and three dimensional guide vanes. By performing a steady flow testing of Wells turbine model, and using numerical computer 23 simulation (quasi-steady analysis), it was observed that the three dimensional case has superior 24 characteristics in the starting and running characteristics. At high pressure values, usually a multi 25 plane Wells turbine systems are used. Such configuration avoids the need for guide vanes and, 26 therefore the turbine would require less maintenance and repairs [27]. The performance of a 27 biplane Wells turbine is based on the gap between the two turbines as described in [27]. It was 28 recommended that a gap-to-chord ratio between the two turbines was 1.0. References [33, 34] 29 investigated experimentally the effects of rotor solidity and blade profile on hysteretic behavior of 30 Wells turbine operating under bi-directional airflow. It is noticed that reducing rotor solidity leads 
1 to decreasing the size of hysteretic loop of pressure coefficient. In order to investigate the relation

2 between the hysteretic behavior of Wells turbine and the rotor solidity, setting angles, and blade 3 thickness, Computational Fluid Dynamics (CFD) simulations were proceed for the flow field 4 around a single blade of a Wells turbine by the following references [35, 36]. Therefore, Torresi 5 et al., [37] studied in details the flow-field characteristics through a high solidity $(\sigma=0.64)$ Wells turbine using blades with constant chord NACA0015 profiles. For high flow rate values, a radical shift of the mass flow through the turbine due to the cascade effect [38] occurs. This leads to flow separation at the outer radii. [39] and experimentally with quasi-steady analysis by [40]. As a result, it was concluded that the 11 Wells turbines performance was affected by the blade sweep area. Paderi M. et al., [41] carried 12 out the experimental characterization of Wells turbine with NACA0015 profiles submitted to a bi13 directional flow, the results also are presented and analyzed the study mentioned in [41]. For 14 various test conditions, the maximum efficiency of the turbine (from $30 \%$ to $43 \%$ ) takes place for 15 the flow coefficient values between 0.19 and 0.21 . A modified Wells turbine with setting angle 16 has been examined by prototype testing and numerical modeling in [42]. It was proven that the 17 modified turbine using blades with a specific setting angle is superior to the normal Wells turbine, 18 and that the optimum setting angle was 2 degrees for compression velocity amplitude to suction 19 velocity ratios of 0.6 and 0.8 , in both with guide vanes and without guide vanes configurations. Exergy analysis has been performed in [43] using the CFD for biplane Wells turbines [7, $2144]$ in steady state where the rotor of the upstream flow has a design point of 0.82 second law 22 efficiency, however the downstream rotor has second law efficiency equals 0.61 . The entropy 23 generation rate, due to viscous dissipation, around different two dimension airfoil sections for 24 Wells turbine blade was studied in [45, 46]. It was observed that, when Reynolds number was 25 increased from $6 \times 10^{4}$ till $1 \times 10^{5}$ the total entropy generation rate increased accordingly more than 26 double for tested airfoils. Although, Reynolds number was increased further to $2 \times 10^{5}$, the total 27 entropy generation rate showed values ranging from 0.25 reduction to 0.2 increase compared to 28 corresponding values at Reynolds number of $1 \times 10^{5}$. For the four different airfoils, the efficiency in compression cycle is higher than that in suction cycle at angle of attack equals to 2 degrees. On

30 contrast, the efficiency for suction cycle was more than the compression cycle with the increase of 31 angle of attack. The researchers in references $[45,46]$ suggested that a possible existence of critical 
1 Reynolds number at which viscous entropy takes least values. A comparison of the entropy 2 generation characteristics between a Wells turbine with a variable chord design and another one with a constant chord was investigated in [47]. The detailed results demonstrated that static pressure difference around new blade is increased and that the value of entropy generation 5 throughout the total running range is decreased also by average $26.02 \%$. Second law analysis of a Wells turbine was numerically performed using the Open FOAM in [48] to express its optimal performance and show how irreversibility factors lead to exergy destruction and also second law 8 efficiency reduction. The dielectric barrier discharge (DBD) plasma actuator is applied in the trailing edge of the turbine blade in order to improve performance and reduce aerodynamic load. It can be noted that by applying plasma the average increase in torque coefficient was about

12 plasma be applied in the flow coefficients almost equal to ones that cause the stall, in which case $1339.56 \%$ increment is observed in the first law efficiency. However, the second law efficiency 14 increases about $39.16 \%$ without considering viscous dissipation term and decreases about $64.63 \%$ 15 with considering the viscous dissipation term. The effects of blade thickness on the performance 16 of a Wells turbine are investigated based on aerodynamic and entropy generation analysis in [49].

17 Two kinds of blade profiles are being investigated, a constant thickness blade and a variable 18 thickness blade. The computation is performed by solving the 3D steady incompressible Reynolds19 averaged Navier-Stokes equations. The results show the interaction between tip leakage vortex 20 and suction surface of the blade is substantially reduced by using the variable thickness blade. The 21 results reveal that entropy generation seems to give an advantageous effect of reducing the 22 separation at the tip section of the variable thickness blade in the deep stall condition. At most, a $2363.37 \%$ increase in torque coefficient and $72.8 \%$ increase in efficiency are achieved by the variable 24 thickness blade in the deep stall condition. The majority of the researchers, who investigated the 25 performance of various airfoil designs and various operational conditions, were analyzing the 26 problem based only on the first law of thermodynamic parameters. However, it is essential to take 27 into account the second law of thermodynamic in order to form a thorough understanding, since it 28 was proven to show highly hopeful results in many similar systems, such as gas turbine in [50, 29 51], and wind turbine in [52-55].

30 Techniques were developed to manipulate the boundary layer, either to increase the lift or 31 decrease the drag, they are classified under the general heading of boundary layer control or flow 
control[56, 57]. Methods of flow control to achieve separation postponement, lift enhancement

2 and drag reduction have been considered in these studies. Such studies have demonstrated that adding suction slot could modify the pressure distribution over an airfoil surface and have an essential impact on both the lift and drag coefficients [58-63]. Also, many studies have been conducted to draw on flow control techniques. Prandtl, 1904, [64] was the first scientist who used boundary layer suction on a cylindrical surface to delay the separation of boundary layer. The oldest recognized experimental studies on boundary layer suction for wings were conducted in the 8 late 1930 and the 1940 [65-67]. Huang et al., [68] investigated both suction and blowing flow control mechanism on an airfoil with NACA 0012 section profile. When jet location and angle of attack were combined, perpendicular suction at the leading edge increased lift coefficient more than other suction situations. Furthermore, the downstream locations with tangential blowing have the maximum increase rate in the lift coefficient. Rosas in [69] was numerically investigated flow separation control through oscillatory fluid injection, in which lift coefficient was increased. The authors in [70] studied the optimization of synthetic jet parameters on a NACA 0015 airfoil to increase the lift and decrease the drag in different angles of attack. It can be concluded that the optimum location for the jet moved toward the leading edge, in addition the optimum angle for the

17 jet increased with the increment of angle of attack. The CFD method has been widely used to study 18 the technique of boundary layer control. Many flow control studies by CFD approaches [71-73] 19 have been conducted to study the blowing and suction jets effects on the aerodynamic performance 20 of blade or wing airfoils.

Aiming at minimizing the overall environmental impact of oscillating water column technology requires a new effort to reduce the aeroacoustic noise associated with Wells turbine operation [74]. A new blade design methodology for a Wells turbine with skewed blades is investigated by $[74,75]$ to be very successful for reducing noise and vibrations. The flow generated sound in normal operation (unstalled) was decreased up to $3 \mathrm{~dB}$ by optimal backward/ forward blade skew. The vast majority of the researchers and investigations focused on the aerodynamic 27 noise prediction for wind turbine [76-81] and around an airfoil [82-88]. However, no study until now study the aeroacoustic noise prediction or reduction of Wells turbine at stall and near-stall conditions under oscillating flow conditions, even, the only research group for the aerodynamic 30 noise prediction of Wells turbine mentioned be in [74, 75], assumed that Wells turbine work under unidirectional flow with steady state condition. 
One of the best locations for applying the Wells turbine energy extractor as OWC system

2 is the Egyptian Northern Coast. The Egyptian Coast is considered the most energetic coast of the 3 Southern Mediterranean Basin, lying between the Nile Delta and the Libyan borders with a 4 potential of above $6.8 \mathrm{~kW} / \mathrm{m}$ wave power in winter season and $3.4 \mathrm{~kW} / \mathrm{m}$ in summer season [89, $590]$ and the wave energy of about $36003 \mathrm{kWh} / \mathrm{m}$. The most active sea states have wave heights ranging from 1 to $4 \mathrm{~m}$ and wave periods between 4 and $8 \mathrm{~s}$. The sea wave in Egypt is comparatively low but on the other hand stable and that are the significant differences between the sea in Egypt and other locations. Subsequently, the potential wave energy can be revealed and exploited [91]. Otherwise, sea states with the wave heights more than $5 \mathrm{~m}$ are not very effective for the annual power [92].

The objective of the present work is to demonstrate the performance of Wells turbine at stall and near-stall conditions which can be effectively improved by using passive flow control technique such as blowing and suction slot with different angles. This is achieved by conducting CFD based first and second law analysis for the Wells turbine airfoil, without and with slot which has different angles, under oscillating and non-oscillating flow conditions. A typical slot is attached to the airfoil profile section, normal to the chord length, and due to the pressure difference between the two surfaces, a suction effect occurs which delays the stall. Hence, there is no need to generate any specific active suction or blowing within the airfoil or the slot. During the compression cycle, this slot pulls the flow from the high pressure area (lower surface) and blows it to the low pressure area (upper surface). On the other hand, during the suction cycle, the slot draws the flow from the upper surface (high pressure) and blows it to the lower surface (low pressure) [93], see Figures 2 A) and B). The slot will be known as a suction slot in the results which were presented henceforward. Moreover, another objective of this study is assessing the effect of slot angle on aerodynamic noise emitted from Wells turbine airfoil under oscillating and non-oscillating flow conditions. According to the literature, this is fairly a first study to use the slot with different angles in Oscillating Water System and Wells turbine design. Furthermore, this is also the first study to investigate the effect of a slot with different angles in aerodynamic performance, entropy generation and aeroacoustic noise of Wells turbine airfoil at the stall and near-stall conditions under oscillating flow conditions. 
The Large Eddy Simulation (LES) are used by the governing equations to obtain by filtering

3 the time-dependent Navier-Stokes equations. The filtering procedure filters out eddies whose

4 scales are smaller than the filter width or grid spacing used in the computations. The resulting

5 equations thus decide the large eddies dynamics. A filtered variable, which denoted by an over-

6 bar, is defined by [94]:

$7 \bar{\phi}(x)=\int_{F D} \phi\left(x^{\prime}\right) G\left(x, x^{\prime}\right) d x^{\prime}$

8 Where FD is the fluid domain, and the filter function which defines the scale of the resolved eddies

9 is represented by G.

10 The finite-volume, in FLUENT, discretization itself implicitly provides the filtering 11 operation [23]:

$12 \bar{\phi}(x)=\frac{1}{V} \int_{V} \phi\left(x^{\prime}\right) d x^{\prime}, x^{\prime} \in V$

13 Where the volume of a computational cell is define by $V . G\left(x, x^{\prime}\right)$, the filter function, implied here

14 is by

$15 G\left(x, x^{\prime}\right)=\left\{\begin{array}{c}1 / V \text { for } x^{\prime} \in V \\ 0 \text { otherwise }\end{array}\right.$

16 The LES model will be applied to essentially incompressible flows. Filtering the 17 incompressible Navier-Stokes equations, one obtains [95]

$18 \frac{\partial \rho}{\partial t}+\frac{\partial \rho \bar{u}_{i}}{\partial x_{i}}=0$

$19 \frac{\partial \bar{u}_{i}}{\partial t}+\frac{\partial \bar{u}_{i}}{\partial x_{j}}\left(\bar{u}_{j}\right)=\frac{\partial}{\partial x_{j}}\left(\mu \frac{\partial \bar{u}_{i}}{\partial x_{j}}\right)-\frac{\partial \bar{\rho}}{\rho \partial x_{i}}+\frac{\partial \tau_{i j}}{\rho \partial x_{j}}$

20 Where, $\tau_{i j}$ is the sub-grid-scale stress equals to:

$21 \tau_{i j}=\rho \overline{u_{i} u_{j}}-\rho \overline{u_{i} u_{j}}$

The sub-grid-scale stresses producing from the filtering process are unknown and need to 23 modeling. The most of sub-grid-scale models are eddy viscosity models of the next form [96]: 
$1 \quad \tau_{i j}-\frac{1}{3} \tau_{k k} \sigma_{i j}=-2 \mu_{t} \bar{S}_{i j}$

2 Where $\bar{S}_{i j}$ is the rate-of-strain tensor for the resolved scale and it is defined by:

$3 \quad \bar{S}_{i j}=\frac{1}{2}\left(\frac{\partial \bar{u}_{i}}{\partial x_{j}}+\frac{\partial \bar{u}_{j}}{\partial x_{i}}\right)$

4 and $\mu_{t}$ represents the sub-grid-scale turbulent viscosity, which the Smagorinsky-Lilly model is 5 applied for it [97]. The majority of sub-grid-scale models for Smagorinsky-Lilly model was 6 presented by Smagorinsky[98] and was further developed by Lilly[99]. In the Smagorinsky-Lilly

7 model, the eddy viscosity is modeled by:

$8 \quad \mu_{t}=\rho L_{s}^{2}|\bar{S}|$

9 Where, the mixing length for sub-grid-scale models is define by $L_{s}$ and $|\bar{S}|=\sqrt{2 \bar{S}_{i j} \bar{S}_{i j}}$. The

$10 L_{s}$ iscomputed using:

$11 L_{s}=\min \left(k d, C_{s} V^{1 / 3}\right)$

12 Where $k=0.42$, dis the distance to the closest wall, $C_{s}$ is the Smagorinsky constant, and $V$ is the 13 volume of the computational cell. Lilly derived a value of 0.23 for $C_{s}$ from homogeneous isotropic 14 turbulence. However, this value was found to cause excessive damping of large-scale fluctuations 15 in the transitional flows or in the existence of mean shear. Due to the turbulence flow at all domain, 16 a dynamic SGS model was not necessary in the LES models. Therefore, $C_{S}=0.1$ has been found 17 to yield the superior results for a vast range of flows [5, 23, 100].

18 The drag and lift coefficients $C_{D}$ and $C_{L}$ are determined from FLUENT (post processing 19 software). For each angle of attack, the average value for drag and lift coefficients was used to 20 determine one value for torque coefficient. Thereafter, the torque coefficient can then be expressed 21 as [29, 101, 102]:

$22 C_{T}=\left(C_{L} \sin \alpha-C_{D} \cos \alpha\right)$

23 The flow coefficient $\bar{\phi}$ based on both axial and tangential velocties of the rotor is given by

$24 \bar{\phi}=\frac{V_{a}}{\omega * R_{m}}$

25 Where the $\alpha$ angle of attack equal to

$26 \alpha=\tan ^{-1} \frac{V_{a}}{\omega R_{m}}$ 
1 and the torque is defined as:

$2 \quad$ Torque $=\frac{1}{2} \rho\left(V_{a}^{2}+\left(\omega R_{m}\right)^{2}\right) A R_{m} C_{T}$

3 The first law of thermodynamics efficiency $\left(\eta_{F}\right)$ is determined by:

$4 \quad \eta_{F}=\frac{\text { Torque* } \omega}{\Delta P * Q}$

The transport equations that govern these models can be found in turbulent flow texts such

6 as [103]. The second law of thermodynamic defines the network transfer rate $\dot{W}$ as [104]:

$7 \quad \dot{W}_{r e v}-\dot{W}=T_{o} S_{g e n}$

8 Which, it has been known as the Gouy-Stodola theorem[105].

9 In the absence of chemical reactions and phase change, the irreversible entropy generation 10 could be expressed in terms of the derivatives of local flow parameters. In viscous flows, there are

11 two main dissipative mechanisms:1) the strain-originated dissipation which corresponds to the 12 viscous entropy generation and 2) the thermal dissipation which correspond to the thermal entropy 13 generation [106]. Thus, it can be written as,

$14 S_{g e n}=S_{V}+S_{t h}$

15 For the present case study (isothermal incompressible flow), the thermal dissipation term 16 is insignificant. Therefore, the local viscous irreversibilities could be stated as:

$17 \quad S_{V}=\frac{\mu}{T_{o}} \phi$

18 where $\phi$ is the viscous dissipation term, which could be expressed in two dimensional Cartesian

19 Coordinates as [106]:

$20 \phi=2\left[\left(\frac{\partial u}{\partial x}\right)^{2}+\left(\frac{\partial v}{\partial y}\right)^{2}\right]+\left(\frac{\partial u}{\partial y}+\frac{\partial v}{\partial x}\right)^{2}$

Equations 18 and 19 were used to create the user defined function (UDF) file, which is

22 used to calculate the local entropy generation form the software (FLUENT). After that, the global

23 entropy generation rate is expressed as:

$24 \quad S_{G}=\iint_{x y} S_{V} d y d x$ 
$1 S_{G}$ is calculated by integral the global value using the FLUENT software.

$3 \quad$ Exergy $=\mathrm{Ke}+\mathrm{S}_{G}$

4 and efficiency of the second law can be written as [52]:

$5 \quad \eta_{S}=\frac{K e}{\text { Exergy }}$

6 Where $K e=\frac{1}{2} V^{2}$

7 From the above equations, several conclusion can be noted. Firstly, the torque coefficient $\left(C_{T}\right)$ 8 relates to the first law efficiency $\left(\eta_{F}\right)$. Secondly, the increase in torque coefficient $\left(C_{T}\right)$ leads to 9 increase in the first law efficiency $\left(\eta_{F}\right)$. Thirdly, the global entropy generation rate $\left(S_{G}\right)$ relates to 10 the second law and efficiency $\left(\eta_{S}\right)$. Finally, the decrease in the global entropy generation rate $\left(S_{G}\right)$ 11 leads to an increase in the second law efficiency $\left(\eta_{S}\right)$.

12 Regarding acoustic simulation, the Lighthill formulation $[108,109]$ for the aeroacoustic noise was

13 the first approach, where the Navier-Stokes equations were rearranged into an inhomogeneous 14 wave equation, shown in equation (23).

$15 \frac{\partial^{2} P^{\prime}}{C_{0}^{2} \partial t^{2}}-\nabla^{2} P^{\prime}=\frac{\partial^{2} Q_{i j}}{\partial x_{i} \partial x_{j}}$

16 Where $c_{0}$ is the ambient speed of the sound, $P^{\prime}=C_{0}^{2} \rho$ and $Q_{i j}$ is Lighthill's stress tensor. The

17 left hand side describes the propagation of the acoustic wave in both the spatial and temporal

18 domains, otherwise, the right hand side represents the source term.

19 Ffowcs-Williams and Hawkings [110] modified and extended Lighthill's equation to treat the

20 problem of sound generated by a body in arbitrary motion in both frequency and time domains.

21 The Ffowcs-Williams and Hawkings (FW-H) equation has two extra source terms which represent

22 monopole and dipole sources, shown in equation (24):

$23 \frac{\partial^{2} P^{\prime}}{C_{0}^{2} \partial t^{2}}-\nabla^{2} P^{\prime}=\frac{\partial^{2}}{\partial x_{i} \partial x_{j}}\left\{Q_{i j} H(f)\right\}-\frac{\partial}{\partial x_{i}}\left\{\left[P_{i j} n_{j}+\rho u_{i}\left(u_{n}-v_{n}\right)\right] \delta(f)\right\}+$

$24 \frac{\partial}{\partial t}\left\{\left[\rho_{0} v_{n}+\rho\left(u_{n}-v_{n}\right)\right] \delta(f)\right\}$

25 and $Q_{i j}=\rho u_{i} u_{j}+P_{i j}-C_{0}^{2}\left(\rho-\rho_{0}\right) \delta_{i j}$ 
1 Where, $P_{i j}$ is the compressive stress tensor and equal to $P^{\prime} \delta_{i j}, u_{i}$ is the fluid velocity in the $i$

2 direction, $v_{i}$ is the surface velocity in the $i$ direction, $n_{i}$ is the unit vector in the $i$ direction, $v_{n}$ is

3 the surface velocity normal to the surface $(f=0), u_{n}$ is the fluid velocity normal to the surface

$4(f=0), H(f)$ is the Heaviside delta function, $\delta(f)$ is the Dirac delta function, $f$ is the

5 mathematical surface of the moving body and $P^{\prime}$ is the acoustic pressure at the far field and equal

6 to $P_{T}^{\prime}+P_{L}^{\prime}$. The solution at a receiver location can be calculated analytically using generalized

7 function theory and the free space Green's function.

8 The thickness contribution $P_{T}^{\prime}$ is given by $[78,110]$,

$94 \pi P_{T}^{\prime}(x, t)=\int_{f=0}\left[\frac{\rho_{0}\left(\dot{u_{n}}+u_{n}\right)}{r\left(1-M_{r}\right)^{2}}\right]_{r e t} d s+\int_{f=0}\left[\frac{\rho_{0} u_{n}\left\{r M_{r}+c_{0}\left(M_{r}-M^{2}\right)\right\}}{r^{2}\left(1-M_{r}\right)^{3}}\right]_{r e t} d s$

10 The loading contribution $P_{L}^{\prime}$ is given by[80, 110],

$114 \pi P_{L}^{\prime}(x, t)=\frac{1}{c_{0}} \int_{f=0}\left[\frac{L_{r}}{r\left(1-M_{r}\right)^{2}}\right]_{r e t} d s+\int_{f=0}\left[\frac{L_{r}-L}{r^{2}\left(1-M_{r}\right)^{2}}\right]_{r e t} d s+$

$12 \int_{f=0} \frac{1}{c_{0}}\left[\frac{L_{r}\left\{r M_{r}+c_{0}\left(M_{r}-M^{2}\right)\right\}}{r^{2}\left(1-M_{r}\right)^{3}}\right]_{r e t} d s$

$13 M$ is local Mach number, $M_{r}$ is the Mach number of a point on the moving surface, $r$ is the distance

14 to the observer. The subscript ret denotes that the integrals are computed at the corresponding

15 retarded times, the dot above a variable represents the source time derivative of that variable.

16 The Sound Pressure Level (SPL) in dB, see equation (28), is obtained with respect to the reference

17 acoustic pressure $P_{\text {ref }}=2 \times 10^{-5} \mathrm{~Pa}$

$18 S P L=20 \log _{10}\left(P^{\prime} / P_{\text {ref }}\right)$

\section{CFD Verification and Validation Result}

In this study, The CFD verification and validation results for the mentioned models are

21 presented. Furthermore, this section proposes a detailed description of the turbulence models used

22 in stall condition, an expression of the discretization technique used and the boundary conditions

23 for the current work. 


\subsection{Computational model and boundary conditions}

Two-dimensional numerical simulation models for NACA 0015 airfoils section were built

3 and then validated by experimental tests under unsteady flow conditions with constant velocity, as well as, under unsteady flow with sinusoidal inlet velocity. GAMBIT code was used for discretizing the computational domain to Cartesian structured finite volume cells. In ANSYS FLUENT, the Green-Gauss cell based evaluation method is used for calculating the gradient terms, which could be applied to the application of such boundary condition types $[75,100,111$, 112].Different interpolation schemes were tested to transfer cell center values to cell face values

9 for the variables of flow field. In addition, several convergence tests have been performed. The 10 second order upwind [113] interpolation scheme was used in this work. Where, there was no 11 noticeable difference in the results when the third order MUSCL scheme was used in the current 12 cases. More than that, the third order MUSCL scheme resulted in high oscillatory residuals during 13 the solution, in some cases. wave in current study. Hence, time-dependent inlet boundary conditions were created. The 16 following function was used to apply the inlet boundary condition (see Figure $3 \mathrm{~A}$ ).

$17 \quad V_{a}=V_{o}+V_{a m} \sin \left(2 \pi f t_{\text {sin }}\right)$

18 Where a time period, $t_{\sin }$, of 6 seconds was used in this study based on the conducted literature 19 survey [5, 36, 100, 114]. Time step is set as 0.0089 second in order to satisfy CFL(Courant 20 Friedrichs Lewy) [115] condition equal to 1 . For the Egyptian coasts boundary condition the $t_{s i n}$ is 21 equal to 4,6 and 8 seconds $(f$ equal to $0.25,0.167$ and $0.125 \mathrm{~Hz}$ ), considering the real data from 22 the site $[89,90]$. Reynolds numbers up to $2 \times 10^{4}$ are created due to the sinusoidal wave condition 23 based on the reference [112]. The dimensions of the whole computational domain, location of 24 airfoil and near views of slot mesh are shown in Figures 3 B) and C).

\subsection{Grid sensitivity test (Verification)}

In order to ensure that the numerical results are minimally dependent on the grid size, several grids had been tested to determine the grid cells required number to create a dependable model. Four grids with different mesh sizes ranging from 112603 up to 446889 cells are studied

29 for performing grid sensitivity test. It can be noticed that the grid with mesh size of 312951 cells 
1 gives good results within reasonable computation time (more details about this result in $[45,93]$ ).

2 Thus, it was chosen to conduct the investigative and analysis of the present work.

\subsection{Validation of the CFD model}

Large Eddy Simulation (LES) model was used to model the flow around NACA0015 airfoil to give the better agreement results with experimental data taken from[112] and [116]. According to the literature survey in [95, 117-124], LES model gave excellent results when they are used to simulate the airfoil in stall condition.

Although, LES is definitely 3D model, there have been numerous successful endeavors to be applied in 2D engineering applications(e.g., flow over obstacles [125], hump [126], block [127], airfoils [123, 128] and Hills[129]). Moreover, numerous 2D models applications including the problems dealing with dam-break [130], mechanism of pollutant[131, 132], heat transfer[133, 134] used LES as a turbulence model. In this work two sets of experimental data from references were used to validate the numerical model. First experimental data from references $[112,135,136]$ is used to validate the stall condition. Details of the first validation case, where Wells turbine prototype under investigation is characterized by the following parameters: hub radius is $101 \mathrm{~mm}$ and $155 \mathrm{~mm}$ for the tip radius. NACA0015 blade profile section with $74 \mathrm{~mm}$ chord length, and number of blades are 7. Furthermore, the hub-to-tip ratio is 0.65 and the solidity is 0.64 , with 0.05 uncertainty in the measurements. Second experimental data from reference [116] is adopted to simulate and validate the sinusoidal wave inlet flow unsteady velocity. In the second validation case, the unsteady forces $\left(F_{D}\right)$ exerted on a square cylinder under oscillating flow with nonzero mean velocity were computed and compared to experimental data. In the experiment, the oscillating air flow was generated by an $\mathrm{AC}$ servomotor wind tunnel. The generated oscillating velocities are almost exact sinusoidal waves.

For unsteady flow with constant velocity, Figure $4 \mathrm{~A}$ shows a very good agreement between the experimental data for the torque coefficient from reference $[112,135,136]$ and the calculated torque coefficients at Reynolds number equals $2 \times 10^{5}$ from CFD results. It can be noted that the CFD model has close stall condition value as the experimental data from reference. Table 1 shows the comparison between those results and the percentage of error. Furthermore, for an unsteady flow with sinusoidal inlet velocity, Figure 4 B shows good agreement between 
1 experimental data for the drag force from reference [116] and the calculated drag force from CFD

2 at two different frequencies ( $1 \mathrm{~Hz}$ and $2 \mathrm{~Hz}$ ). It can be seen from Figure $4 \mathrm{~B}$ that the CFD model

3 has approximately the same characteristics of oscillating flow velocity as the experimental data

4 from reference. The error percentage for the two frequencies is also shown in Table 2.

4. Results and Discussion

A single suction slot with certain diameter $\left(D_{s s}\right)$ representing $0.1 \%$ [93] of the blade chord and located at distance $\left(L_{s s}\right)$ equal to $50 \%$ of the blade chord with different angles for the suction slot positions $\left(\alpha_{s s}\right)$ (anticlockwise and clockwise) was created, with a shape of NACA0015 from reference $[112,135,136]$, see Figure 5. The angles for the suction slot were varied to get an optimum value of $C_{T}$ and $S_{G}$. Table 3 highlights the different test cases that were investigated in

11 this work. The angle of suction slots at upper and lower surface was defined with $\left(\alpha_{s s}\right)$ of upper

12 surface only in the analysis and results which were presented hereafter. First, test cases under unsteady flow with non-oscillating velocity were investigated in order to obtain an indication about

14 the well-performing suction slot angles. Second, these well-performing angles were investigated 15 under sinusoidal wave condition to decide which angle provides an optimum value of $C_{T}$ and $S_{G}$.

16 Third, investigate the effect of a slot with different angles in aeroacoustic noise of Wells turbine 17 airfoil at the stall and near-stall conditions under oscillating and non-oscillating flow conditions. 18 Finally a comparative analysis with different sinusoidal wave frequencies depend on operating conditions from Egyptian Northern Coast was investigated as well.

\subsection{Different suction slot angles under non-oscillating inlet velocity}

Figure $6 \mathrm{~A}$ shows the $C_{T}$ values of suction slot with different angles. It can be noticed that the suction slot with a non-zero angle gives a higher $C_{T}$ than that with 0 degree. For instance, the suction slots with $\alpha_{s s}$ equal to 35 degrees clockwise, 65 degrees anticlockwise and 55 degrees anticlockwise give $C_{T}$ higher than that with 0 degree by $22 \%, 20 \%$ and $19 \%$, respectively. Table 4

25 lists $C_{T}$ values for the investigated $\alpha_{s s}$ angles. The $S_{G}$ values of suction slot with different angles

26 are shown in Figure 6 B. It can be concluded that, the suction slot with $\alpha_{s s}$ equal to 15 degrees 27 anticlockwise, 10 degrees clockwise and 10 degrees anticlockwise gives $S_{G}$ lower than that with 0 degree by $13 \%, 13 \%$ and $3 \%$, respectively, see Table 5 for more details. The slot increases $C_{T}$ and 
1 delays the stall angle, furthermore, at some $\alpha_{s s}$ not equal to zero produce higher improvement

2 in $C_{T}$ than $\alpha_{s s}$ equal to zero due to the improvement in the flow layers around the aerofoil. On the

3 other hand, $S_{G}$ value depends on the velocity gradient and the increases in velocity magnitude

4 around the aerofoil lead to increase in $S_{G}$. Furthermore, at some $\alpha_{s s}$ not equal to zero, the change

5 in velocity gradient was lower than $\alpha_{s s}$ equal to zero due to the improvement in the flow layers

6 around the aerofoil. More details about the flow layers and pressure distribution around the aerofoil

7 will be shown in upcoming sections.

\section{sinusoidal inlet velocity}

From the previous section, it was noted that three values of $\alpha_{s s}(35$ degrees clockwise and 65,55 degrees anticlockwise) provide the highest values of $C_{T}(60 \%, 58 \%$, and $57 \%)$ at the stall

12 regime. In addition, two values of $\alpha_{S S}$ (15 degrees anticlockwise and 10 degrees clockwise) have 13 shown to provide the lowest $S_{G}$ value (8\%) at the stall regime. In this section, the optimum $\alpha_{s s}$ for 14 single suction slot at the middle of the airfoil was investigated based on both $C_{T}$ and $S_{G}$ values 15 under sinusoidal wave condition. Figures 7 and 8 illustrate the hysteretic behavior due to the 16 reciprocating flow.

Figure 7 A) shows the comparison between the suction slot with 0 degree and that with 55 degrees anticlockwise. It can be noted that both the accelerating flow and decelerating flow of suction slot with $\alpha_{s S}$ equal to 55 degrees anticlockwise have higher $C_{T}$ than that with suction slot angel $\alpha_{s s}$ equal to 0 degree by $6 \%$ (accelerating) and 5\% (decelerating).Furthermore, the accelerating flow for $\alpha_{s S}$ equal to 65 degrees anticlockwise has a lower $C_{T}$ than that for $\alpha_{s S}$ equal to 0 degree by $-7 \%$, see Figure $7 \mathrm{~B}$ ), while for the decelerating flow it provides a $3 \%$ higher $C_{T}$ than that for $\alpha_{s s}$ equal to 0 degree. From the comparison in Figure $7 \mathrm{C}$ ) between the suction slot

24 with 0 degree and that with 35 degrees clockwise, it can be noted that the $C_{T}$ is the same as an 25 average value in accelerating flow but for the decelerating flow the 35 degrees clockwise has 26 higher $C_{T}$ than the 0 degree by $7 \%$. Figure $8 \mathrm{~A}$ ) shows that the accelerating flow for suction slot 27 with $\alpha_{s s}$ equal to 15 degrees anticlockwise has a lower $C_{T}$ than that of the suction slot with $\alpha_{s s}$ 28 equal to 0 degree by $-2 \%$, while the decelerating flow has a higher $C_{T}$ than the suction slot with $29 \alpha_{s S}$ equal to 0 degree by $4 \%$. Finally, Figure 8 B) shows that both the accelerating flow and 
1 decelerating flow of suction slot with $\alpha_{s s}$ equal to 10 degrees clockwise has higher $C_{T}$ than that

2 of the suction slot with $\alpha_{S S}$ equal to 0 degree by $4 \%$ (accelerating) and $9 \%$ (decelerating).

3 Figure 9 shows the instantaneous torque coefficient at compression cycle for different 4 suction slot angles, these values are at angle of attack of 13.6degrees.It can be concluded that all 5 five angles in Figure $9 \mathrm{~A}$ ) and B) have higher peak value of $C_{T}$ than the suction slot with $\alpha_{S S}$ equal 6 to 0 degree and also as average for the compression cycle. For more details about other angles of 7 attack see Table 6.Figure 10 shows the average value of torque coefficient during the compression 8 cycle. It can be noted that the suction slot with $\alpha_{s s}$ equal to 10 degrees clockwise has the highest 9 improvement in $C_{T}$ value before the stall by $21 \%$. Furthermore, both the suction slot with $\alpha_{s s}$ 10 equal to 55 degrees anticlockwise and the suction slot with 10 degrees clockwise have the highest 11 improvement in $C_{T}$ value after the stall by $44 \%$, see Table 6 .

Table 7 highlights the comparison between the values of $S_{G}$ for NACA0015 with suction 13 slot at different position angles under sinusoidal inlet velocity. It can be concluded that both the 14 suction slots with $\alpha_{s s}$ equal to 15 degrees anticlockwise and the suction slot with $\alpha_{s s}$ equal to 10 15 degrees clockwise have $S_{G}$ lower than the suction slot with $\alpha_{s s}$ equal to 0 degree. Where, the suction slot with $\alpha_{s s}$ equal to 10 degrees clockwise has the lowest increase in $S_{G}$ value before the

17 stall by $20 \%$. Furthermore, the suction slot with $\alpha_{s s}$ equal to 15 degrees anticlockwise has the 18 lowest increase in $S_{G}$ value after the stall by $18 \%$.

Figure 11shows the comparison between the second law efficiency of NACA0015 without and with suction slot which have different angles. The comparison was provided as an average 21 value for the compression stage with various angles of attack. The increase in $S_{G}$ (Table 7) leads 22 to decrease in second law efficiency in most cases than that without suction slots. Otherwise, the 23 suction slot with $\alpha_{s s}$ equal to 15 degrees anticlockwise and 10 degrees clockwise give a higher 24 second law efficiency than the NACA0015 without suction slot and with suction slot have $\alpha_{s s}$ 25 equal to 0 degree. Where, the suction slot with $\alpha_{s s}$ equal to 15 degrees anticlockwise provides a 26 higher second law efficiency than the NACA0015 without suction slot by $0.4 \%$ before the stall 27 (Figure 11A, B and C) and 0.7\% after the stall (Figure $11 \mathrm{D}$ and $\mathrm{E}$ ) as an average value. Also it 28 provides a higher second law efficiency than suction slot with $\alpha_{s S}$ equal to 0 degree by $0.5 \%$ after 29 the stall (Figure $11 \mathrm{D}$ and E) but the same value as average before the stall (Figure $11 \mathrm{~A}, \mathrm{~B}$ and 
1 C). On the other hand, the suction slot with $\alpha_{s s}$ equal to 10 degrees clockwise has higher second 2 law efficiency than the NACA0015 without suction slot by $0.5 \%$ before the stall (Figure $11 \mathrm{~A}, \mathrm{~B}$ and $\mathrm{C}$ ) and $0.2 \%$ after the stall (Figure $11 \mathrm{D}$ and $\mathrm{E}$ ) as an average value. Furthermore, it has the

4 same improvement in second law efficiency from suction slot with $\alpha_{s s}$ equal to 0 degree as an 5 average value before the stall (Figure $11 \mathrm{~A}, \mathrm{~B}$ and C) and after the stall (Figure $11 \mathrm{D}$ and E).

The most important reason behind the improvement in the cases for the $\alpha_{s s}$ not equal to 0 more than the cases for the $\alpha_{s s}$ equal to 0 due to the flow layers and pressure distribution around the aerofoil. Therefore, Figures 12, 13 and 14 were highlighting the flow layers and pressure distribution around the aerofoil at different $\alpha_{s s}$ values.

The effect of suction slot on the separation layers around the trailing edge area can be noted at Figure 12.Where, the mean velocity magnitude path lines around the NACA0015 without and with suction slot for different $\alpha_{s s}$ were presented. These values were at the instantaneous velocities of $2.92 \mathrm{~m} / \mathrm{s}$ (Figure 12A) and $1.8 \mathrm{~m} / \mathrm{s}$ (Figure 12B) for the decelerating flow and at angle of attack 14 of 13.6 degrees (stall angle). Also, the improvement effect of suction slot on separation layer increased in the second half of the cycle (deceleration flow) because the separation region around the end of the blade increased, especially at the decelerating flow at Figure 12B).

From Figure 13, it can be noted that the low pressure zones around the aerofoil, especially at the trailing edge area, were reduced by adding the suction slot. The slot with angle not equal to zero gives better result from that with zero degree, for example, 35 (clockwise) degrees or 10 (clockwise) degrees. The slot with 35 or 10 degrees were reduced the low pressure area around the aerofoil and also the difference between the pressure at the upper and lower surface higher than

22 the slot with zero degree. Therefore, the slot with 35 or 10 degrees have more improvement in the separation layer and the torque coefficient than the slot with zero degree.

The flow structures over the NACA0015 aerofoil without and with suction slot has different slot angles in oscillating flow are shown in Figure 14. Figure 14shows the contours of 26 velocity magnitude (Figure 14A) and entropy (Figure 14B) at maximum velocity $2.92 \mathrm{~m} / \mathrm{s}$ and 2713.6 degrees angle of attack (stall angle). The improvement on flow structures was clear, due to 28 the suction slot, when comparing the NACA 0015 airfoil section without and with slot. Mostly, in 29 the separated layer regime that located on the end of aerofoil. The suction slot effects directly on 
1 the flow structures that located on the end of blade, and then leads to an improvement in the 2 separation regime. However, adding a suction slot shows a bad effect on the entropy generation 3 rate, wherever higher entropy generation values were obtained for all suction slots cases. The

4 suction slot with $\alpha_{s S}$ equal to 55 degrees anticlockwise generates the highest value of entropy with 5 an increase of $63 \%$ than the NACA0015 without suction slot case. In addition the lowest value for aerofoil with suction slot was obtained with $\alpha_{s S}$ equal to 15 degrees anticlockwise, with an increase of $18 \%$ only than the NACA0015 without suction slot case. From Figure $12 \mathrm{~A}$ and B it can be concluded that the attached slot with angle not equal to zero to the aerofoil lead to increase in velocity magnitude around the aerofoil, furthermore, it also lead to increase in the entropy generation in Figure 14 B where the entropy value depends on the velocity gradient, see equation (19).

The Ffowcs-Williams and Hawkings (FW-H) acoustic analogy is used to calculate the acoustic 14 pressure at a far field receiver located at 35 chord and 128 chord, perpendicular to the chord and 15 the results that obtained of sound pressure level are investigate and analyze. Figures 15 and 16 show the sound pressure level in AB for NACA0015 under non-oscillating velocity at two far field 17 receivers with different slot angles and different angles of attack. It can be noted that, the sound 18 pressure level $(S P L)$ has the highest value at the stall angle (13.6 degrees). Furthermore, the 19 NACA0015 with $\alpha_{S S}$ not equal to zero have direct effect on the value of $S P L$, however, $\alpha_{S S}$ equal to 65 degrees anticlockwise decreased from SPL by $-12.7 \%$ before the stall and by $-11.6 \%$ after 21 the stall regime at first receiver. The value of $S P L$ was decreased, with $\alpha_{S S}$ equal to 65 degrees 22 anticlockwise, by $-20.1 \%$ before the stall and by $-21 \%$ after the stall regime at second receiver. 23 Under non-oscillating velocity condition, NACA0015 with a $\alpha_{S S}$ not equal to zero are preferable 24 than that equal to zero, except the $\alpha_{S S}$ equal to 35 degrees clockwise at 14.4 degrees. However, 25 the maximum reduction create due to $\alpha_{S S}$ equal to 65 degrees anticlockwise by $-16.6 \%$ at 11.7 26 degrees at a far field receiver located at 35 chord, on the other hand, the $\alpha_{S S}$ equal to 65 degrees 27 anticlockwise give the maximum reduction at a far field receiver located at 128 chord by $-26.4 \%$ 28 at 11.7 degrees, see Table 8 for more details about the overall sound pressure level in $\mathrm{dB}$ for 29 NACA0015 under non-oscillating velocity with different angles of attack. 
The sound pressure levels for NACA0015 under oscillating velocity at a far field receivers located

2 at 35 chord and 128 chord with different slot angles and different angles of attack were shown in

3 Figures 17 and 18. Compared with the non-oscillating velocity, the SPL increase due to the

4 oscillating velocity condition at all angles of attack. It can be concluded that, the stall regime has

5 the highest value of (SPL) at 13.6 and 14.4 degrees. Moreover, the NACA0015 with $\alpha_{S S}$ equal to

635 degrees clockwise has the lowest value of $S P L$ at 11.3 degrees by $-4.1 \%$ at first receiver and -

$7 \quad 19 \%$ at second receiver. The $\alpha_{S S}$ equal to 10 degrees clockwise has the lowest value of SPL with

8 angle of attack 11.7 degrees by $-5.2 \%$ at the receiver located 35 chord and by $-17 \%$ at the receiver

9 located 35 chord. The lowest value of $S P L$ at 12.3 degrees given by $\alpha_{S S}$ equal to 55 degrees

10 anticlockwise, which it was decreased by $-5.2 \%$ at first receiver and $-12.3 \%$ at second receiver. At

11 stall regime, the $\alpha_{S S}$ equal to 10 degrees clockwise has the lowest value of $S P L$ with 13.6 and 14.4

12 degrees at the two receivers. Where, the $S P L$ was decreased by $-7.3 \%$ at receiver one and by -

$1321.2 \%$ at receiver two after the stall regime. Table 9 show for more details about the overall sound

14 pressure level in $\mathrm{dB}$ for NACA0015 under oscillating velocity with different angles of attack.

15 Finally, the maximum reduction create due to $\alpha_{S S}$ equal to 10 degrees clockwise by $-8 \%$ at 13.6

16 degrees at a far field receiver located at 35 chord, on the other hand, the $\alpha_{S S}$ equal to 10 degrees

17 clockwise give the maximum reduction at a far field receiver located at 128 chord by $-23.2 \%$ at

1814.4 degrees.

\subsection{Different frequencies effect}

It was concluded from previous section that the optimum $\alpha_{S S}$ is 10 degrees clockwise. Since this suction slot angle gives the highest $C_{T}$ before and after the stall (Table 6). On the other hand,

22 it gives a lower $S_{G}$ than other angles before the stall and also it gives lower $S_{G}$ than 0 degree angle

23 after the stall (Table 7).So, this optimum $\alpha_{S S}$ is studied using the OWC technique depend on the 24 real data from the Egyptian site under different frequencies ( $f$ equal to 0.25 and $0.125 \mathrm{~Hz}$ ) and time 25 periods (4 and 8 seconds).

The $C_{T}$ for both $\alpha_{S S}$ equal to 0 degree and 10 degrees clockwise have the same value (as an average) at the accelerating flow but for decelerating flow the 10 degrees clockwise has higher $C_{T}$ than the 0 degree by $1 \%$ (Figure $19 \mathrm{~A}$ ). The suction slot with $\alpha_{S S}$ equal to 10 degrees clockwise

29 has a higher peak value of $C_{T}$ than the suction slot with $\alpha_{S S}$ equal to 0 degree at angle of attack of 3013.6 degrees. On the other hand, as an average value for the compression cycle, the $\alpha_{S S}$ equal to 
110 degrees clockwise has a lower value of $C_{T}$ than the $\alpha_{S S}$ equal to 0 degree by $3 \%$ (Figures 19B) 2 and C)). For more details about other angles of attack for sinusoidal wave with time period equal to 4 second, see Table 10. It can be noted that from Figures 20 A), B) and C), the suction slot with

$4 \alpha_{s S}$ equal to 10 degrees clockwise has higher improvement in $C_{T}$ value before the stall than the aerofoil without slot by $7 \%$. However, the suction slot with $\alpha_{s s}$ equal to 0 degree gives higher improvement in $C_{T}$ value after the stall by degrees $10 \%$ than the aerofoil without slot. See Table 10 for more details about sinusoidal wave with time period equal to 8 seconds. clockwise gives $S_{G}$ value lower than the suction slot with $\alpha_{s S}$ equal to 0 degree at different time period before and after the stall, except at the time period equal to 4 seconds, where the suction 11 slot with $\alpha_{s S}$ equal to 0 degree has the lowest increase in $S_{G}$ value after the stall by $12 \%$.

The increase in $S_{G}$ (Table 11) leads to the decrease in second law efficiency in most cases 13 than that without suction slots, see Figure 21. Where, the suction slot with $\alpha_{s S}$ equal to 10 degrees 14 clockwise under sinusoidal wave with time period equal to 4 seconds has lower second law 15 efficiency than the NACA0015 without suction slot by $0.3 \%$ before the stall (Figures $21 \mathrm{~A}, \mathrm{~B}$ and $16 \mathrm{C}$ ) and after the stall (Figures $21 \mathrm{D}$ and E) as an average value. Furthermore, it also has the highest 17 second law efficiency than suction slot with $\alpha_{s s}$ equal to 0 degree as an average value before the stall (Figures $21 \mathrm{~A}, \mathrm{~B}$ and C) by $0.1 \%$ and lower than it after the stall (Figures $21 \mathrm{D}$ and E) by $190.2 \%$.On the other hand, the suction slot with $\alpha_{s s}$ equal to 10 degrees clockwise under sinusoidal 20 wave with time period equal to 6 seconds has a higher second law efficiency than the NACA0015 21 without suction slot by $0.5 \%$ before the stall (Figures $21 \mathrm{~A}, \mathrm{~B}$ and C) and $0.2 \%$ after the stall 22 (Figures $21 \mathrm{D}$ and $\mathrm{E}$ ) as an average value. Also, the 10 degrees clockwise has the same 23 improvement in second law efficiency compare with the 0 degree as an average value before the 24 stall (Figures $21 \mathrm{~A}, \mathrm{~B}$ and C) and after the stall (Figures $21 \mathrm{D}$ and E).

Finally, the suction slot with $\alpha_{s s}$ equal to 10 degrees clockwise under sinusoidal wave with 26 time period equal to 8 seconds gives a lower second law efficiency than the NACA0015 without 27 suction slot by $0.6 \%$ before the stall (Figures $21 \mathrm{~A}, \mathrm{~B}$ and C) and after the stall (Figures $21 \mathrm{D}$ and 28 E) as an average value. Furthermore, it has the highest second law efficiency when compared to 
1 suction slot with $\alpha_{s S}$ equal to 0 degree as an average value before the stall (Figures $21 \mathrm{~A}, \mathrm{~B}$ and

2 C) by $0.1 \%$ and lower than it after the stall (Figures $21 \mathrm{D}$ and $\mathrm{E}$ ) by $0.6 \%$.

As it was mentioned above, the flow layers and pressure distribution around the aerofoil 4 are the most important reason behind the improvement in the cases with $\alpha_{s s}$ not equal to 0 .

5 Therefore, Figures 22 and 23 were highlighting the flow layers and pressure distribution around the aerofoil at different conditions, such as $t_{\sin }$ and $\alpha_{s s}$.

The separation layer at the end of blade was effected by the suction slot (Figure $22 \mathrm{~A}$ ) can be noted at the different time periods from the path lines colored by mean velocity magnitude 9 around the NACA0015 at $1.8 \mathrm{~m} / \mathrm{s}$ velocity for the decelerating flow and at angle of attack of 13.6 10 degrees (stall angle). More than that, both the low pressure zones and the difference between the 11 upper and lower surface were decreased especially for the slot with $\alpha_{s s}$ equal to 10 degrees 12 clockwise at different time periods, see Figures $22 \mathrm{~B}$ and C. It can be noted that from Figure 23 13 the suction slots have a negative effect on the entropy generation at the different time periods.

14 However, the suction slot with $\alpha_{S S}$ equal to 10 degrees clockwise has the lower $S_{G}$ value with an 15 increase of only $10 \%$ before the stall and $14 \%$ after the stall than the NACA0015 without suction 16 slot by under sinusoidal wave with time period equal to 4 seconds. In addition, it has the lowest 17 value under sinusoidal wave with time period equal to 8 seconds with an increase than the 18 NACA0015 without suction slot by $16 \%$ before the stall and $18 \%$ after the stall.

\section{Conclusions}

Several cases were solved to determine the optimum angle for single suction slot at the middle of two-dimensional airfoil. The optimum value has been decided based on two criteria: 1)

22 maximizing the obtained torque coefficient value to maximize the first law of thermodynamics 23 efficiency, and 2) minimizing the generated entropy value to maximize the second law of 24 thermodynamics efficiency. For this purpose, the entropy generation minimization method was 25 used to obtain the local entropy viscosity predictions of the different cases. Furthermore, the effect 26 of a single suction slot with angle equal and not equal to zero attached to airfoil section on the 27 aeroacoustic noise at the far field. The aerodynamic noise under different operating conditions, 28 (such as, before and after the stall regime and non-oscillating and oscillating velocity) and different 
1 design parameters, (such as, airfoil section without slot and with slot have angle equal and not 2 equal to zero) was analyze and investigate. Then, the comparative analysis based on actual location data relevant to northern coast of Egypt was applied using the airfoil with optimum angle of suction slot. The two-dimensional incompressible unsteady flow was used to simulate these cases under different conditions.

The modeling results show that optimum angle for suction slot is 10 degrees clockwise. This angel gives the highest improvement in the torque coefficient by $21 \%$ before the stall and $44 \%$ after the stall. These values are higher than the suction slot with 0 degree by $3 \%$ before the

9 stall and $15 \%$. On the other hand, this angel gives the lowest global entropy generation rate than 10 the suction slot with 0 degree by $4 \%$ before the stall and 3\%.The airfoils with optimum locations

11 for multi suction slots under conditions based on Egyptian northern coast with different frequency

12 were investigated. The suction slot with angle equal to 10 degrees clockwise is mostly providing 13 a higher torque coefficient and a lower global entropy generation rate than the suction slot with 14 angle equal to 0 degree at different time periods ( 4,6 and 8 seconds) before and after the stall. The 15 delay of stall condition lead to the improvement in the torque coefficient after the stall. The suction 16 slot increases the torque coefficient and delays the stall angle which further leads to an increase 17 the efficiency of first law. Otherwise, it decreases the efficiency of second law. For-that, if the 18 turbine will be under the passive flow control by using the suction slot, it is strongly recommended 19 to use the suction slot with angle to progress the performance at the stall condition with minimize 20 the increase in entropy generation. Otherwise, it may not be effective. Moreover than that, the 21 aerodynamics noise can be reduction by a single slot with angle not equal to zero. The suction slot 22 with angle equal to 10 degrees clockwise is decreased the aeroacoustic noise at the stall regime by $23-7.3 \%$ and by $-21.2 \%$ at a far field receiver located at 35 chord and 128 chord respectively.

To conclude, future study and research should concentrate on progress the efficiency of 25 first law with a minimize entropy generation, by using numerical algorism[137] and experimental 26 laboratory studies, to enhance the overall Wells turbine performance under flow control method. 27 In addition, the passive flow control using slot with angle given very promising result for Wells 28 turbine, therefore, it be worth to investigate its effect on other turbine such as water turbine[138]. 29 Moreover, there are many parameters that can be used future study to reduction the aerodynamics 30 noise such as the number of suction slots, the distance between suction slots, the location of suction 
1 slots and the angle of suction slots. Furthermore, the operating conditions for the Egyptian northern

2 coast are very appropriate for the OWC system with a wave energy extractor such as Wells turbine.

3 Therefore, it is very important that to consider to the potential of wave energy in Egypt as the path

4 to minimize fossil fuel usage.

\section{Acknowledgements}

The authors would like to acknowledge the support provided by the Department of Naval Architecture, Ocean and Marine Engineering at Strathclyde University, UK and the Marine Engineering Department at Arab Academy for Science, Technology and Maritime Transport.

References

1. Falcao, A.F.d.O.J., P.A.P., OWC wave energy devices with air flow control. Ocean Engineering, 1999. 26(12): p. 1275-1295.

2. Falcao, A.F.d., Stochastic Modelling in wave power-equipment optimisation: maximum energy production versus maximum profit. Ocean Engineering, 2004. 31(2004): p. 1407-1421.

3. Torres, F.R., P.R.F. Teixeira, and E. Didier, Study of the turbine power output of an oscillating water column device by using a hydrodynamic - Aerodynamic coupled model. Ocean Engineering, 2016. 125: p. 147-154.

4. Shaaban, S., Aero-economical optimization of Wells turbine rotor geometry. Energy Conversion and Management, 2016. 126: p. 20-31.

5. Kinoue, Y., et al., Hysteretic Characteristics of Monoplane and Biplane Wells Turbine for Wave Power Conversion. Energy Conversion and Management, 2004. 45(9-10): p. 1617-1629.

6. Setoguchi, T. and M. Takao, Current status of self rectifying air turbines for wave energy conversion. Energy Conversion and Management, 2006. 47(15-16): p. 2382-2396.

7. Shaaban, S., Insight Analysis of Biplane Wells Turbine Performance. Energy Conversion and Management, 2012. 59: p. 50-57.

8. Torres, F.R., P.R.F. Teixeira, and E. Didier, A methodology to determine the optimal size of a wells turbine in an oscillating water column device by using coupled hydro-aerodynamic models. Renewable Energy, 2018. 121: p. 9-18.

9. Halder, P., A. Samad, and D. Thévenin, Improved design of a Wells turbine for higher operating range. Renewable Energy, 2017. 106: p. 122-134.

10. Shehata, A.S., et al., Wells turbine for wave energy conversion: a review. International journal of energy research, 2017. 41(1): p. 6-38.

11. Shehata, A.S., et al., Comparative analysis of different wave turbine designs based on conditions relevant to northern coast of Egypt. Energy, 2017. 120: p. 450-467.

12. Boccotti, P., Comparison between a U-OWC and a conventional OWC. Ocean Engineering, 2007. 34: p. 799-805.

13. Boccotti, P., Caisson breakwaters embodying an OWC with a small opening-Part I: Theory. Ocean Engineering, 2007. 34(5-6): p. 806-819. 
14. Halder, P., S.H. Rhee, and A. Samad, Numerical optimization of Wells turbine for wave energy

15. Scarpetta, F., et al., CFD simulation of the unsteady flow in an Oscillating Water Column: comparison between numerical and experimental results for a small scale experimental device, in Proceedings of the 12th European Wave and Tidal Energy Conference. 2017: Cork, Ireland. p. 988(001)-988(007).

16. Wang, S., et al., Turbulence modeling of deep dynamic stall at relatively low Reynolds number. Journal of Fluids and Structures 2012. 33: p. 191-209.

17. Hitoshi Hotta, Y.W., A study on the matching between the air turbine and phase control for the OWC wave power generator. Ocean Engineering, 1985. 12(6): p. 585-586.

18. Masahiro Inoue, K.K., Toshiaki Setoguchi, Katsumi Shimamoto, On the starting and quasi-steady characteristics of wells turbine under oscillating flow condition. Ocean Engineering, 1985. 12(6): p. 563.

19. Masami Suzuki, C.A., Tetsuo Tagori, Fundamental studies on oscillating water column wave power generator with wells turbine. Ocean Engineering, 1985. 12(6): p. 565.

20. Yukihisa Washio, H.H., Takeaki Miyazaki, Yoshio Masuda, Full-scale performance tests on tandem wells turbine. Ocean Engineering, 1985. 12(6): p. 564.

21. Folley, M., R. Curran, and T. Whittaker, Comparison of LIMPET Contra-rotating Wells Turbine with Theoretical and Model Test Predictions. Ocean Engineering, 2006. 33(8-9): p. 1056-1069.

22. Okuhara, S., et al., Wells Turbine for Wave Energy Conversion -Improvement of the Performance by Means of Impulse Turbine for Bi-Directional Flow. Open Journal of Fluid Dynamics, 2013. 03(02): p. 36-41.

23. Mamun, M., The Study on the Hysteretic Characteristics of the Wells Turbine in a Deep Stall Condition, in Energy and Material Science Graduate School of Science and Engineering. 2006, Saga University: Japan. p. 141.

24. T. Setoguchi, S.S., H. Maeda, M. Takao and K. Kaneko, A Review of Impulse Turbine for Wave Energy Conversion. Renewable Energy, 2001. 23(2): p. 261-292.

25. Liu, Z., et al., Numerical study on a modified impulse turbine for OWC wave energy conversion. Ocean Engineering, 2016. 111: p. 533-542.

26. Shehata, A.S., Investigation and Improvement of Wells Turbine Performance- Fluid Analysis \& 2nd Law of Thermodynamics Study, in Department of Naval Architecture, Ocean and Marine Engineering. 2017, University of Strathclyde: Glasgow G4 OLZ, U.K. p. 291.

27. Raghunathan, S., The Wells Air Turbine for Wave Energy Conversion. Progress Aerospace Sciences, 1995. 31: p. 335-386.

28. Dixon, S.L., Fluid Mechanics, Thermodynamics of Turbomachinery. 1998: Pergamon Press Ltd.

29. Sheldahl, R.E. and P.C. Klimas, Aerodynamic Characteristics of Seven Symmetrical Airfoil Sections Through 180-Degree Angle of Attack for Use in Aerodynamic Analysis of Vertical Axis Wind Turbines, in Sandia National Laboratories energy report. 1981: the United States of America. p. 118.

30. Raghunathan, S., A methodology for Wells turbine design for wave energy conversion. ARCHIVE: Proceedings of the Institution of Mechanical Engineers, Part A: Journal of Power and Energy 1990-1996 (vols 204-210), 1995. 209(31): p. 221-232.

31. Brito-Melo, A., L.M.C. Gato, and A.J.N.A. Sarmento, Analysis of Wells turbine design parameters by numerical simulation of the OWC performance. Ocean Engineering, 2002. 29: p. 1463-1477.

32. Setoguchi, T., et al., Effect of Guide Vane Shape on the Performance of a Wells Turbine. Renewable Energy, 2001. 23: p. 1-15. 
33. Thakker, A. and R. Abdulhadi, Effect of Blade Profile on the Performance of Wells Turbine under Unidirectional Sinusoidal and Real Sea Flow Conditions. International Journal of Rotating Machinery, 2007. 2007: p. 1-9.

34. Thakker, A. and R. Abdulhadi, The Performance of Wells Turbine Under Bi-Directional Airflow. Renewable Energy, 2008. 33(11): p. 2467-2474.

35. Kim, T.H., et al., Hysteretic Characteristics of Wells Turbine for Wave Power Conversion, in The Twelfth International Offshore and Polar Engineering Conference. 2002, The International Society of Offshore and Polar Engineers: Kitakyushu, Japan. p. 687-693.

36. Setoguchi, T., et al., Hysteretic Characteristics of Wells Turbine for Wave Power Conversion. Renewable Energy, 2003. 28(13): p. 2113-2127.

37. Torresi, M., et al., Accurate numerical simulation of a high solidity Wells turbine. Renewable Energy, 2008. 33(4): p. 735-747.

38. Raghunathan, S., C.P. Tan, and N.A.J. Wells, Wind Tunnel Tests on Airfoils in Tandem Cascade. AIAA Journal, 1981. 19(11): p. 1490-1492.

39. Kim, T.H., et al., Numerical investigation on the effect of blade sweep on the performance of Wells turbine. Renewable Energy, 2002. 25: p. 235-248.

40. Setoguchi, T., et al., Effect of Rotor Geometry on the Performance of Wells Turbine, in The Thirteenth International Offshore and Polar Engineering Conference. 2003, The International Society of Offshore and Polar Engineers: Honolulu, Hawaii, USA. p. 374-381.

41. Paderi, M. and P. Puddu, Experimental investigation in a Wells turbine under bi-directional flow. Renewable Energy, 2013. 57: p. 570-576.

42. Setoguchi, T., et al., A modified Wells turbine for wave energy conversion. Renewable Energy, 2003. 28: p. 79-91.

43. Christopher Koroneos, Thomas Spachos, and N. Moussiopoulos, Exergy analysis of renewable energy sources. Renewable Energy, 2003. 28(2003): p. 295-310.

44. Mohamed, M.H., et al., Multi-objective Optimization of the Airfoil Shape of Wells Turbine used for Wave Energy Conversion. Energy, 2011. 36(1): p. 438-446.

45. Shehata, A.S., et al., Entropy Generation Due to Viscous Dissipation around a Wells Turbine Blade: A Preliminary Numerical Study. Energy Procedia, 2014. 50: p. 808-816.

46. Shehata, A.S., et al., Performance Analysis of Wells Turbine Blades Using the Entropy Generation Minimization Method. Renewable Energy86 .2016, : p. 1123-1133.

47. Soltanmohamadi, R. and E. Lakzian, Improved design of Wells turbine for wave energy conversion using entropy generation. Meccanica, Springer Netherlands., 2015. 51(8): p. 17131722.

48. Mahboubidoust, A. and A. Ramiar, Investigation of DBD plasma actuator effect on the aerodynamic and thermodynamic performance of high solidity Wells turbine. Renewable Energy, 2017. 112: p. 347-364.

49. Nazeryan, M. and E. Lakzian, Detailed entropy generation analysis of a Wells turbine using the variation of the blade thickness. Energy, 2018. 143: p. 385-405.

50. Alklaibi, A.M., M.N. Khan, and W.A. Khan, Thermodynamic analysis of gas turbine with air bottoming cycle. Energy, 2016. 107: p. 603-611.

51. Yucer, C.T., Thermodynamic analysis of the part load performance for a small scale gas turbine jet engine by using exergy analysis method. Energy, 2016. 111: p. 251-259.

52. Pope, K., I. Dincer, and G.F. Naterer, Energy and Exergy Efficiency Comparison of Horizontal and Vertical Axis Wind Turbines. Renewable Energy, 2010. 35(9): p. 2102-2113.

53. Baskut, O., O. Ozgener, and L. Ozgener, Effects of Meteorological Variables on Exergetic Efficiency of Wind Turbine Power Plants. Renewable and Sustainable Energy Reviews, 2010. 14(9): p. 3237-3241. 
54. Redha, A.M., I. Dincer, and M. Gadalla, Thermodynamic Performance Assessment of Wind Energy Systems: An Application. Energy, 2011. 36(7): p. 4002-4010.

55. Baskut, O., O. Ozgener, and L. Ozgener, Second Law Analysis of Wind Turbine Power Plants: Cesme, Izmir Example. Energy, 2011. 36(5): p. 2535-2542.

56. Shehata, A.S., et al., Enhancement of performance of Wave Turbine during Stall Using Passive Flow Control: First and Second Law Analysis. Renewable Energy, 2017. 113: p. 369-392.

57. Ismail, M.F. and K. Vijayaraghavan, The effects of aerofoil profile modification on a vertical axis wind turbine performance. Energy, 2015. 80: p. 20-31.

58. Yousefi, K., R. Saleh, and P. Zahedi, Numerical study of blowing and suction slot geometry optimization on NACA 0012 airfoil. Journal of Mechanical Science and Technology, 2014. 28(4): p. $1297-1310$.

59. Chapin, V.G. and E. Benard, Active Control of a Stalled Airfoil Through Steady or Unsteady Actuation Jets. Journal of Fluids Engineering, 2015. 137(9): p. 091103.

60. Schatz, M., B. G"unther, and F. Thiele, Computational Investigation of Separation Control for High-Lift Airfoil Flows. Active Flow Control, ed. P.D.R. King. Vol. 95. 2007, Berlin, Germany. 173189.

61. Chawla, J.S., et al., Efficiency improvement study for small wind turbines through flow control. Sustainable Energy Technologies and Assessments, 2014. 7: p. 195-208.

62. Fernandez, E., R. Kumar, and F. Alvi, Separation Control on a Low-Pressure Turbine Blade using Microjets. Journal of Propulsion and Power, 2013. 29(4): p. 867-881.

63. Volino, R.J., O. Kartuzova, and M.B. Ibrahim, Separation Control on a Very High Lift Low Pressure Turbine Airfoil Using Pulsed Vortex Generator Jets. Journal of Turbomachinery, 2011. 133(4): p. 041021.

64. Schlichting, H., Boundary layer theory. McGraw-Hill, New York, USA, 1968: p. 347-362.

65. Richards, E.J. and C.H. Burge, An airfoil designed to give laminar flow over the surface with boundary layer suction. Aeronautical Research Council, R\&M 2263, 1943.

66. Walker, S.W. and W.G. Raymer, Wind tunnel test on the 30 percent symmetrical griffth aerofoil with ejection of air. Aeronautical Research Council, R\&M 2475, 1946.

67. Braslow, A.L., A history of suction type laminar flow control with emphasis on flight research, NASA History Division. Monograph in Aerospace History, 1999. 13.

68. Huang, L., P.G. Huang, and R.P. LeBeau, Numerical study of blowing and suction control mechanism on NACA0012 airfoil. Journal of Aircraft, 2004. 41(5): p. 1005-1013.

69. C. R. Rosas, Numerical simulation of flow separation control by oscillatort fluid injection. 2005, A\&M University: Texas

70. Akcayoz, E. and I.H. Tuncer, Numerical investigation of flow control over an airfoil using synthetic jets and its optimization. International Aerospace Conference, Turkey, 2009.

71. Kim, S.H. and C. Kim, Separation control on NACA23012 using synthetic jet. Aerospace Science and Technology, 2009. 13(4): p. 172-182.

72. Rumsey, C.L. and T. Nishino, Numerical study comparing RANS and LES approaches on a circulation control airfoil. International Journal of Heat and Fluid Flow, 2011. 32(5): p. 847-864.

73. B. Yagiz, O. Kandil, and Y.V. Pehlivanoglu, Drag minimization using active and passive flow control techniques. Aerospace Science and Technology, 2012. 17(1): p. 21-31.

74. Starzmann, R. and T. Carolus, Effect of Blade Skew Strategies on the Operating Range and Aeroacoustic Performance of the Wells Turbine. Journal of Turbomachinery, 2013. 136(1): p. 011003.

75. Starzmann, R. and T. Carolus, Model-Based Selection of Full-Scale Wells Turbines for Ocean Wave Energy Conversion and Prediction of their Aerodynamic and Acoustic Performances. Proceedings 
of the Institution of Mechanical Engineers, Part A: Journal of Power and Energy, 2013. 228(1): $p$.

76. Maizi, M., et al., Noise reduction of a horizontal wind turbine using different blade shapes. Renewable Energy, 2018. 117: p. 242-256.

77. Botha, J.D.M., A. Shahroki, and H. Rice, An implementation of an aeroacoustic prediction model for broadband noise from a vertical axis wind turbine using a CFD informed methodology. Journal of Sound and Vibration, 2017. 410: p. 389-415.

78. Wasala, S.H., et al., Aeroacoustic noise prediction for wind turbines using Large Eddy Simulation. Journal of Wind Engineering and Industrial Aerodynamics, 2015. 145: p. 17-29.

79. Shaltout, M.L., et al., Tradeoff analysis of energy harvesting and noise emission for distributed wind turbines. Sustainable Energy Technologies and Assessments, 2015. 10: p. 12-21.

80. Kaviani, H.R. and A. Nejat, Aerodynamic noise prediction of a MW-class HAWT using shear wind profile. Journal of Wind Engineering and Industrial Aerodynamics, 2017. 168: p. 164-176.

81. Solís-Gallego, I., et al., LES-based numerical prediction of the trailing edge noise in a small wind turbine airfoil at different angles of attack. Renewable Energy, 2018. 120: p. 241-254.

82. Rumpfkeil, M.P., Using steady flow analysis for noise predictions. Computers \& Fluids, 2017. 154: p. 347-357.

83. Gea-Aguilera, F., J. Gill, and X. Zhang, Synthetic turbulence methods for computational aeroacoustic simulations of leading edge noise. Computers \& Fluids, 2017. 157: p. 240-252.

84. Wang, J., et al., Numerical study on reduction of aerodynamic noise around an airfoil with biomimetic structures. Journal of Sound and Vibration, 2017. 394: p. 46-58.

85. Avallone, F., W.C.P. van der Velden, and D. Ragni, Benefits of curved serrations on broadband trailing-edge noise reduction. Journal of Sound and Vibration, 2017. 400: p. 167-177.

86. Shen, X., et al., Surface curvature effects on the tonal noise performance of a low Reynolds number aerofoil. Applied Acoustics, 2017. 125: p. 34-40.

87. Miotto, R.F., W.R. Wolf, and L.D. de Santana, Numerical computation of aeroacoustic transfer functions for realistic airfoils. Journal of Sound and Vibration, 2017. 407: p. 253-270.

88. Siozos-Rousoulis, L., C. Lacor, and G. Ghorbaniasl, $A$ flow control technique for noise reduction of a rod-airfoil configuration. Journal of Fluids and Structures, 2017. 69: p. 293-307.

89. Mørk, G., et al., ASSESSING THE GLOBAL WAVE ENERGY POTENTIAL, in 29th International Conference on Ocean, Offshore Mechanics and Arctic Engineering. 2010, ASME: Shanghai, China.

90. Barstow, S., et al., WorldWaves wave energy resource assessments from the deep ocean to the coast, in The 8th European Wave and Tidal Energy Conference. 2009, Proceedings of the 8th European Wave and Tidal Energy Conference: Uppsala, Sweden.

91. Zodiatis, G., et al., Wave energy potential in the Eastern Mediterranean Levantine Basin. An integrated 10-year study. Renewable Energy, 2014. 69: p. 311-323.

92. Ayat, B., Wave power atlas of Eastern Mediterranean and Aegean Seas. Energy, 2013. 54: p. 251-262.

93. Shehata, A.S., et al., Passive flow control for aerodynamic performance enhancement of airfoil with its application in Wells turbine - Under oscillating flow condition. Ocean Engineering, 2017. 136: p. 31-53.

94. SB., P., Turbulent flows. Cambridge University Press, 2000.

95. DAHLSTROM, S., LARGE EDDY SIMULATION OF THE FLOW AROUND A HIGH-LIFT AIRFOIL, in Department of Thermo and Fluid Dynamics. 2003, CHALMERS UNIVERSITY OF TECHNOLOGY: Goteborg, Sweden. p. 62.

96. Moin P, S.K., Cabot W, Lee S., A dynamic subgrid-scale model for compressible turbulence and scalar transport. Physics Fluids A, 1991. 3(11): p. 2746-57. 
97. DK., L., A proposed modification of the Germano subgrid-scale closure method. Physics Fluids A, 1992. 4(3): p. 633-5.

98. Hinze, J.O., Turbulence. 1975, New York: McGraw-Hill Publishing Co.

99. Launder, B.E. and D.B. Spalding, Lectures in Mathematical Models of Turbulence. 1972, London, England: Academic Press.

100. Mamun, M., et al., Hysteretic Flow Characteristics of Biplane Wells Turbine. Ocean Engineering, 2004. 31(11-12): p. 1423-1435.

101. Curran, R., et al., Performance Prediction of Contrarotating Wells Turbines for Wave Energy Converter Design. Journal of Energy Engineering, 1998. 124(2): p. 35-53.

102. Whittaker, T.J.T., T.P. Stewart, and R. Curran, Design synthesis of oscillating water column wave energy converters: performance matching. Proceedings of the Institution of Mechanical Engineers, Part A: Journal of Power and Energy, 1997. 211(6): p. 489-505.

103. Hirsch, C., Numerical Computation of Internal and External Flows: The Fundamentals of Computational Fluid Dynamics. 2007: Elsevier Science.

104. Bejan, A., Entropy Generation Minimization- The New Thermodynamics of Finite-Size Devices and Finite-Time Processes. Applied Physics Reviews, 1996. 79(3): p. 1191-1218.

105. A. Stodola, Steam and Gas Turbines (McGraw-Hill, New York). 1910.

106. Iandoli, C.L., 3-D Numerical Calculation of the Local Entropy Generation Rates in a Radial Compressor Stage. International journal of thermodynamics, 2005. 8: p. 83-94.

107. Bejan, A., Entropy Generation Minimization: The Method of Thermodynamic Optimization of Finite-Size Systems and Finite-Time Processes. 1995: Taylor \& Francis.

108. Lighthill, M.J., On sound generated aerodynamically I. General theory. Proceedings of the royal society a mathematical physical and engineering sciences, 1952. 211(1107): p. 564-587.

109. Lighthill, M.J., Sound generated aerodynamically.II.Turbulence as a source of sound. Proceedings of the royal society a mathematical physical and engineering sciences, 1954. 222(1148): p. 1-32.

110. Williams, J.E.F. and D.L.Hawkings, Theory relating to the noise of rotating machinery. Journal of Sound and Vibration, 1969. 10(1): p. 10-21.

111. Mohamed, M.H. and S. Shaaban, Optimization of Blade Pitch Angle of an Axial Turbine Used for Wave Energy Conversion. Energy, 2013. 56: p. 229-239.

112. Torresi, M., S.M. Camporeale, and G. Pascazio, Detailed CFD Analysis of the Steady Flow in a Wells Turbine Under Incipient and Deep Stall Conditions. Journal of Fluids Engineering, 2009. 131(7): p. 071103.

113. Smagorinsky, J., General Circulation Experiments with the Primitive Equations. I. The Basic Experiment. Month. Wea. Rev., 1963. 91: p. pp.99-164.

114. Kinoue, Y., et al., Mechanism of Hysteretic Characteristics of Wells Turbine for Wave Power Conversion. Journal of Fluids Engineering, 2003. 125(2): p. 302.

115. DE Moura, C.A.K., Carlos S., The Courant-Friedrichs-Lewy (CFL) Condition: 80 Years After Its Discovery. 1 ed. 2013, Boston: Birkhäuser Basel.

116. Nomura, T., et al., Aerodynamic Forces on a Square Cylinder in Oscillating Flow with Mean Velocity. Journal of Wind Engineering and Industrial Aerodynamics, 2003. 91: p. 199-208.

117. Kawai, S. and K. Asada, Wall-modeled large-eddy simulation of high Reynolds number flow around an airfoil near stall condition. Computers \& Fluids, 2013. 85: p. 105-113.

118. Richez, F., et al., Zonal RANS/LES coupling simulation of a transitional and separated flow around an airfoil near stall. Theoretical and Computational Fluid Dynamics, 2007. 22(3-4): p. 305-315.

119. Alferez, N., I. Mary, and E. Lamballais, Study of Stall Development Around an Airfoil by Means of High Fidelity Large Eddy Simulation. Flow, Turbulence and Combustion, 2013. 91(3): p. 623-641.

120. Kim, Y., I.P. Castro, and Z.T. Xie, Large-Eddy Simulations for Wind Turbine Blade: Dynamic Stall and Rotational Augmentation. 2015. 20: p. 369-375. 
121. AlMutairi, J., I. AlQadi, and E. ElJack, Large Eddy Simulation of a NACA-0012 Airfoil Near Stall. 2015. 20: p. 389-395.

122. Armenio, V., B. Geurts, and J. Fröhlich, Large Eddy Simulation of Flow Around an Airfoil Near Stall. 2010. 13: p. 541-545.

123. Hitiwadi, M., et al., Large Eddy Simulations of 2D and Open-tip Airfoils Using Voxel Meshes. Procedia Engineering, 2013. 61: p. 32-39.

124. Bromby, D.Y.a.W., Large-Eddy Simulation of Unsteady Separation Over a Pitching Airfoil at High Reynolds Number, in Seventh International Conference on Computational Fluid Dynamics (ICCFD7). 2012: Big Island, Hawaii.

125. SKYLLINGSTAD, E.D. and H.W. WIJESEKERA, Large-Eddy Simulation of Flow over TwoDimensional Obstacles: High Drag States and Mixing. Journal of physical oceanography, 2004. 34: p. 94-112.

126. Avdis, A., S. Lardeau, and M. Leschziner, Large Eddy Simulation of Separated Flow over a Twodimensional Hump with and without Control by Means of a Synthetic Slot-jet. Flow, Turbulence and Combustion, 2009. 83(3): p. 343-370.

127. Cheng, W.-C. and F. Porté-Agel, Evaluation of subgrid-scale models in large-eddy simulation of flow past a two-dimensional block. International Journal of Heat and Fluid Flow, 2013. 44: p. 301-311.

128. Christian Tenaud and L.T. Phuoc, Large eddy simulation of unsteady, compressible, separated flow around NACA 0012 airfoil, in Fifteenth International Conference on Numerical Methods in Fluid Dynamics. 1997. p. pp 424-429.

129. Ashvinkumar Chaudhari, et al., Large Eddy Simulation of Boundary-Layer Flows over TwoDimensional Hills, in Industrial Mathematics at ECMI 2012. 2012, Springer International Publishing Switzerland 2014. p. 211-218.

130. Özgökmen, T.M., et al., Large eddy simulation of stratified mixing in two-dimensional dam-break problem in a rectangular enclosed domain. Ocean Modelling, 2007. 16(1-2): p. 106-140.

131. Michioka, T., et al., Large-Eddy Simulation for the Mechanism of Pollutant Removal from a TwoDimensional Street Canyon. Boundary-Layer Meteorology, 2010. 138(2): p. 195-213.

132. Chung, T.N.H. and C.-H. Liu, On the Mechanism of Air Pollutant Removal in Two-Dimensional Idealized Street Canyons: A Large-Eddy Simulation Approach. Boundary-Layer Meteorology, 2013. 148(1): p. 241-253.

133. Andrej Horvata, I.K., Jure Marnb, Two dimensional large eddy simulation of turbulent natural convection due to internal heat generation. international journal of heat and mass transfer, 2001. 44(21): p. 3985-3995.

134. Matos, A.d., F.A.A. Pinho, and A. Silveira!Neto, Large-eddy simulation of turbulent $\sim$ ow over a two! dimensional cavity with temperature uctuations. International Journal of Heat and Mass Transfer, 1999. 42: p. 3848.

135. Torresi, M., S. Camporeale, and G. Pascazio, Performance of a Small Prototype of a High Solidity Wells Turbine, in Seventh European Conference on Turbomachinery Fluid Dynamics and Thermodynamics. 2007: Athens, Greece

136. Torresi, M., S. Camporeale, and G. Pascazio, Experimental and Numerical Investigation on the Performance of a Wells Turbine Prototype, in Seventh European Wave and Tidal Energy Conference. 2007: Porto, Portugal

137. Selim, M.M., R.P. Koomullil, and A.S. Shehata, Incremental approach for radial basis functions mesh deformation with greedy algorithm. Journal of Computational Physics, 2017. 340: p. 556574.

138. Elbatran, A.H., Y.M. Ahmed, and A.S. Shehata, Performance study of ducted nozzle Savonius water turbine, comparison with conventional Savonius turbine. Energy, 2017. 134: p. 566-584. 
Table 1 The error percentage between measured torque coefficient from reference (Torresi 2007) and calculated torque coefficient from CFD under unsteady flow with non-oscillating velocity

\begin{tabular}{|c||c|c|c|c|c|c|c|c||}
\hline \multirow{2}{*}{$\begin{array}{c}\text { Torque } \\
\text { Coefficient }\end{array}$} & \multicolumn{8}{|c||}{ Angle of attack (Degree) } \\
\cline { 2 - 10 } & 8.7 & 10.1 & 10.6 & 11.3 & 11.7 & 12.304 & 13.6 & 14.4 \\
\hline Experimental & 0.04881 & 0.06305 & 0.07119 & 0.08068 & 0.08746 & 0.0922 & 0.08136 & 0.07254 \\
\hline CFD & 0.050918 & 0.066887 & 0.07264 & 0.07928 & 0.08564 & 0.09103 & 0.08304 & 0.067587 \\
\hline Error \% & 4 & 6 & 2 & -2 & -2 & -1 & 2 & -7 \\
\hline \hline
\end{tabular}

Table 2 The error percentage between measured $F_{D}$ from reference (Nomura, Suzuki et al. 2003) and calculated $F_{D}$ from CFD under unsteady flow with sinusoidal inlet velocity

\begin{tabular}{|c|c|c|c|c|c|c|c|c|c|c|c|c|c|}
\hline \multicolumn{14}{|c|}{ Frequency 2 Hz } \\
\hline \multirow{2}{*}{$F_{D}(\mathbf{g f})$} & \multicolumn{13}{|c|}{ Time (Second) } \\
\hline & 14.02 & 14.1 & 14.12 & 14.2 & 14.3 & 14.34 & 14.4 & 14.5 & 14.6 & 14.7 & 14.8 & 14.9 & 15 \\
\hline Experimental & 3.4 & 7.7 & 9.9 & 14.4 & 12.9 & 3.4 & 4.11 & 2.3 & 7.5 & 14.7 & 10.7 & 3.9 & 2.7 \\
\hline CFD & 3.8 & 7.8 & 9.8 & 14.5 & 12.5 & 3.5 & 3.4 & 2.7 & 7.8 & 14.9 & 10.9 & 3.8 & 2.4 \\
\hline Error \% & 11 & 1 & -1 & 1 & -4 & 1 & -17 & 17 & 4 & 1 & 2 & -2 & -11 \\
\hline \multicolumn{14}{|c|}{ Frequency $1 \mathrm{~Hz}$} \\
\hline Experimental & 4.5 & 6.9 & 12.6 & 14.1 & 14.3 & 13 & 10.2 & 7.8 & 4.7 & 2.8 & 2.3 & 2.5 & 3 \\
\hline CFD & 4.6 & 7.2 & 12.6 & 13.1 & 14.3 & 13.2 & 10.3 & 8.6 & 4.5 & 2.7 & 2.2 & 2.6 & 3.3 \\
\hline Error \% & 2 & 4 & 0 & -7 & 0 & 1 & 1 & 10 & -4 & 1 & -4 & 4 & 10 \\
\hline
\end{tabular}


Table 3 The suction slot with different position angles at NACA0015.

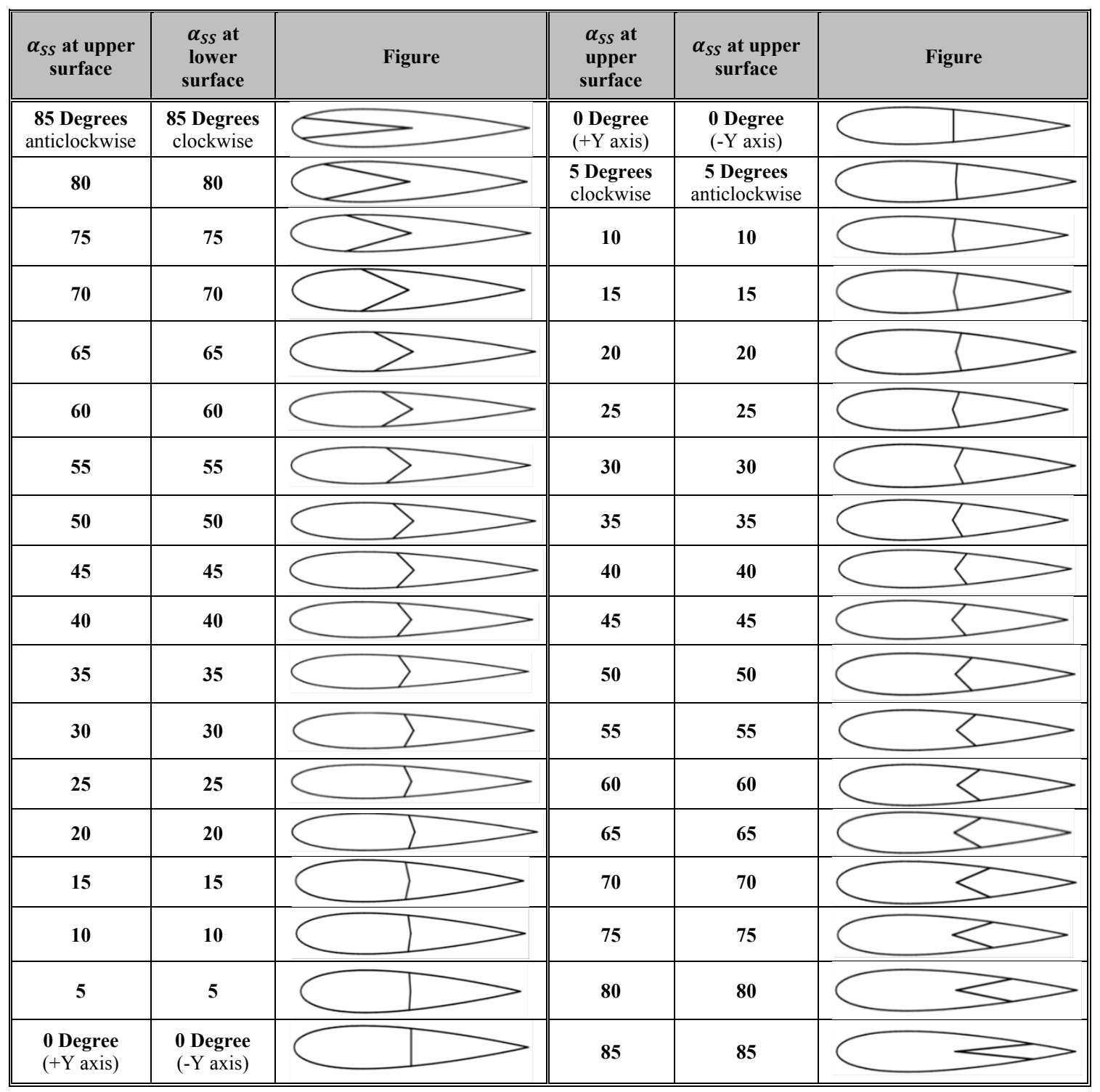


Table 4 The value of improvement in torque coefficient for suction slot with different position angles under non-oscillating velocity.

\begin{tabular}{|c|c|c|c|c|c|}
\hline $\begin{array}{c}\boldsymbol{\alpha}_{\boldsymbol{S S}} \\
\text { (anticlockwise) }\end{array}$ & $\boldsymbol{C}_{\boldsymbol{T}}$ & improvement & $\begin{array}{c}\boldsymbol{\alpha}_{\boldsymbol{S S}} \\
\text { (clockwise) }\end{array}$ & $\boldsymbol{C}_{\boldsymbol{T}}$ & improvement \\
\hline \hline $\mathbf{8 5}$ Degrees & 0.098 & $17 \%$ & $\mathbf{0}$ Degree & 0.115 & $38 \%$ \\
\hline $\mathbf{8 0}$ & 0.111 & $32 \%$ & $\mathbf{5}$ & 0.106 & $26 \%$ \\
\hline $\mathbf{7 5}$ & 0.097 & $16 \%$ & $\mathbf{1 0}$ & 0.130 & $55 \%$ \\
\hline $\mathbf{7 0}$ & 0.097 & $16 \%$ & $\mathbf{1 5}$ & 0.095 & $13 \%$ \\
\hline $\mathbf{6 5}$ & 0.133 & $58 \%$ & $\mathbf{2 0}$ & 0.125 & $49 \%$ \\
\hline $\mathbf{6 0}$ & 0.129 & $53 \%$ & $\mathbf{2 5}$ & 0.113 & $35 \%$ \\
\hline $\mathbf{5 5}$ & 0.132 & $57 \%$ & $\mathbf{3 0}$ & 0.101 & $20 \%$ \\
\hline $\mathbf{5 0}$ & 0.121 & $44 \%$ & $\mathbf{3 5}$ & 0.134 & $60 \%$ \\
\hline $\mathbf{4 5}$ & 0.100 & $19 \%$ & $\mathbf{4 0}$ & 0.107 & $27 \%$ \\
\hline $\mathbf{4 0}$ & 0.094 & $11 \%$ & $\mathbf{4 5}$ & 0.114 & $35 \%$ \\
\hline $\mathbf{3 5}$ & 0.106 & $26 \%$ & $\mathbf{5 0}$ & 0.116 & $38 \%$ \\
\hline $\mathbf{3 0}$ & 0.104 & $24 \%$ & $\mathbf{5 5}$ & 0.118 & $40 \%$ \\
\hline $\mathbf{2 5}$ & 0.128 & $52 \%$ & $\mathbf{6 0}$ & 0.112 & $33 \%$ \\
\hline $\mathbf{2 0}$ & 0.102 & $21 \%$ & $\mathbf{6 5}$ & 0.112 & $33 \%$ \\
\hline $\mathbf{1 5}$ & 0.125 & $49 \%$ & $\mathbf{7 0}$ & 0.096 & $15 \%$ \\
\hline $\mathbf{1 0}$ & 0.120 & $42 \%$ & $\mathbf{7 5}$ & 0.107 & $28 \%$ \\
\hline $\mathbf{5}$ & 0.118 & $41 \%$ & $\mathbf{8 0}$ & 0.112 & $33 \%$ \\
\hline $\mathbf{0}$ & 0.115 & $38 \%$ & $\mathbf{8 5}$ & 0.099 & $18 \%$ \\
\hline
\end{tabular}

Improvement in $\boldsymbol{C}_{\boldsymbol{T}}$ value higher than that for slot with 0 Degree 
Table 5 The value of global entropy generation rate for suction slot with different position angles under non-oscillating velocity.

\begin{tabular}{|c|c|c||c|c|c||}
\hline $\begin{array}{c}\boldsymbol{\alpha}_{\boldsymbol{S S}} \\
\text { (anticlockwise) }\end{array}$ & $\boldsymbol{S}_{\boldsymbol{G}}$ & increased by & $\begin{array}{c}\boldsymbol{\alpha}_{\boldsymbol{S S}} \\
\text { (clockwise) }\end{array}$ & $\boldsymbol{S}_{\boldsymbol{G}}$ & increased by \\
\hline $\mathbf{8 5}$ Degrees & 0.147 & $71 \%$ & $\mathbf{0 ~ D e g r e e ~}$ & 0.104 & $21 \%$ \\
\hline $\mathbf{8 0}$ & 0.138 & $60 \%$ & $\mathbf{5}$ & 0.105 & $22 \%$ \\
\hline $\mathbf{7 5}$ & 0.144 & $68 \%$ & $\mathbf{1 0}$ & 0.093 & $8 \%$ \\
\hline $\mathbf{7 0}$ & 0.138 & $60 \%$ & $\mathbf{1 5}$ & 0.104 & $21 \%$ \\
\hline $\mathbf{6 5}$ & 0.121 & $40 \%$ & $\mathbf{2 0}$ & 0.113 & $31 \%$ \\
\hline $\mathbf{6 0}$ & 0.143 & $66 \%$ & $\mathbf{2 5}$ & 0.120 & $39 \%$ \\
\hline $\mathbf{5 5}$ & 0.112 & $30 \%$ & $\mathbf{3 0}$ & 0.117 & $36 \%$ \\
\hline $\mathbf{5 0}$ & 0.118 & $37 \%$ & $\mathbf{3 5}$ & 0.106 & $23 \%$ \\
\hline $\mathbf{4 5}$ & 0.158 & $84 \%$ & $\mathbf{4 0}$ & 0.148 & $72 \%$ \\
\hline $\mathbf{4 0}$ & 0.166 & $93 \%$ & $\mathbf{4 5}$ & 0.117 & $36 \%$ \\
\hline $\mathbf{3 5}$ & 0.108 & $25 \%$ & $\mathbf{5 0}$ & 0.139 & $62 \%$ \\
\hline $\mathbf{3 0}$ & 0.131 & $52 \%$ & $\mathbf{5 5}$ & 0.118 & $37 \%$ \\
\hline $\mathbf{2 5}$ & 0.119 & $38 \%$ & $\mathbf{6 0}$ & 0.143 & $66 \%$ \\
\hline $\mathbf{2 0}$ & 0.104 & $21 \%$ & $\mathbf{6 5}$ & 0.111 & $29 \%$ \\
\hline $\mathbf{1 5}$ & 0.093 & $8 \%$ & $\mathbf{7 0}$ & 0.119 & $39 \%$ \\
\hline $\mathbf{1 0}$ & 0.101 & $18 \%$ & $\mathbf{7 5}$ & 0.129 & $50 \%$ \\
\hline $\mathbf{5}$ & 0.110 & $28 \%$ & $\mathbf{8 0}$ & 0.124 & $44 \%$ \\
\hline $\mathbf{0}$ & 0.104 & $21 \%$ & $\mathbf{8 5}$ & 0.137 & $59 \%$ \\
\hline & Increased in $\boldsymbol{S}_{\boldsymbol{G}}$ value $10 w 6$ than that for slot with 0 Degree \\
\hline
\end{tabular}


Table 6 The value of improvement in torque coefficient for NACA0015 with suction slot at different position angles under sinusoidal inlet velocity

\begin{tabular}{|c|c|c|c|c|c|}
\hline \multirow{2}{*}{ Torque Coefficient } & \multicolumn{5}{|c|}{ Angle of attack (Degree) } \\
\hline & 11.3 & 11.7 & 12.3 & 13.6 & 14.4 \\
\hline NACA0015 Without suction slot & 0.080 & 0.088 & 0.093 & 0.083 & 0.071 \\
\hline Suction slots with $\alpha_{S S}=0$ (degree) & 0.102 & 0.099 & 0.105 & 0.102 & 0.095 \\
\hline Improvement by & $27 \%$ & $13 \%$ & $13 \%$ & $23 \%$ & $35 \%$ \\
\hline Average value & \multicolumn{3}{|c|}{ Before the stall (18\%) } & \multicolumn{2}{|c|}{ After the stall (29\%) } \\
\hline $\begin{array}{c}\text { Suction slots with } \alpha_{S S}=55 \\
\text { Anticlockwise }\end{array}$ & 0.099 & 0.102 & 0.107 & 0.110 & 0.109 \\
\hline Improvement by & $23 \%$ & $16 \%$ & $15 \%$ & $33 \%$ & $54 \%$ \\
\hline Average value & \multicolumn{3}{|c|}{ Before the stall (18\%) } & \multicolumn{2}{|c|}{ After the stall (44\%) } \\
\hline $\begin{array}{c}\text { Suction slots with } \alpha_{S S}= \\
65 \text { Anticlockwise }\end{array}$ & 0.1 & 0.105 & 0.105 & 0.106 & 0.083 \\
\hline Improvement by & $24 \%$ & $19 \%$ & $13 \%$ & $29 \%$ & $16 \%$ \\
\hline Average value & \multicolumn{3}{|c|}{ Before the stall (19\%) } & \multicolumn{2}{|c|}{ After the stall (23\%) } \\
\hline Suction slots with $\alpha_{S S}=35$ Clockwise & 0.100 & 0.104 & 0.108 & 0.110 & 0.101 \\
\hline Improvement by & $25 \%$ & $18 \%$ & $16 \%$ & $33 \%$ & $42 \%$ \\
\hline Average value & \multicolumn{3}{|c|}{ Before the stall (20\%) } & \multicolumn{2}{|c|}{ After the stall $(38 \%)$} \\
\hline $\begin{array}{c}\text { Suction slots with } \alpha_{S S}= \\
15 \text { Anticlockwise }\end{array}$ & 0.1 & 0.102 & 0.107 & 0.109 & 0.093 \\
\hline Improvement by & $24 \%$ & $16 \%$ & $15 \%$ & $33 \%$ & $31 \%$ \\
\hline Average value & \multicolumn{3}{|c|}{ Before the stall (18\%) } & \multicolumn{2}{|c|}{ After the stall (32\%) } \\
\hline Suction slots with $\alpha_{S S}=10$ Clockwise & 0.102 & 0.106 & 0.109 & 0.112 & 0.108 \\
\hline Improvement by & $27 \%$ & $20 \%$ & $16 \%$ & $35 \%$ & $53 \%$ \\
\hline Average value & \multicolumn{3}{|c|}{ Before the stall (21\%) } & \multicolumn{2}{|c|}{ After the stall (44\%) } \\
\hline
\end{tabular}


Table 7 the value of global entropy generation rate for NACA0015 with suction slot at different position angles under sinusoidal inlet velocity

\begin{tabular}{|c|c|c|c|c|c|}
\hline \multirow{2}{*}{$\begin{array}{l}\text { The global entropy generation rate } \\
\qquad(\mathrm{W} / \mathrm{K})\end{array}$} & \multicolumn{5}{|c|}{ Angle of attack (Degree) } \\
\hline & 11.3 & 11.7 & 12.3 & 13.6 & 14.4 \\
\hline NACA0015 Without suction slot & 0.053 & 0.052 & 0.053 & 0.054 & 0.060 \\
\hline $\begin{array}{c}\text { Suction slots with } \alpha_{S S}= \\
0 \text { (degree) }\end{array}$ & 0.064 & 0.065 & 0.066 & 0.071 & 0.072 \\
\hline$S_{G}$ increased by & $20 \%$ & $27 \%$ & $26 \%$ & $33 \%$ & $19 \%$ \\
\hline Average value & \multicolumn{3}{|c|}{ Before the stall (24\%) } & \multicolumn{2}{|c|}{ After the stall (26\%) } \\
\hline $\begin{array}{c}\text { Suction slots with } \alpha_{S S}= \\
55 \text { Anticlockwise }\end{array}$ & 0.077 & 0.082 & 0.081 & 0.087 & 0.087 \\
\hline$S_{G}$ increased by & $45 \%$ & $59 \%$ & $55 \%$ & $63 \%$ & $43 \%$ \\
\hline Average value & \multicolumn{3}{|c|}{ Before the stall (53\%) } & \multicolumn{2}{|c|}{ After the stall (52\%) } \\
\hline $\begin{array}{c}\text { Suction slots with } \alpha_{S S}= \\
65 \text { Anticlockwise }\end{array}$ & 0.078 & 0.081 & 0.081 & 0.083 & 0.081 \\
\hline$S_{G}$ increased by & $47 \%$ & $57 \%$ & $54 \%$ & $55 \%$ & $35 \%$ \\
\hline Average value & \multicolumn{3}{|c|}{ Before the stall (53\%) } & \multicolumn{2}{|c|}{ After the stall (45\%) } \\
\hline $\begin{array}{c}\text { Suction slots with } \alpha_{S S}= \\
35 \text { Clockwise }\end{array}$ & 0.072 & 0.074 & 0.075 & 0.077 & 0.085 \\
\hline$S_{G}$ increased by & $35 \%$ & $43 \%$ & $42 \%$ & $44 \%$ & $41 \%$ \\
\hline Average value & \multicolumn{3}{|c|}{ Before the stall (40\%) } & \multicolumn{2}{|c|}{ After the stall (42\%) } \\
\hline $\begin{array}{c}\text { Suction slots with } \alpha_{S S}= \\
15 \text { Anticlockwise }\end{array}$ & 0.062 & 0.065 & 0.064 & 0.068 & 0.067 \\
\hline$S_{G}$ increased by & $16 \%$ & $27 \%$ & $21 \%$ & $26 \%$ & $10 \%$ \\
\hline Average value & \multicolumn{3}{|c|}{ Before the stall (21\%) } & \multicolumn{2}{|c|}{ After the stall (18\%) } \\
\hline $\begin{array}{l}\text { Suction slots with } \alpha_{S S}= \\
10 \text { Clockwise }\end{array}$ & 0.063 & 0.062 & 0.063 & 0.068 & 0.073 \\
\hline$S_{G}$ increased by & $18 \%$ & $20 \%$ & $21 \%$ & $27 \%$ & $20 \%$ \\
\hline Average value & \multicolumn{3}{|c|}{ Before the stall (20\%) } & \multicolumn{2}{|c|}{ After the stall (23\%) } \\
\hline
\end{tabular}

Minimum value 
Table 8 The overall sound pressure level in dB for NACA0015 under non-oscillating velocity at a far field receivers with different slot angle and different angles of attack

\begin{tabular}{|c|c|c|c|c|c|}
\hline \multirow{3}{*}{$\begin{array}{l}\text { Overall sound pressure level at } 35 \text { Chord } \\
\qquad \text { (dB) }\end{array}$} & \multicolumn{5}{|c|}{ Angle of attack (Degree) } \\
\hline & \multicolumn{3}{|c|}{ Before the stall } & \multicolumn{2}{|c|}{ After the stall } \\
\hline & 11.3 & 11.7 & 12.3 & 13.6 & 14.4 \\
\hline NACA0015 Without suction slot & 28.7 & 28.3 & 28.9 & 29.1 & 27.9 \\
\hline $\begin{array}{c}\text { Suction slots with } \alpha_{S S}=0 \\
\text { (degree) }\end{array}$ & 25.8 & 25.3 & 28.3 & 28.7 & 27.9 \\
\hline $\begin{array}{l}\text { Suction slots with } \alpha_{S S}=65 \text { Anticlockwise } \\
\text { (degree) }\end{array}$ & 25.5 & 23.6 & 25.9 & 25.2 & 25.2 \\
\hline $\begin{array}{c}\text { Suction slots with } \alpha_{S S}=35 \text { Clockwise } \\
\text { (degree) }\end{array}$ & 26.9 & 25.9 & 26.4 & 26.7 & 29.1 \\
\hline Max Noise Reduction by & $-11.2 \%$ & $-16.6 \%$ & $-10.4 \%$ & $-13.4 \%$ & $-9.7 \%$ \\
\hline \multicolumn{6}{|l|}{$\begin{array}{l}\text { Overall sound pressure level at } 128 \text { Chord } \\
\qquad \text { (dB) }\end{array}$} \\
\hline NACA0015 Without suction slot & 16.2 & 15.9 & 16.8 & 17.6 & 15.9 \\
\hline $\begin{array}{c}\text { Suction slots with } \alpha_{S S}=0 \\
\text { (degree) }\end{array}$ & 13.8 & 13.4 & 16.7 & 16.9 & 15.8 \\
\hline $\begin{array}{l}\text { Suction slots with } \alpha_{S S}=65 \text { Anticlockwise } \\
\text { (degree) }\end{array}$ & 13.7 & 11.7 & 13.7 & 13.2 & 13.2 \\
\hline $\begin{array}{c}\text { Suction slots with } \alpha_{S S}=35 \text { Clockwise } \\
\text { (degree) }\end{array}$ & 14.9 & 13.9 & 14.3 & 14.7 & 16.9 \\
\hline Max Noise Reduction by & $-15.4 \%$ & $-26.4 \%$ & $-18.5 \%$ & $-25 \%$ & $-17 \%$ \\
\hline
\end{tabular}


Table 9 The overall sound pressure level in dB for NACA0015 under oscillating velocity at a far field receivers with different slot angle and different angles of attack

\begin{tabular}{|c|c|c|c|c|c|}
\hline \multirow{3}{*}{$\begin{array}{l}\text { Overall sound pressure level at } 35 \text { Chord } \\
\qquad \text { (dB) }\end{array}$} & \multicolumn{5}{|c|}{ Angle of attack (Degree) } \\
\hline & \multicolumn{3}{|c|}{ Before the stall } & \multicolumn{2}{|c|}{ After the stall } \\
\hline & 11.3 & 11.7 & 12.3 & 13.6 & 14.4 \\
\hline NACA0015 Without suction slot & 36.2 & 36.6 & 36.7 & 39.8 & 38.4 \\
\hline Suction slots with $\alpha_{S S}=0$ (degree) & 34.9 & 35.2 & 35.8 & 37.3 & 36.9 \\
\hline Suction slots with $\alpha_{S S}=10$ Clockwise (degree) & 36.1 & 34.7 & 36.7 & 36.6 & 35.9 \\
\hline Suction slots with $\alpha_{S S}=35$ Clockwise (degree) & 34.7 & 34.8 & 37.6 & 37.3 & 37.8 \\
\hline Suction slots with $\alpha_{S S}=65$ Anticlockwise (degree) & 35 & 36.3 & 35.5 & 36.9 & 37 \\
\hline Suction slots with $\alpha_{S S}=55$ Anticlockwise (degree) & 34.9 & 35.1 & 34.8 & 37.5 & 36.3 \\
\hline Suction slots with $\alpha_{S S}=15$ Anticlockwise (degree) & 35 & 36.3 & 36.9 & 37.9 & 38.1 \\
\hline Max Noise Reduction by & $-4.1 \%$ & $-5.2 \%$ & $-5.2 \%$ & $-8 \%$ & $-6.5 \%$ \\
\hline \multicolumn{6}{|l|}{$\begin{array}{l}\text { Overall sound pressure level at } 128 \text { Chord } \\
\qquad \text { (dB) }\end{array}$} \\
\hline NACA0015 Without suction slot & 21.1 & 21.2 & 21.2 & 25.5 & 23.3 \\
\hline Suction slots with $\alpha_{S S}=0$ (degree) & 17.4 & 18.2 & 18.8 & 20.9 & 19.3 \\
\hline Suction slots with $\alpha_{S S}=10$ Clockwise (degree) & 20.2 & 17.6 & 20.9 & 20.6 & 17.9 \\
\hline Suction slots with $\alpha_{S S}=35$ Clockwise (degree) & 17.1 & 17.7 & 22.9 & 21 & 22.8 \\
\hline Suction slots with $\alpha_{S S}=65$ Anticlockwise (degree) & 18.3 & 20.1 & 19.1 & 21.2 & 21 \\
\hline Suction slots with $\alpha_{S S}=55$ Anticlockwise (degree) & 17.5 & 18.1 & 18.6 & 22.2 & 19.9 \\
\hline Suction slots with $\alpha_{S S}=15$ Anticlockwise (degree) & 19.1 & 22.5 & 19.9 & 22.1 & 20.6 \\
\hline Max Noise Reduction by & $-19 \%$ & $-17 \%$ & $-12.3 \%$ & $-19.2 \%$ & $-23.2 \%$ \\
\hline
\end{tabular}


Table 10 comparison between the torque coefficients values at different time periods under sinusoidal inlet velocity.

\begin{tabular}{|c|c|c|c|c|c|}
\hline \multirow{2}{*}{$\begin{array}{l}\text { Torque Coefficient } \\
\text { (4 Second) }\end{array}$} & \multicolumn{5}{|c|}{ Angle of attack (Degree) } \\
\hline & 11.3 & 11.7 & 12.3 & 13.6 & 14.4 \\
\hline NACA0015 Without suction slot & 0.116 & 0.118 & 0.124 & 0.115 & 0.110 \\
\hline $\begin{array}{c}\text { Suction slots with } \alpha_{S S}=0 \\
\text { (degree) }\end{array}$ & 0.125 & 0.128 & 0.125 & 0.130 & 0.118 \\
\hline Improvement by & \multicolumn{3}{|c|}{ Before the stall (6\%) } & \multicolumn{2}{|c|}{ After the stall (10\%) } \\
\hline $\begin{array}{c}\text { Suction slots with } \alpha_{S S}= \\
10 \text { Clockwise }\end{array}$ & 0.124 & 0.126 & 0.131 & 0.128 & 0.117 \\
\hline Improvement by & \multicolumn{3}{|c|}{ Before the stall (7\%) } & \multicolumn{2}{|c|}{ After the stall (9\%) } \\
\hline \multicolumn{6}{|l|}{$\begin{array}{l}\text { Torque Coefficient } \\
\text { (6 Second) }\end{array}$} \\
\hline NACA0015 Without suction slot & 0.080 & 0.088 & 0.093 & 0.083 & 0.071 \\
\hline $\begin{array}{c}\text { Suction slots with } \alpha_{S S}=0 \\
\text { (degree) }\end{array}$ & 0.102 & 0.099 & 0.105 & 0.102 & 0.095 \\
\hline Improvement by & \multicolumn{3}{|c|}{ Before the stall (18\%) } & \multicolumn{2}{|c|}{ After the stall (29\%) } \\
\hline $\begin{array}{c}\text { Suction slots with } \alpha_{S S}= \\
10 \text { Clockwise }\end{array}$ & 0.102 & 0.106 & 0.109 & 0.112 & 0.108 \\
\hline Improvement by & \multicolumn{3}{|c|}{ Before the stall (21\%) } & \multicolumn{2}{|c|}{ After the stall (44\%) } \\
\hline \multicolumn{6}{|l|}{$\begin{array}{l}\text { Torque Coefficient } \\
\text { (8 Second) }\end{array}$} \\
\hline NACA0015 Without suction slot & 0.082 & 0.078 & 0.084 & 0.088 & 0.075 \\
\hline $\begin{array}{c}\text { Suction slots with } \alpha_{S S}=0 \\
\text { (degree) }\end{array}$ & 0.086 & 0.092 & 0.093 & 0.099 & 0.081 \\
\hline Improvement by & \multicolumn{3}{|c|}{ Before the stall (11\%) } & \multicolumn{2}{|c|}{ After the stall (11\%) } \\
\hline $\begin{array}{c}\text { Suction slots with } \alpha_{S S}= \\
10 \text { Clockwise }\end{array}$ & 0.088 & 0.092 & 0.097 & 0.101 & 0.093 \\
\hline Improvement by & \multicolumn{3}{|c|}{ Before the stall (13\%) } & \multicolumn{2}{|c|}{ After the stall (20\%) } \\
\hline
\end{tabular}

Maximum value 
Table 11 comparison between the global entropy generation rate values at different time periods under sinusoidal inlet velocity.

\begin{tabular}{|c|c|c|c|c|c|}
\hline \multirow{2}{*}{$\begin{array}{l}\text { Global entropy generation rate } \\
\text { (4 Second) }\end{array}$} & \multicolumn{5}{|c|}{ Angle of attack (Degree) } \\
\hline & 11.3 & 11.7 & 12.3 & 13.6 & 14.4 \\
\hline NACA0015 Without suction slot & 0.057 & 0.059 & 0.057 & 0.065 & 0.066 \\
\hline $\begin{array}{c}\text { Suction slots with } \alpha_{S S}=0 \\
\text { (degree) }\end{array}$ & 0.066 & 0.066 & 0.069 & 0.073 & 0.074 \\
\hline$S_{G}$ increased by & \multicolumn{3}{|c|}{ Before the stall (16\%) } & \multicolumn{2}{|c|}{ After the stall (12\%) } \\
\hline $\begin{array}{l}\text { Suction slots with } \alpha_{S S}= \\
10 \text { Clockwise }\end{array}$ & 0.063 & 0.063 & 0.065 & 0.071 & 0.079 \\
\hline$S_{G}$ increased by & \multicolumn{3}{|c|}{ Before the stall (10\%) } & \multicolumn{2}{|c|}{ After the stall (14\%) } \\
\hline \multicolumn{6}{|l|}{$\begin{array}{l}\text { Global entropy generation rate } \\
\text { (6 Second) }\end{array}$} \\
\hline NACA0015 Without suction slot & 0.053 & 0.052 & 0.053 & 0.054 & 0.060 \\
\hline $\begin{array}{c}\text { Suction slots with } \alpha_{S S}=0 \\
\text { (degree) }\end{array}$ & 0.064 & 0.065 & 0.066 & 0.071 & 0.072 \\
\hline$S_{G}$ increased by & \multicolumn{3}{|c|}{ Before the stall (24\%) } & \multicolumn{2}{|c|}{ After the stall (26\%) } \\
\hline $\begin{array}{l}\text { Suction slots with } \alpha_{S S}= \\
10 \text { Clockwise }\end{array}$ & 0.063 & 0.062 & 0.063 & 0.068 & 0.073 \\
\hline$S_{G}$ increased by & \multicolumn{3}{|c|}{ Before the stall (20\%) } & \multicolumn{2}{|c|}{ After the stall (23\%) } \\
\hline \multicolumn{6}{|l|}{$\begin{array}{l}\text { Global entropy generation rate } \\
\qquad \text { (8 Second) }\end{array}$} \\
\hline NACA0015 Without suction slot & 0.053 & 0.053 & 0.054 & 0.056 & 0.060 \\
\hline $\begin{array}{c}\text { Suction slots with } \alpha_{s S}=0 \\
\text { (degree) }\end{array}$ & 0.063 & 0.062 & 0.064 & 0.065 & 0.073 \\
\hline$S_{G}$ increased by & \multicolumn{3}{|c|}{ Before the stall (18\%) } & \multicolumn{2}{|c|}{ After the stall (19\%) } \\
\hline $\begin{array}{l}\text { Suction slots with } \alpha_{S S}= \\
10 \text { Clockwise }\end{array}$ & 0.061 & 0.061 & 0.064 & 0.066 & 0.072 \\
\hline$S_{G}$ increased by & \multicolumn{3}{|c|}{ Before the stall (16\%) } & \multicolumn{2}{|c|}{ After the stall (18\%) } \\
\hline
\end{tabular}

Minimum value 

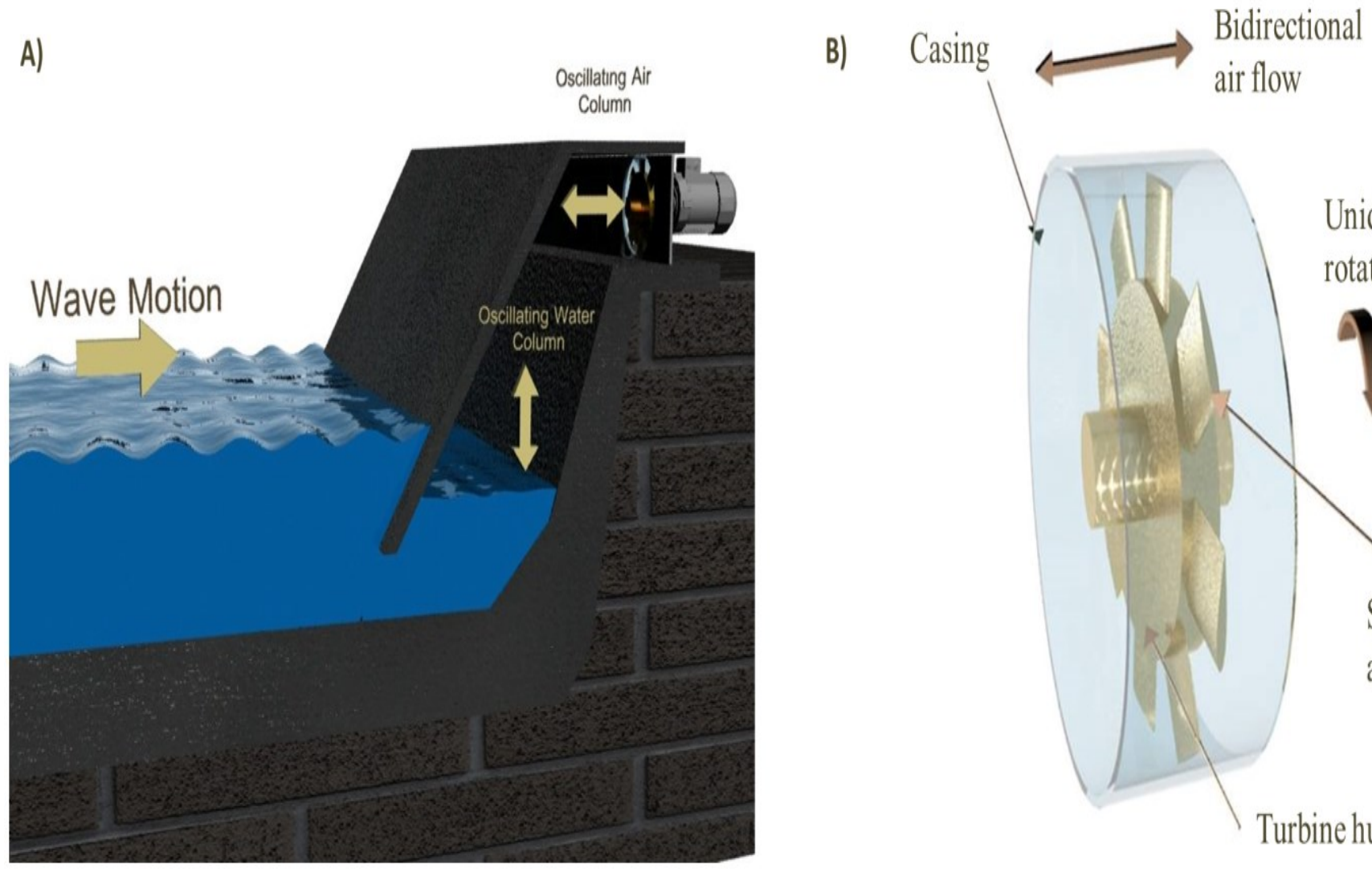

Figure Error! No text of specified style in document. OWC energy converters A) An illustration of the principle of operation of OWC system, where the wave motion is used to drive a turbine through the oscillation of air column B) Typical structure of Wells turbine rotor.

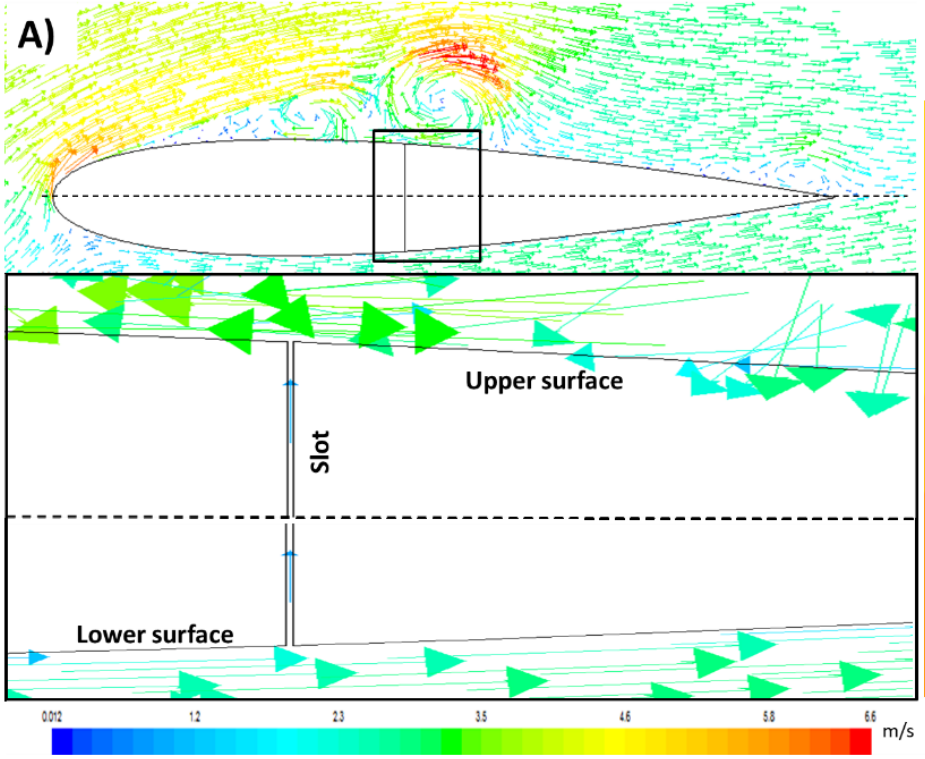

\section{Compression cycle}

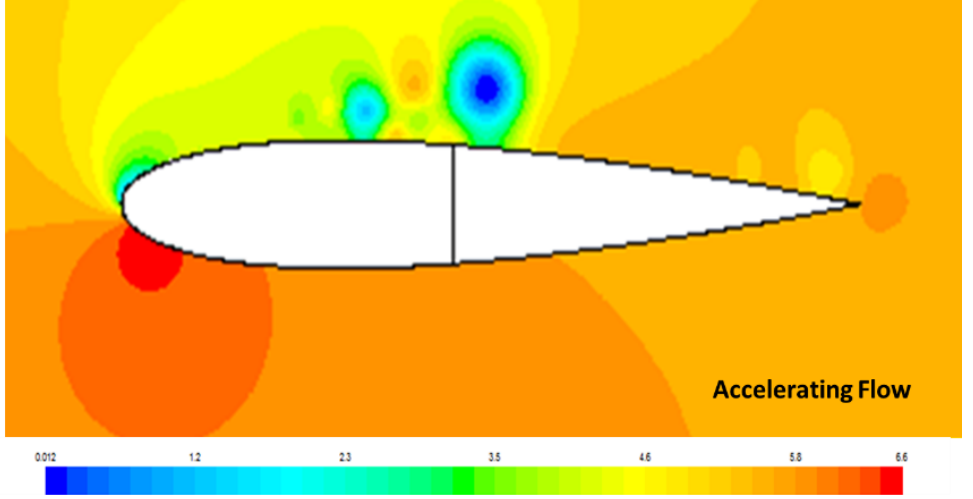




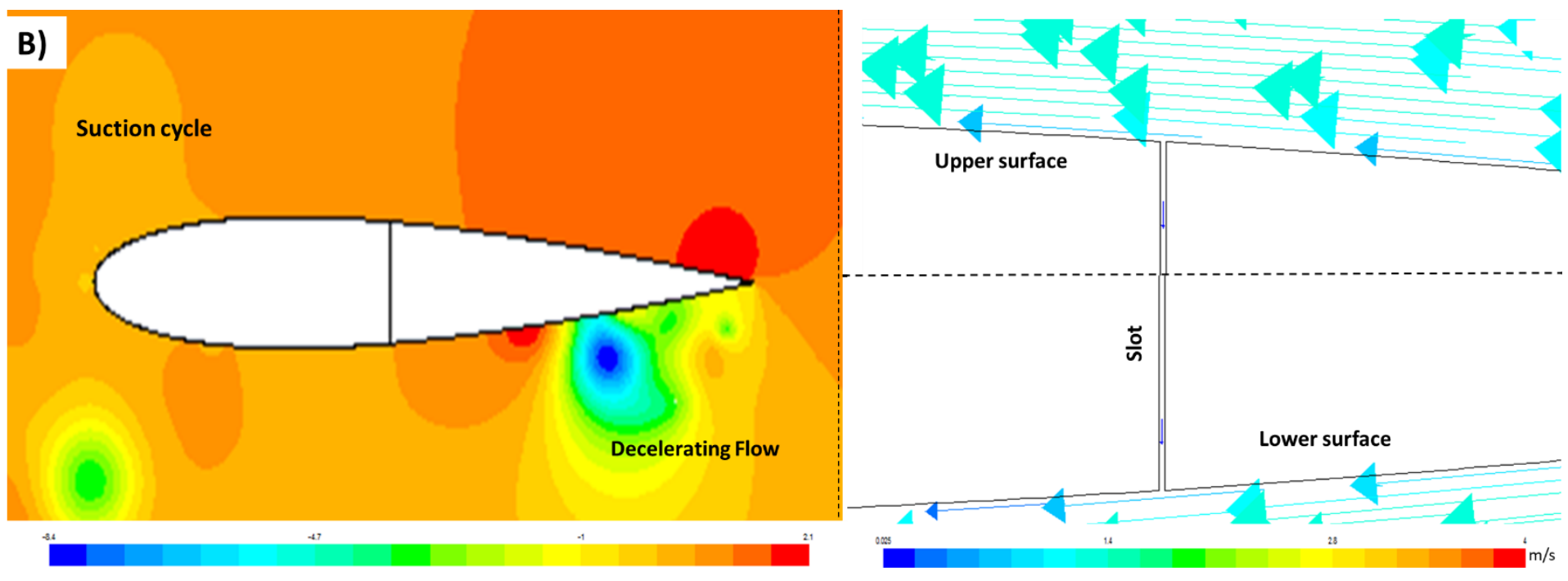

Figure 2 Factors affecting determination of the slot velocity direction for the pressure distribution and velocity vector direction $A$ ) accelerating flow at compression cycle B) decelerating flow at suction cycle. 

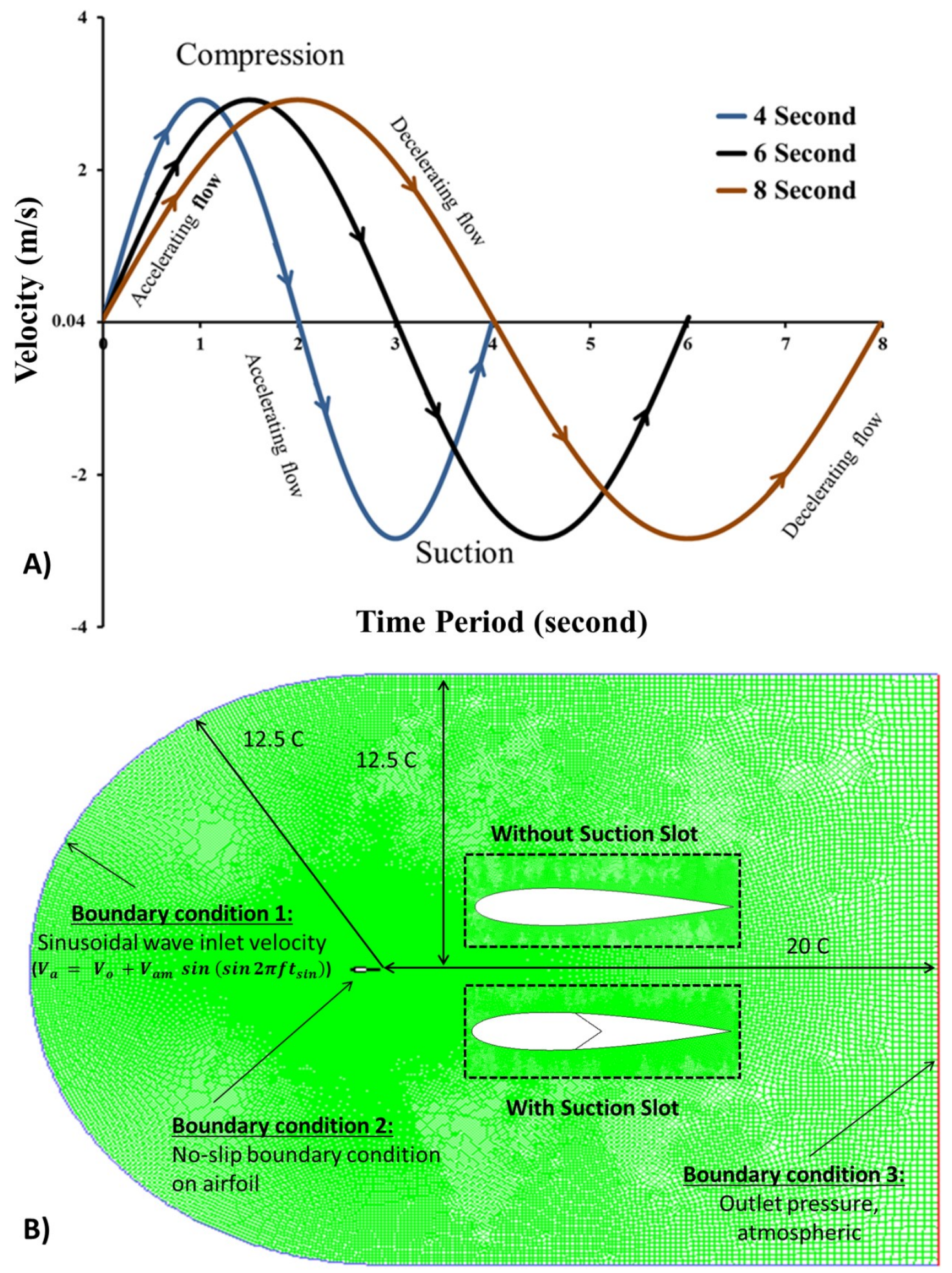


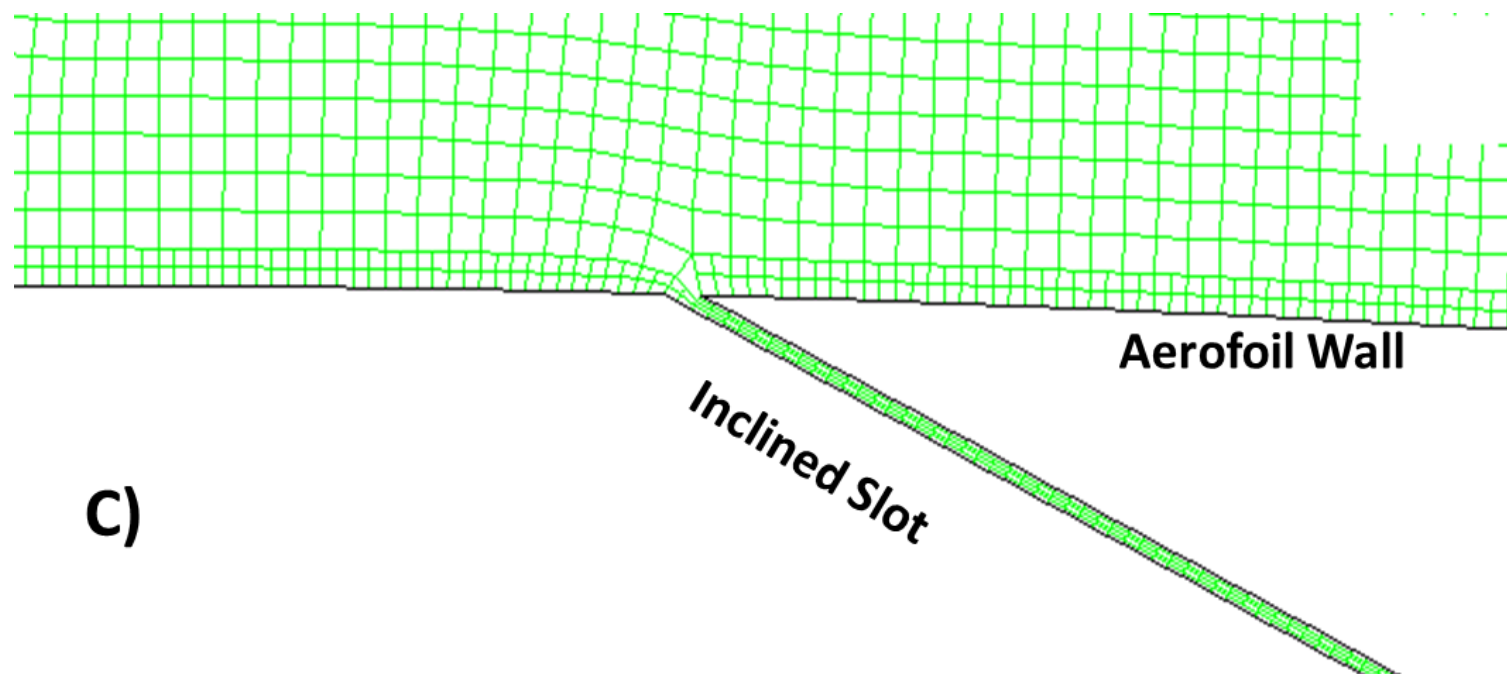

Figure 3 Boundary conditions A) The sinusoidal wave boundary condition, which represents a regular oscillating water column. B) Dimensions of whole computational domain and location of airfoil. C) The near views of slot mesh. 


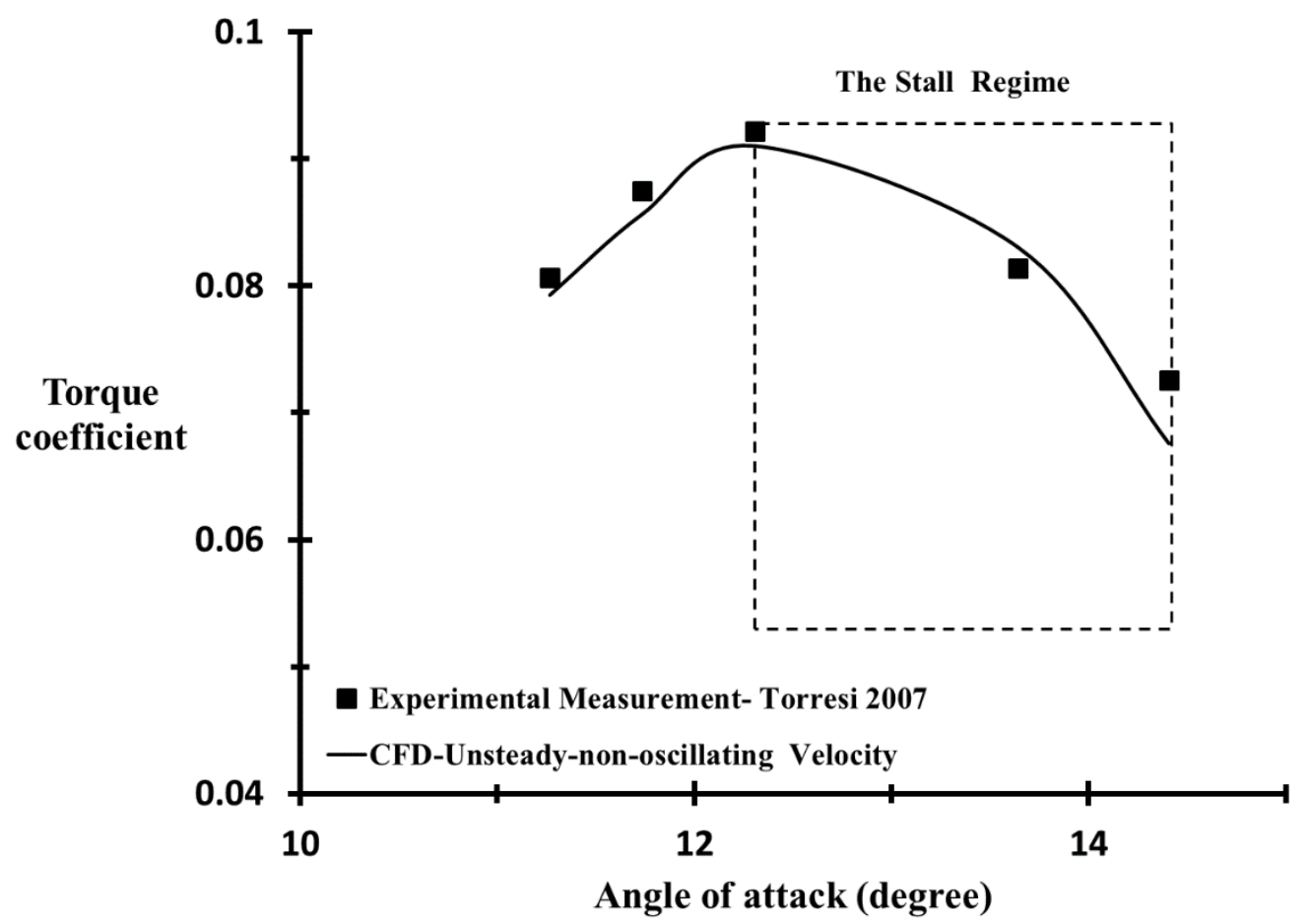

A) Unsteady flow with non-oscillating velocity

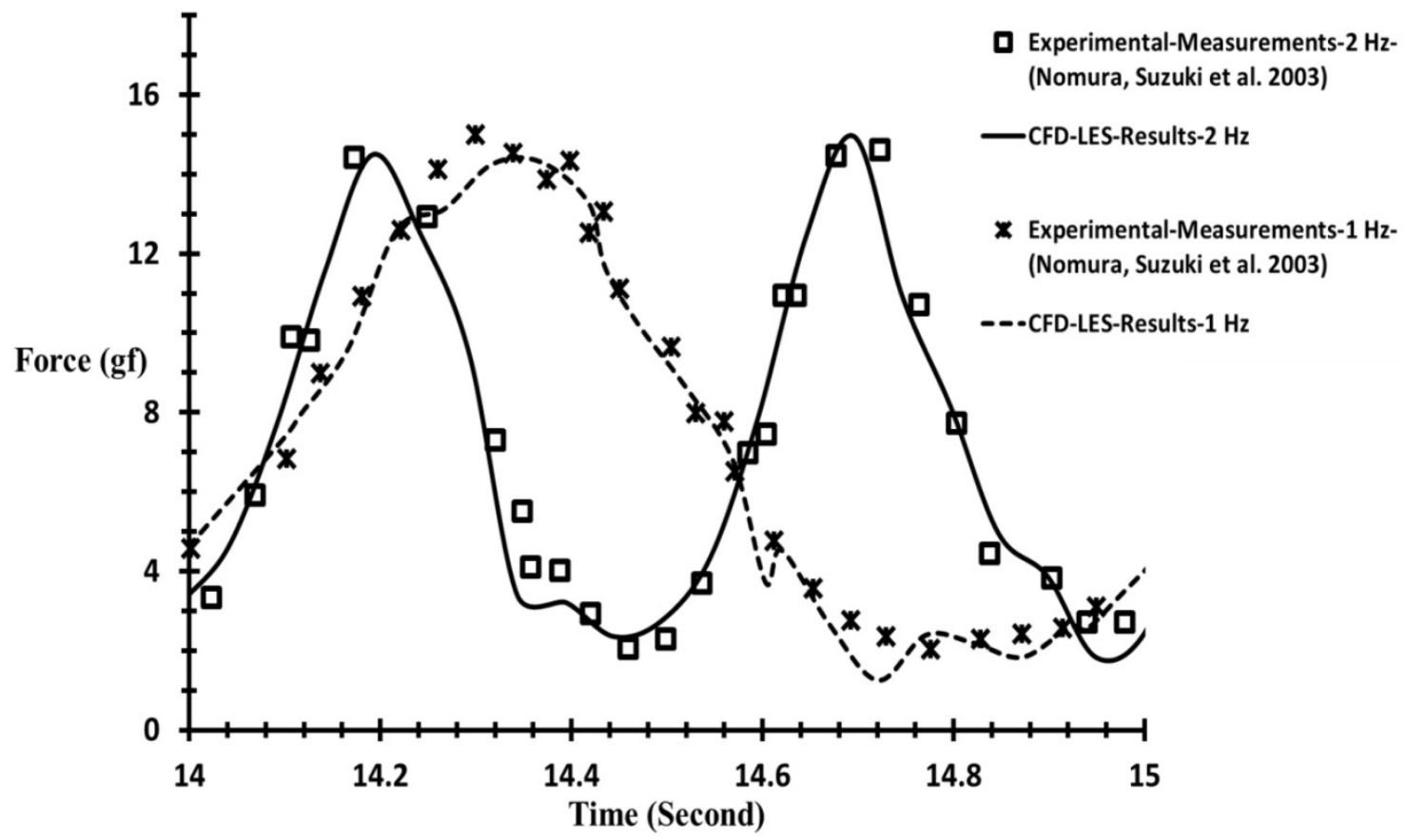

B) Sinusoidal flow with frequencies $2 \mathrm{~Hz}$ and $1 \mathrm{~Hz}$

Figure 4 The validation results A) Measured torque coefficient from reference (Torresi 2007) and calculated torque coefficient from present CFD. B) Measured unsteady in-line force $F_{D}$ from reference (Nomura, Suzuki et al. 2003), (angle of attack= 0 degree) and $F_{D}$ calculated from the present CFD. 


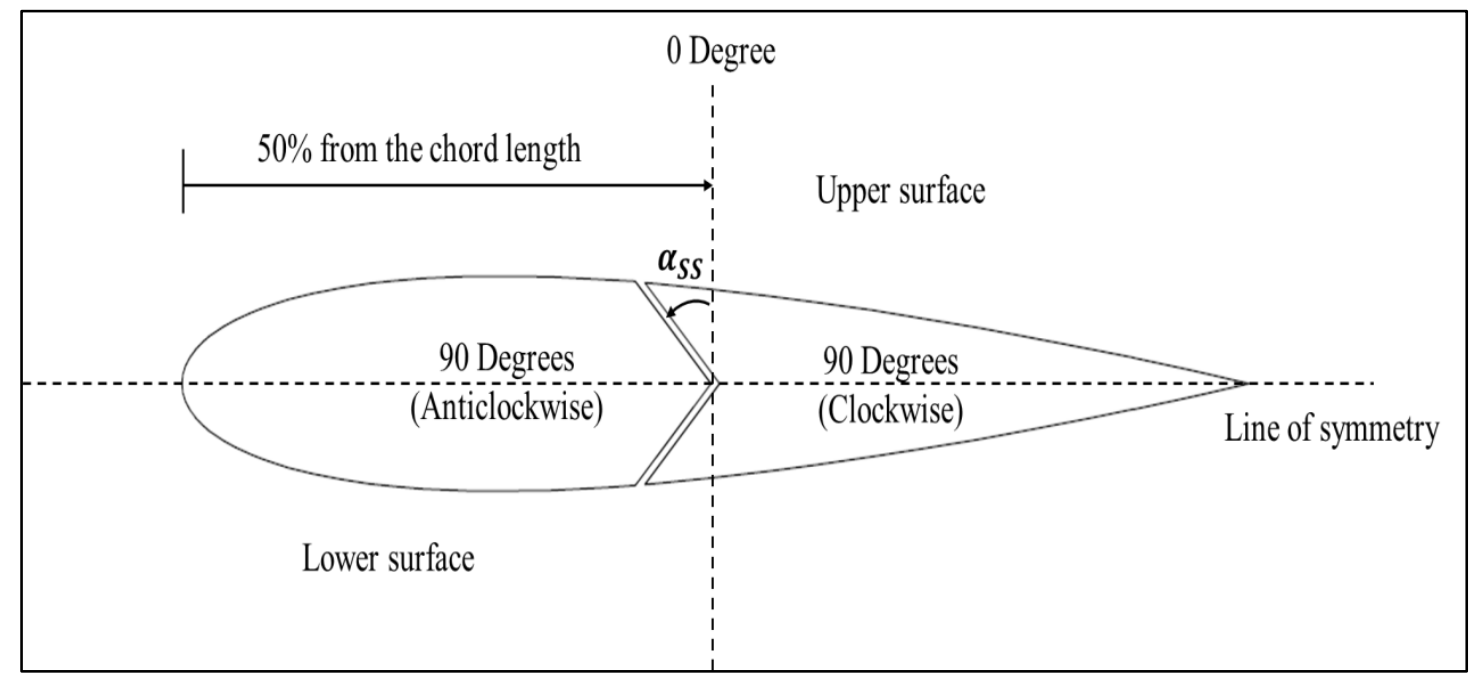

Figure 5 Airfoil diagram with suction slot has angle. 

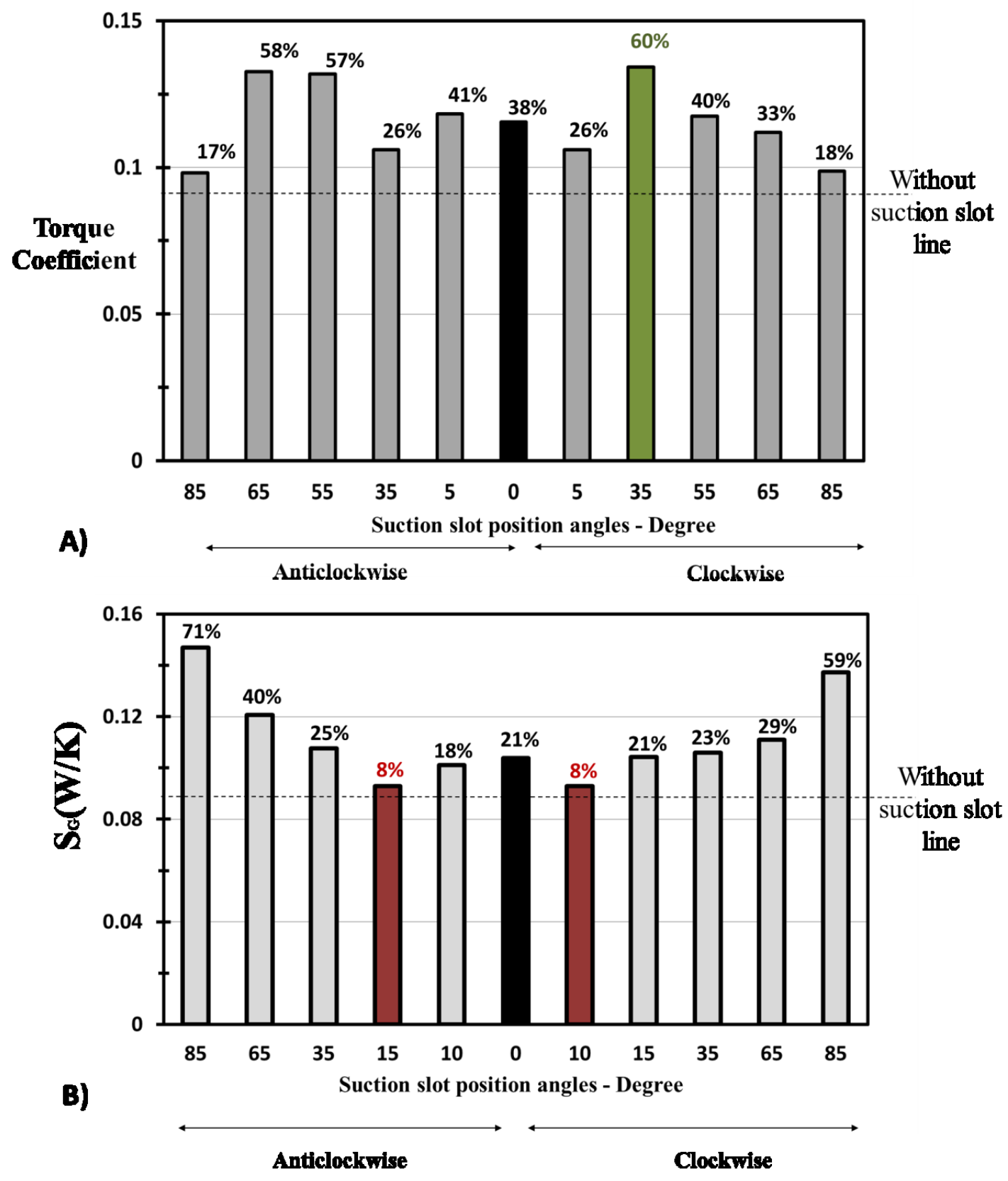

Figure 6 The effect of suction slot with different angle at the stall angle (13.6 Degree) and $f=0.167$ $\mathrm{Hz} \mathrm{A)} \mathrm{Torque} \mathrm{coefficient.} \mathrm{B)} \mathrm{The} \mathrm{global} \mathrm{entropy} \mathrm{generation} \mathrm{rate.}$ 

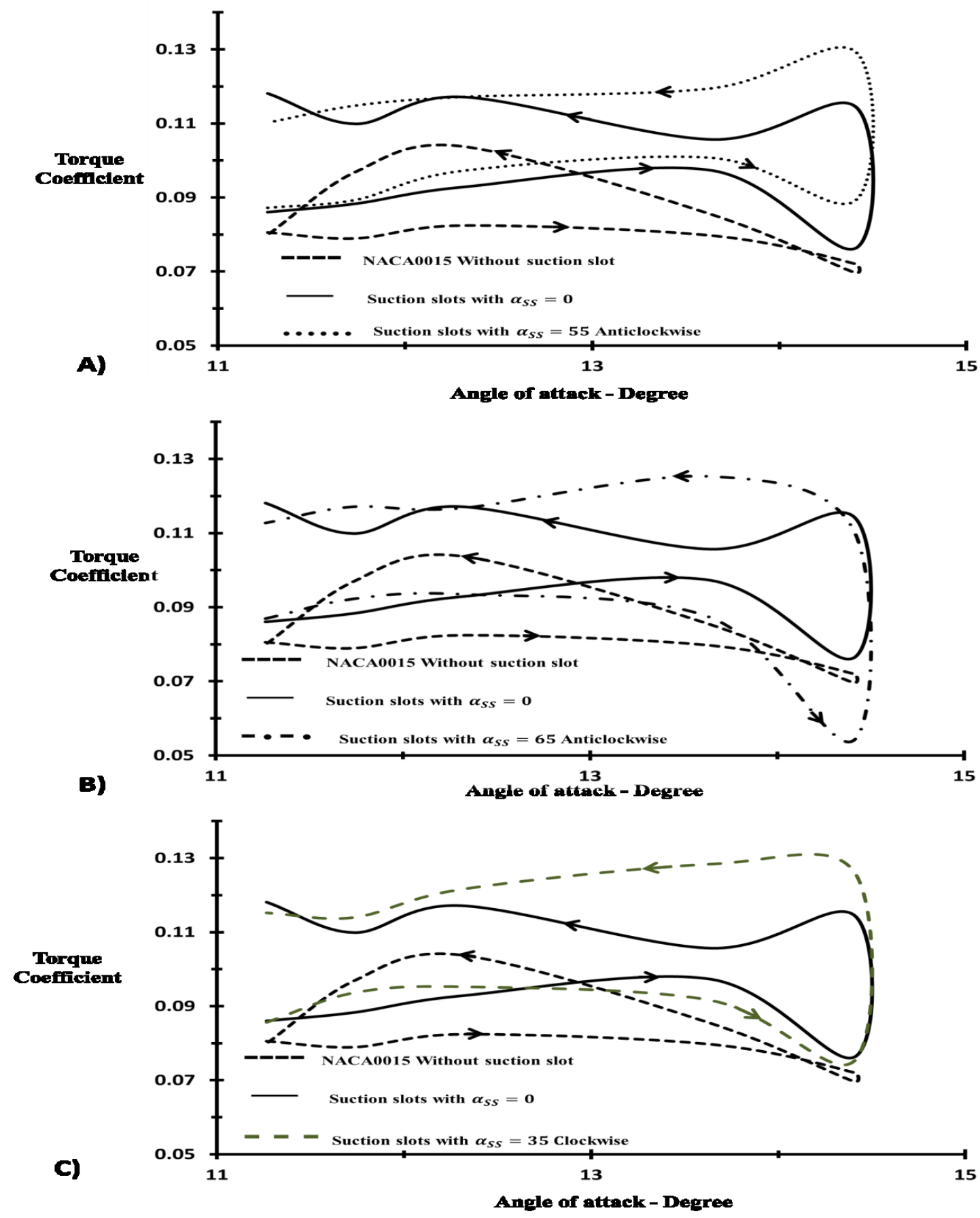

Figure 7 Hysteretic behavior comparisons between the optimum angles of suction slot with sinusoidal inlet velocity and $f=0.167 \mathrm{~Hz} \mathrm{A)} 55$ degrees anticlockwise B) 65 degrees anticlockwise C) 35 degrees clockwise. 

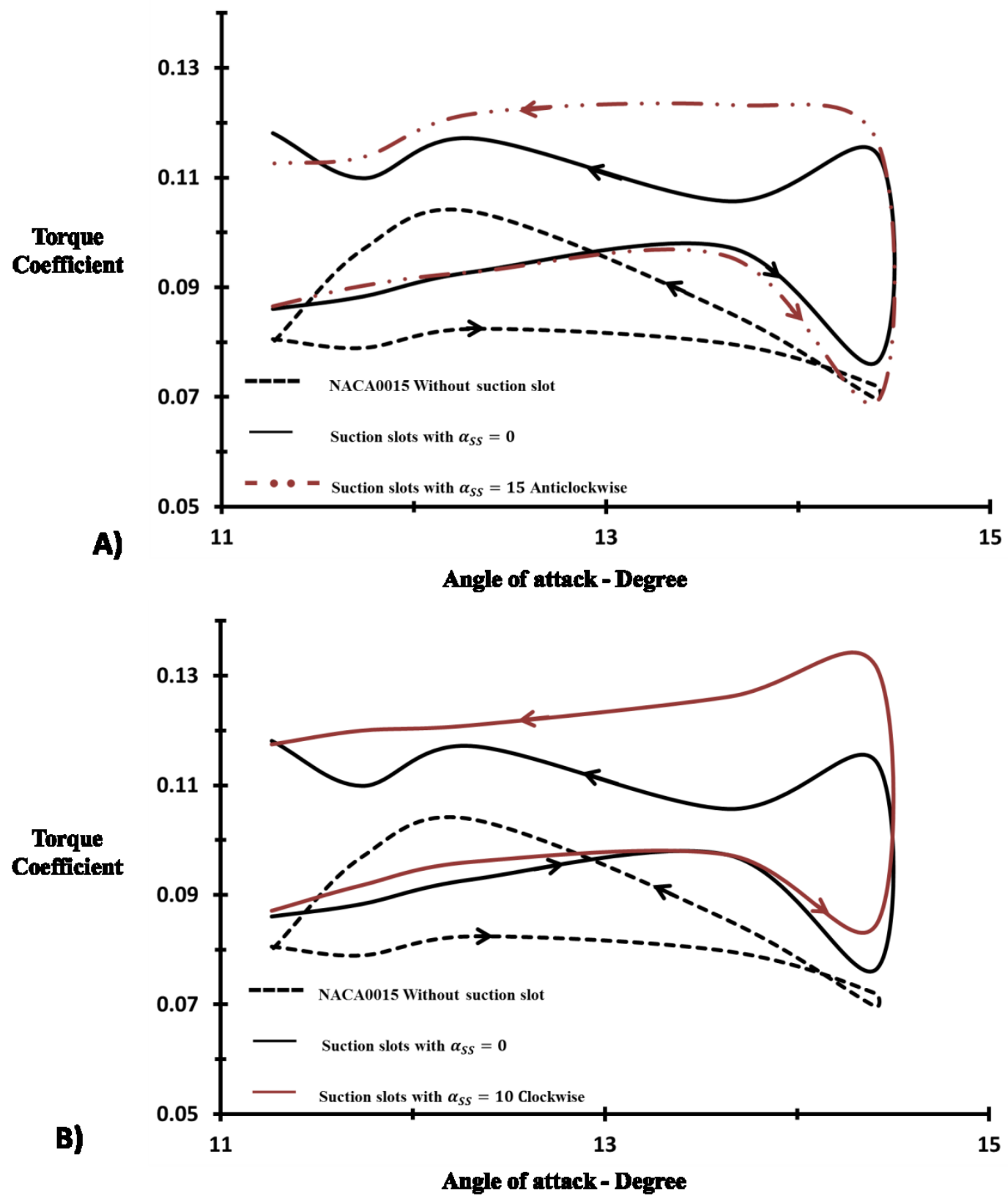

Figure 8 Hysteretic behavior comparisons between the optimum angles of suction slot with sinusoidal inlet velocity and $f=0.167 \mathrm{~Hz}$ A) 15 degrees anticlockwise B) 10 degrees clockwise. 


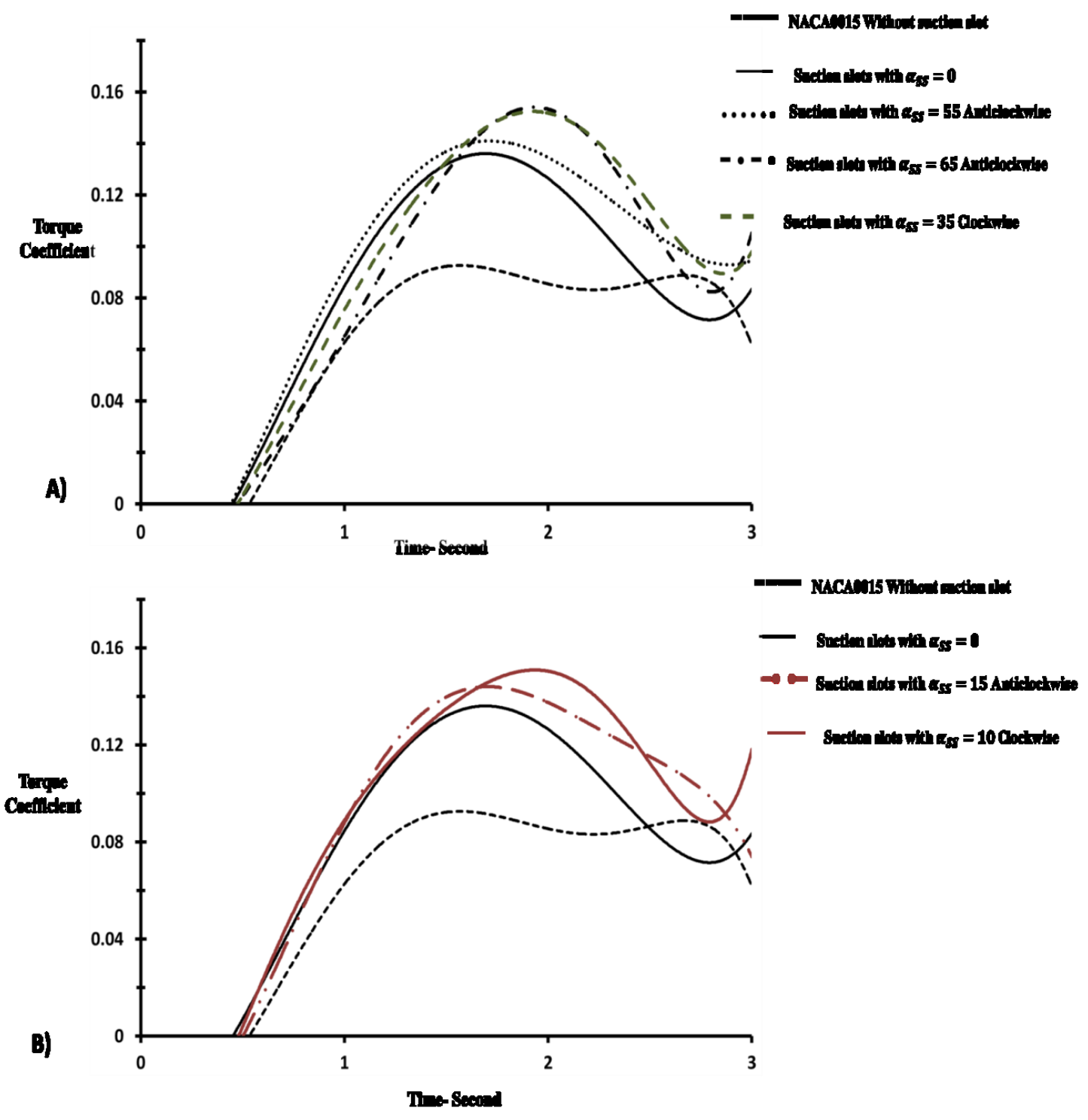

Figure 9 Comparison between the instantaneous torque coefficients for the optimum angles of suction slot with sinusoidal inlet velocity and $f=0.167 \mathrm{~Hz} \mathrm{~A}$ ) based on Force analysis B) based on velocity analysis. 

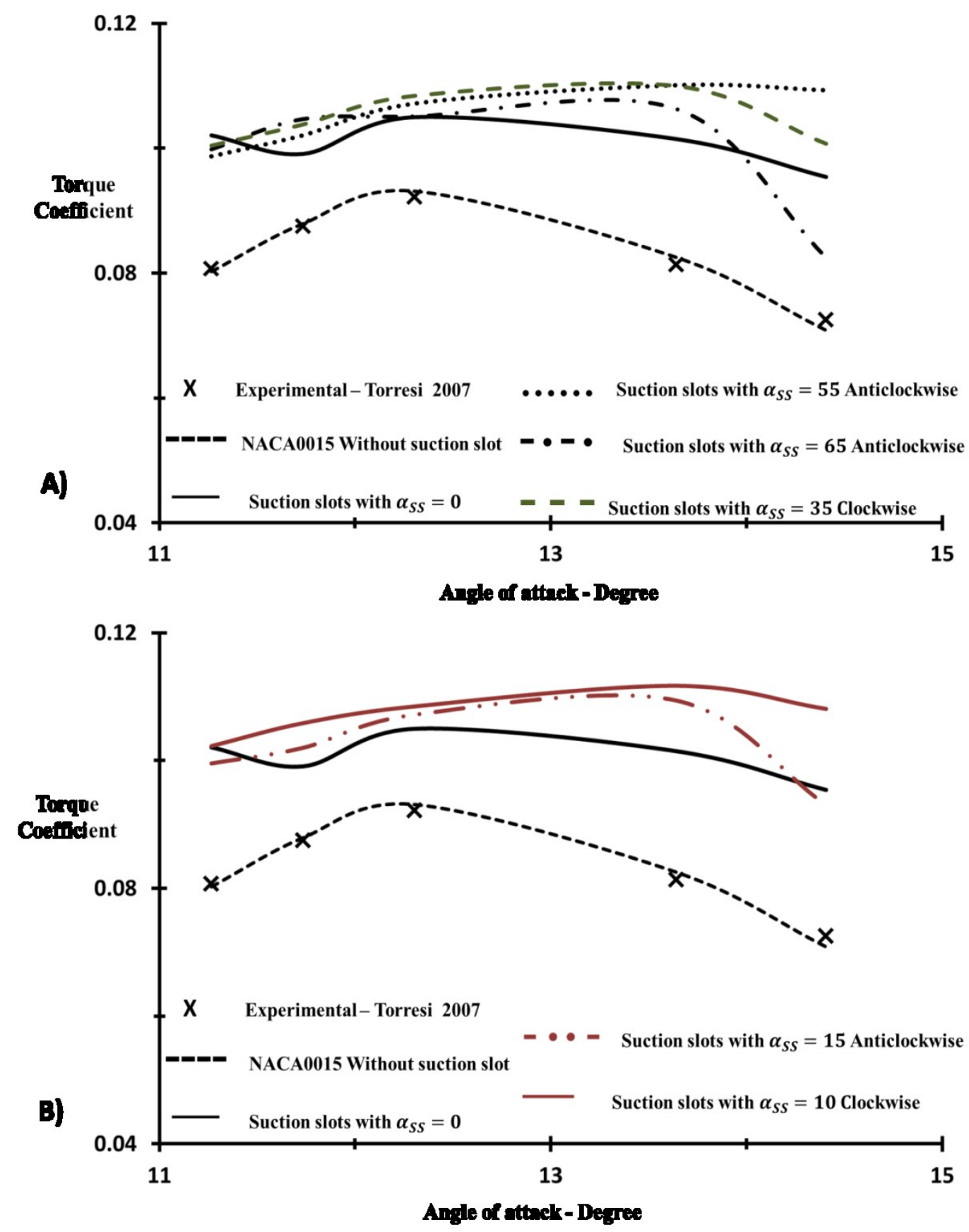

Figure 10 Comparison between the average torque coefficients for the optimum angles of suction slot with sinusoidal inlet velocity and $f=0.167 \mathrm{~Hz} \mathrm{~A}$ ) based on Force analysis B) based on velocity analysis. 

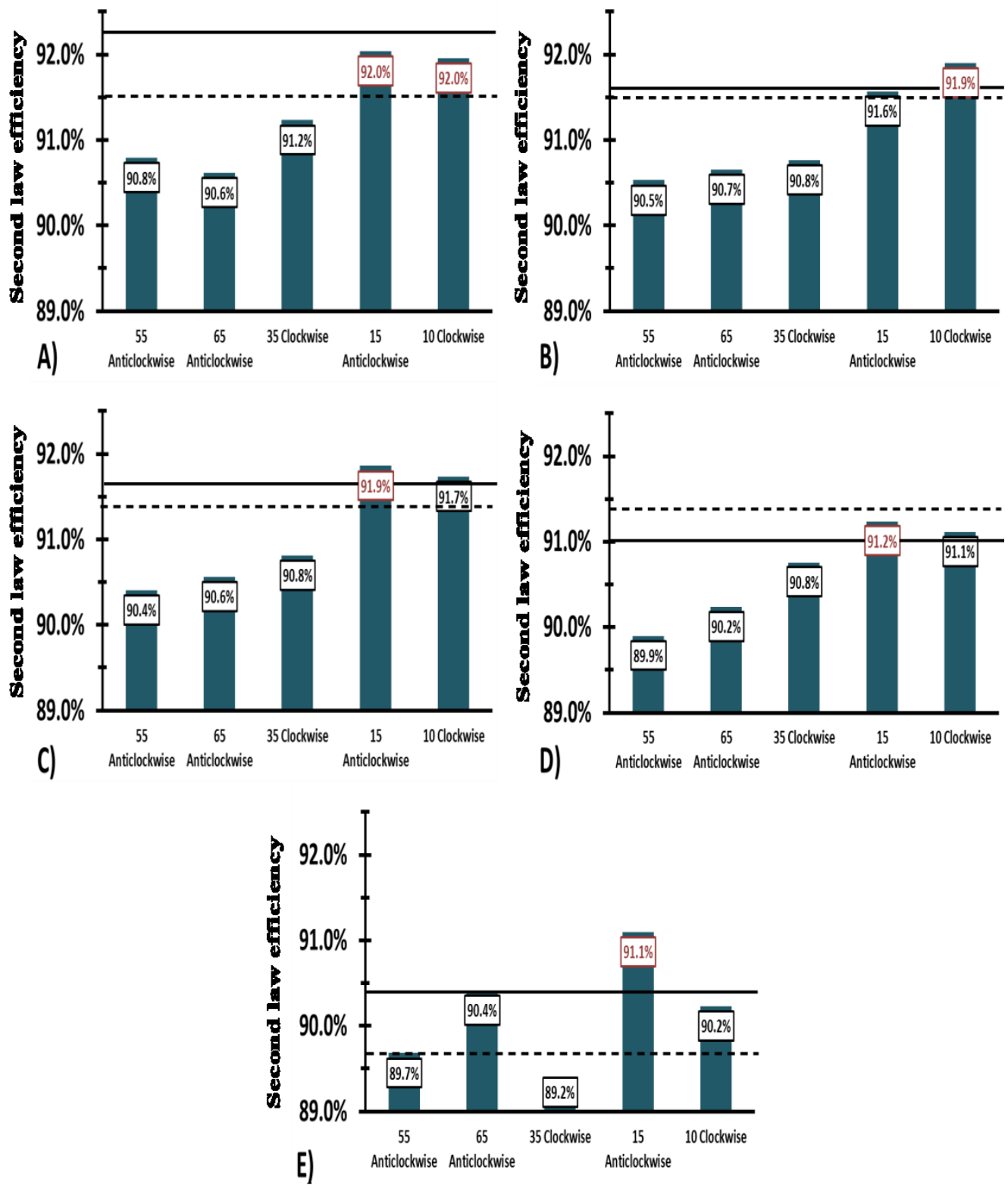

Figure 11 Comparison between the second law efficiency for the compression cycle for NACA0015 with suction slots at different angles "----without suction slot" " $-\alpha_{S S}=0$ degree" $(f=0.167 \mathrm{~Hz})$ A) 11.3 B) 11.7 C) 12.3 D) 13.6 E) 14.4. 


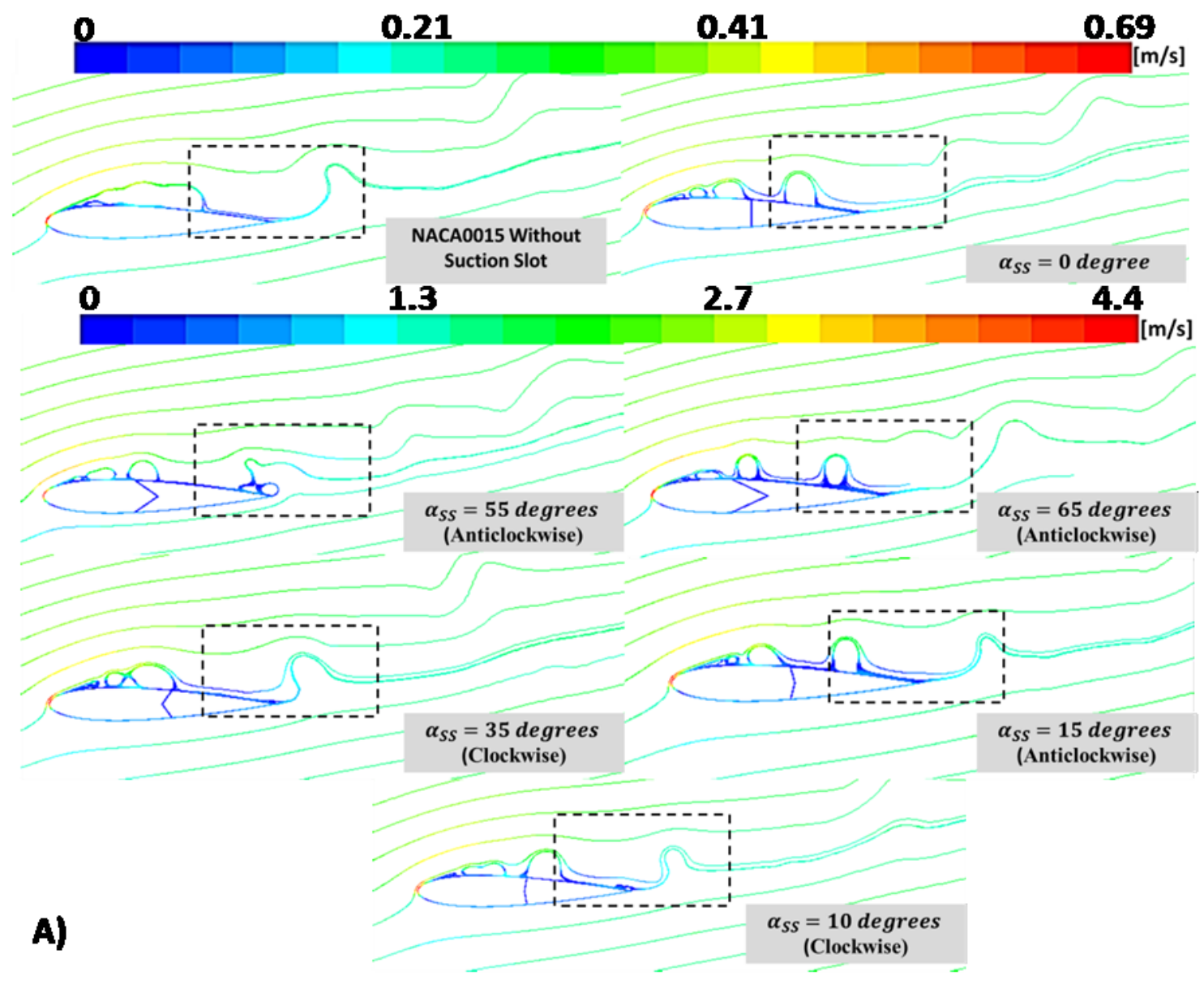




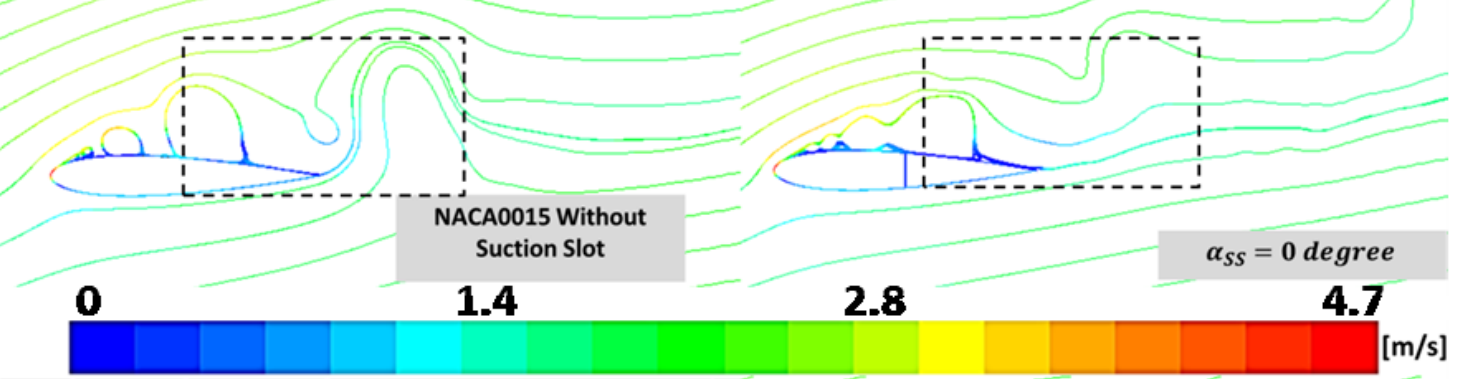

\section{B)}
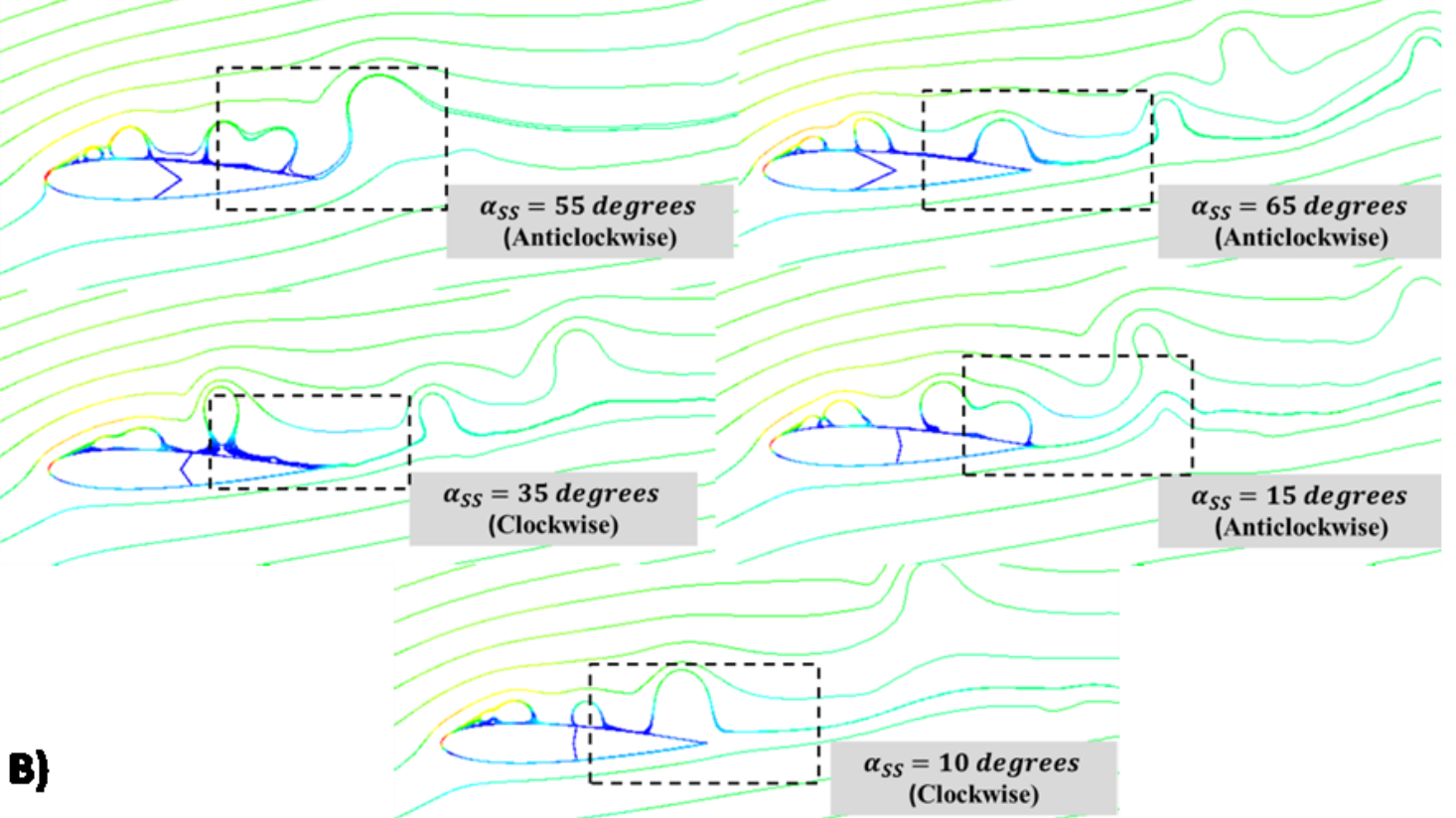

Figure 12 Path-line colored by mean vorticity magnitude for sinusoidal flow around NACA0015 without suction slot and with the optimum angles of suction slot under sinusoidal inlet velocity at the stall angle (13.6 Degree) and $f=0.167 \mathrm{~Hz}$ A) $2.92 \mathrm{~m} / \mathrm{s}$-maximum velocity B) $1.8 \mathrm{~m} / \mathrm{s}$-decelerating flow 


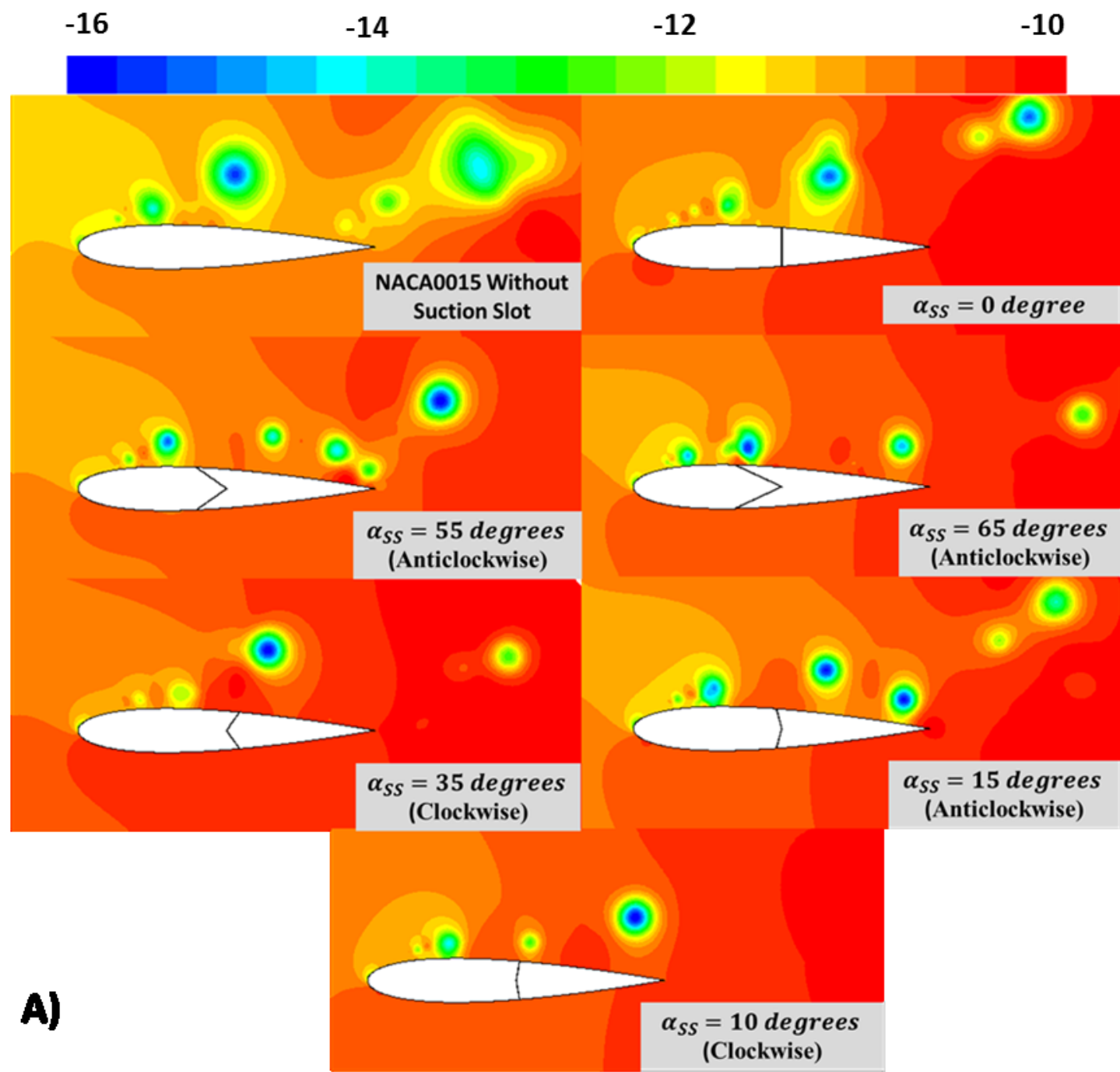




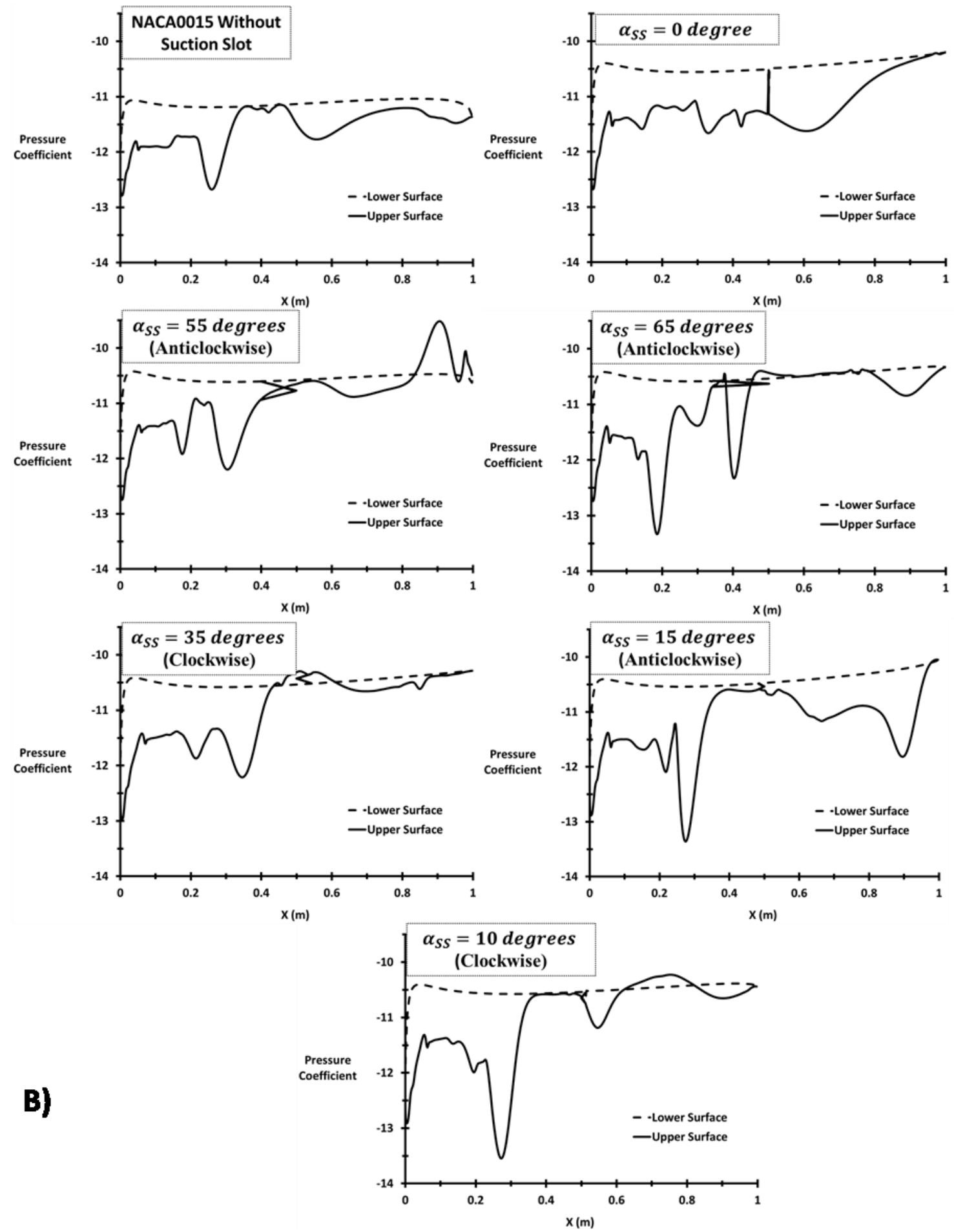

Figure 13 The pressure distribution around NACA0015 without slot and with the optimum angles of suction slot under sinusoidal velocity and $f=0.167 \mathrm{~Hz} \mathrm{~A}$ ) Contours of pressure coefficient B) pressure coefficient at the upper and lower surface 


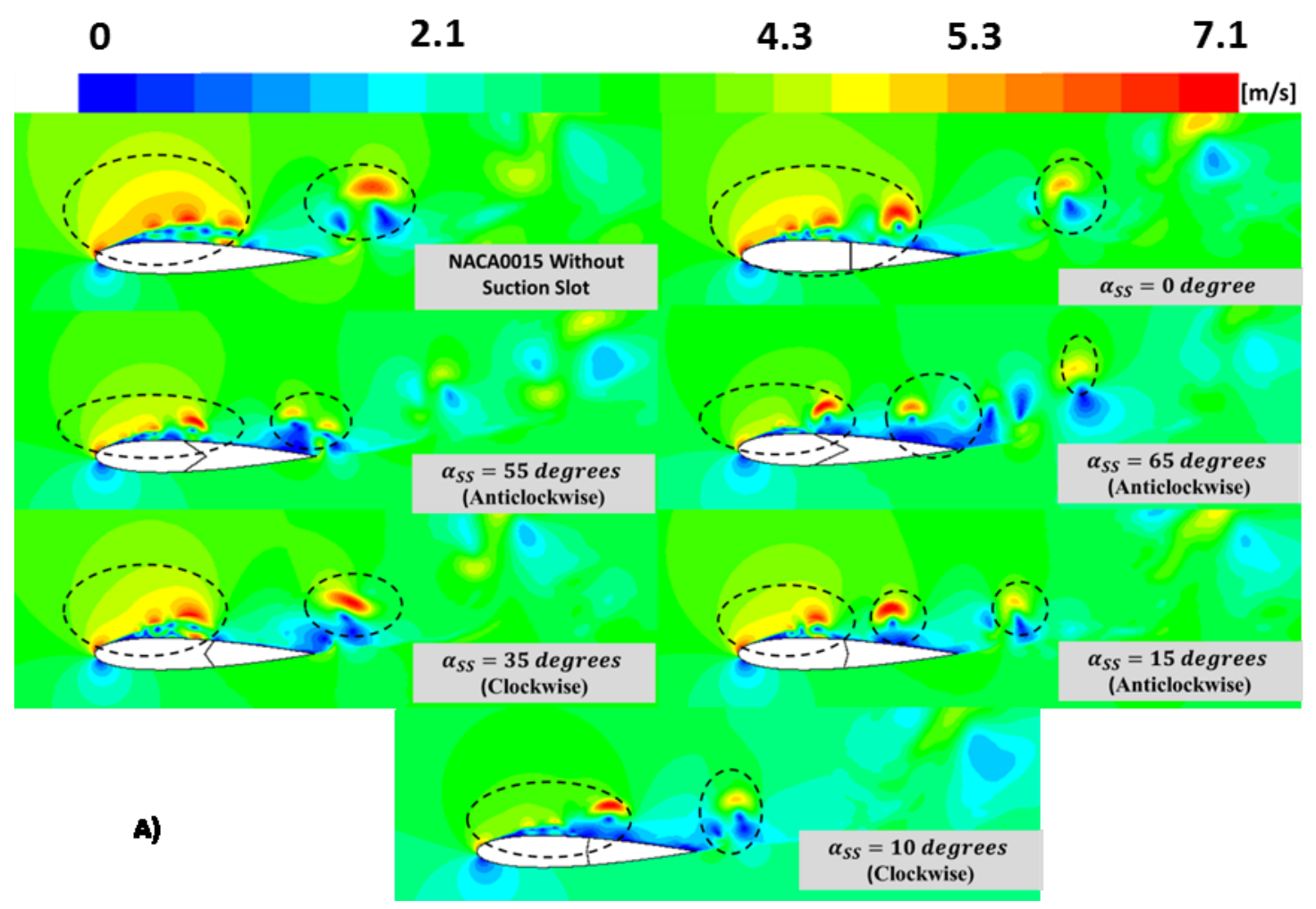



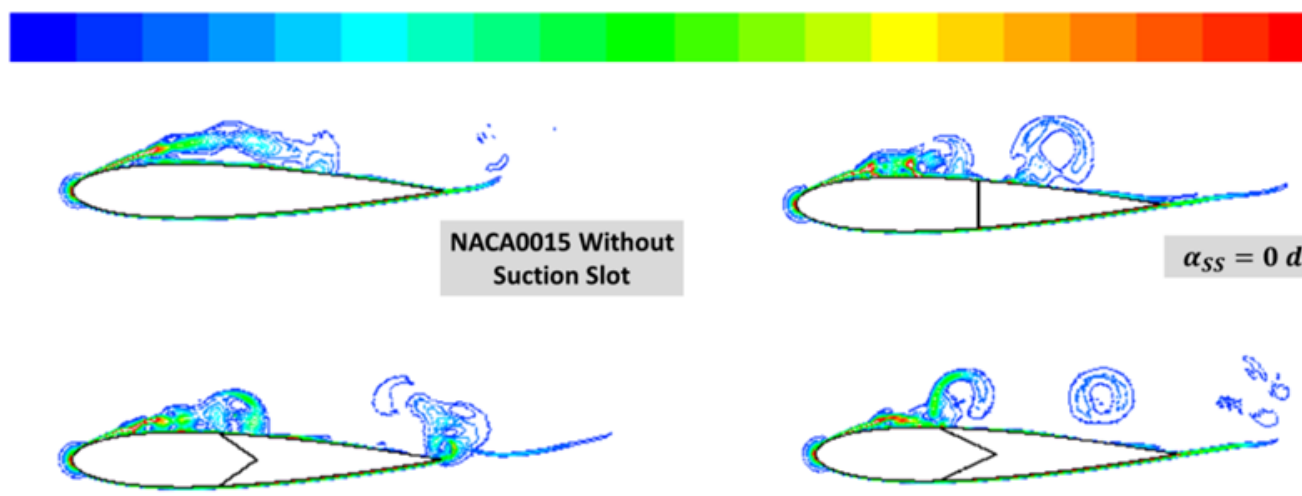

$$
\alpha_{S S}=55 \text { degrees }
$$
(Anticlockwise)
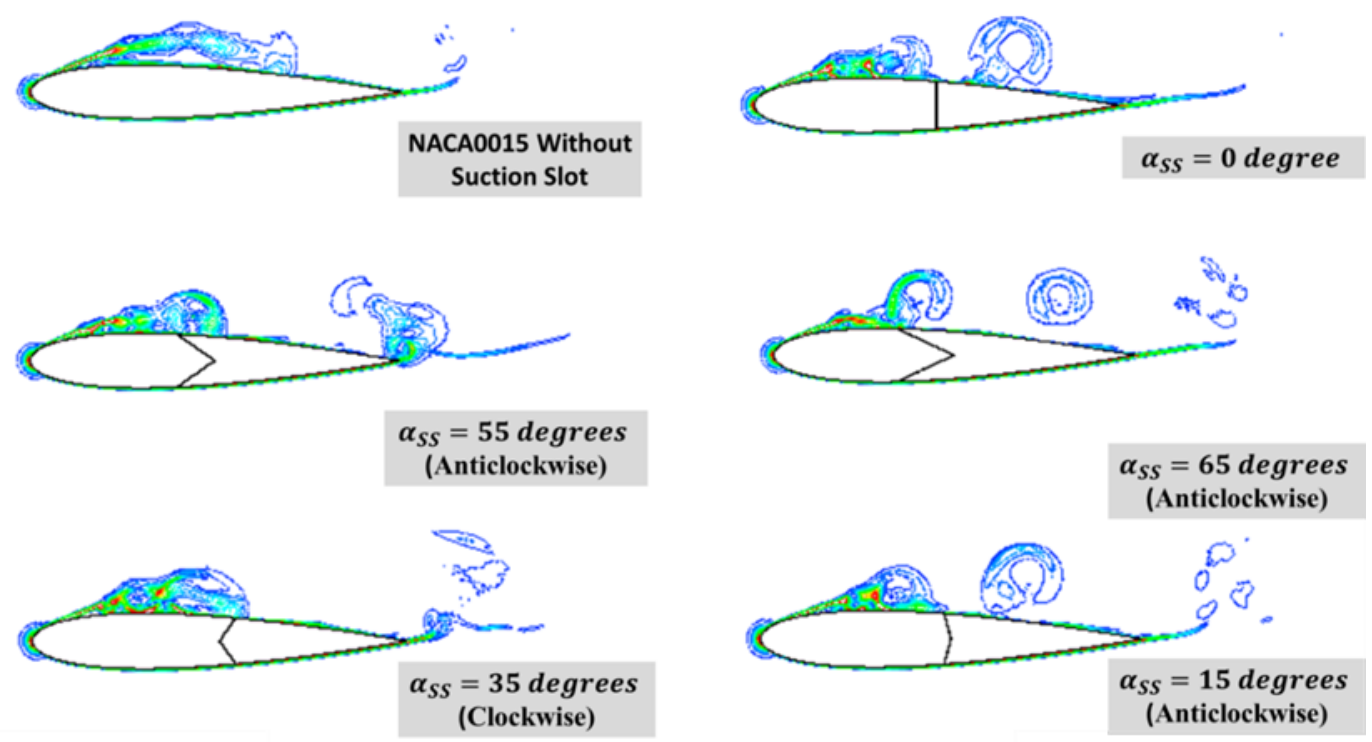

B)

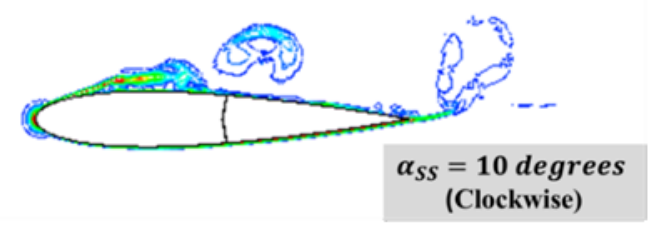

Figure 14 The Contour at the stall angle (13.6 Degree) for sinusoidal flow around NACA0015 without suction slot and with the optimum angles of suction slot at maximum velocity $2.92 \mathrm{~m} / \mathrm{s}$ under sinusoidal velocity and $f=0.167 \mathrm{~Hz}$ A) Velocity magnitude B) Global entropy generation rate 


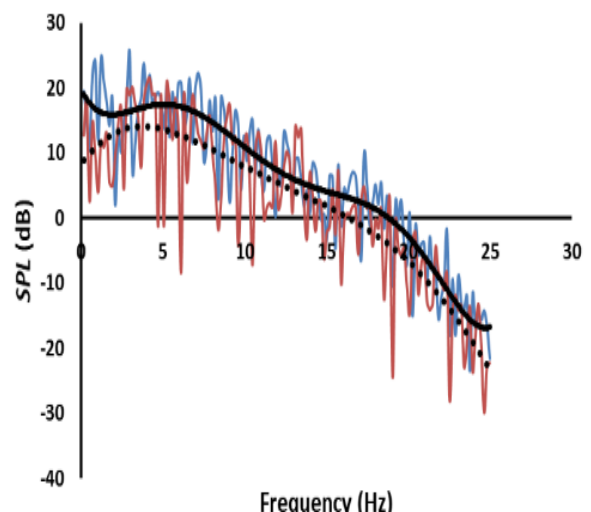

Frequency $(\mathrm{Hz})$
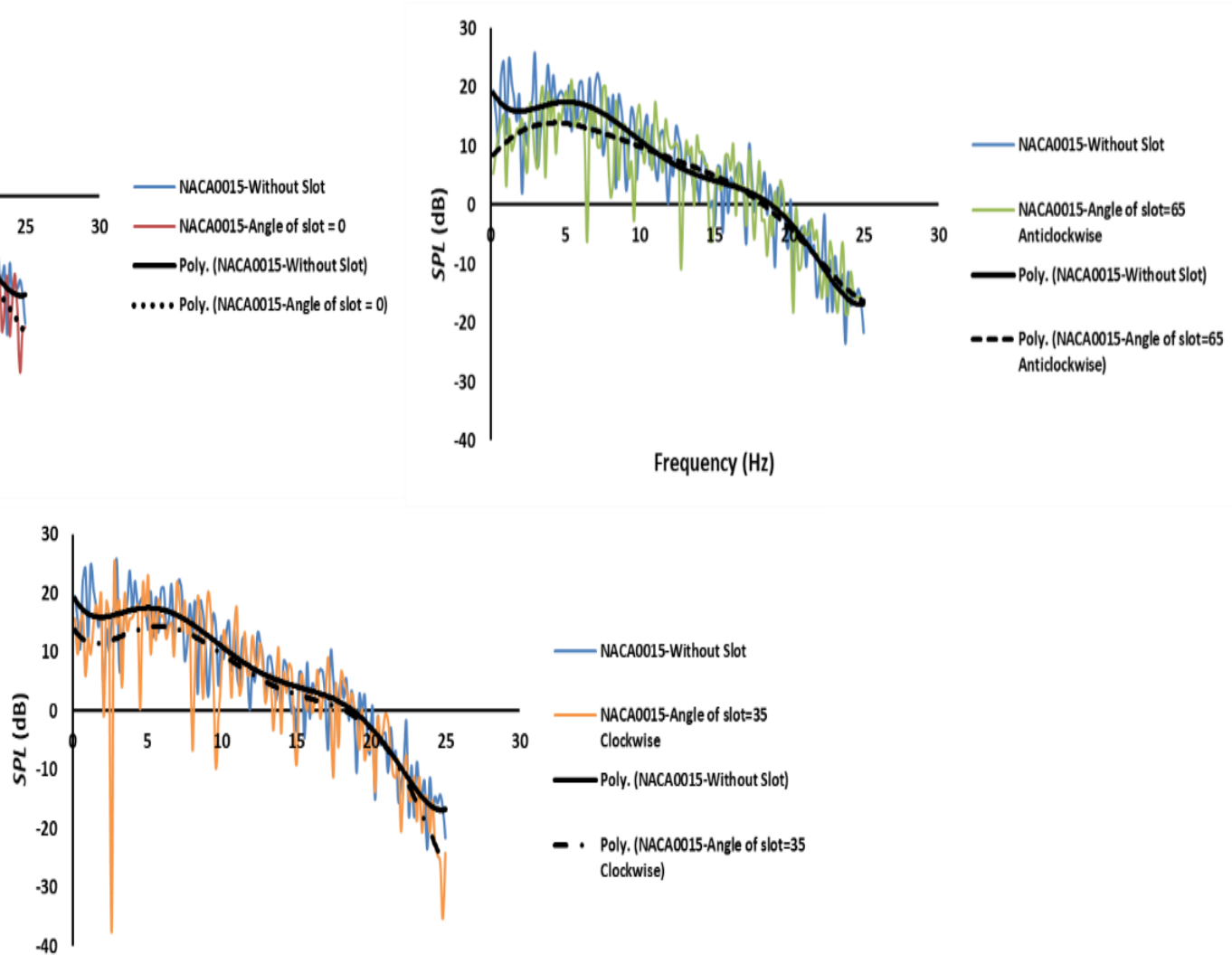

Frequency $(\mathrm{Hz})$

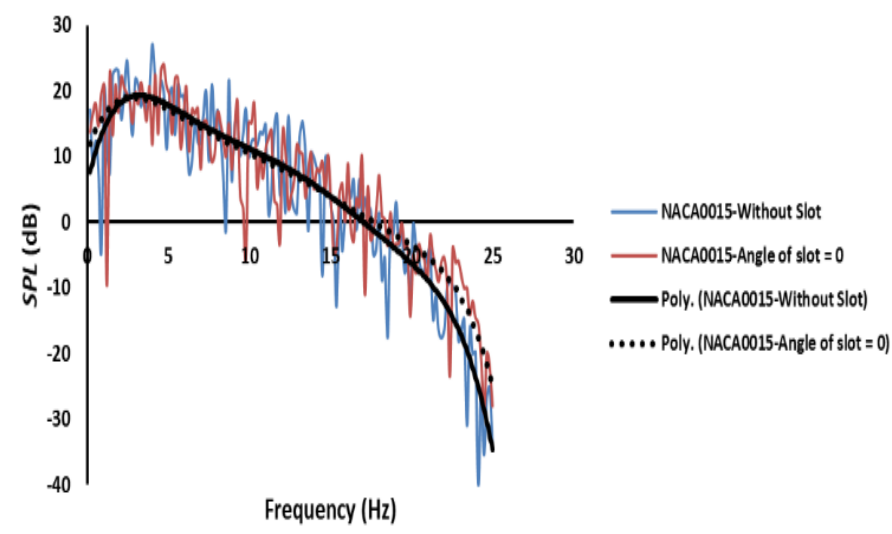

Frequency $(\mathrm{Hz})$

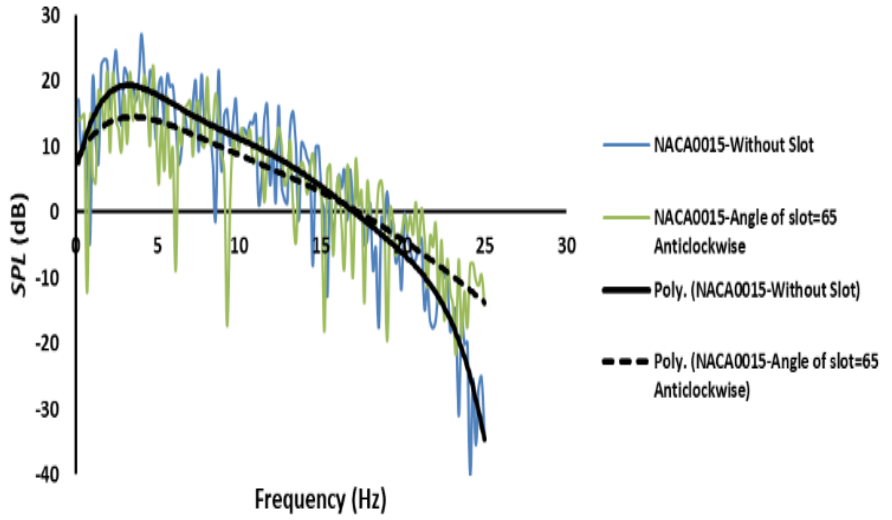

Frequency $(\mathrm{Hz})$
B)

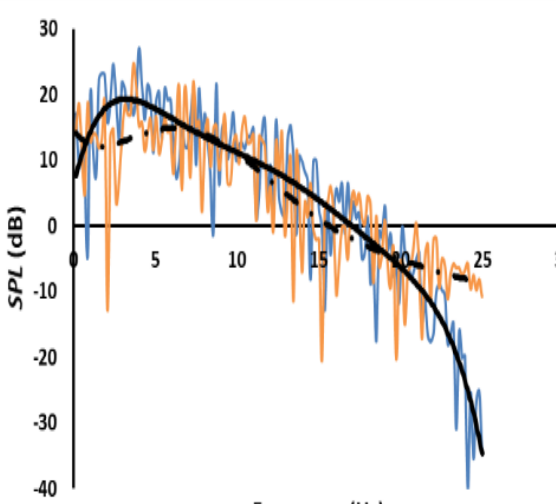

Frequency $(\mathrm{Hz})$
NACA0015-Without Slot

NACA0015-Angle of slot=35 Clockwise

—Poly. (NACA0015-Without Slot)

- Poly. (NACA0015-Angle of slot=35 Clockwise) 

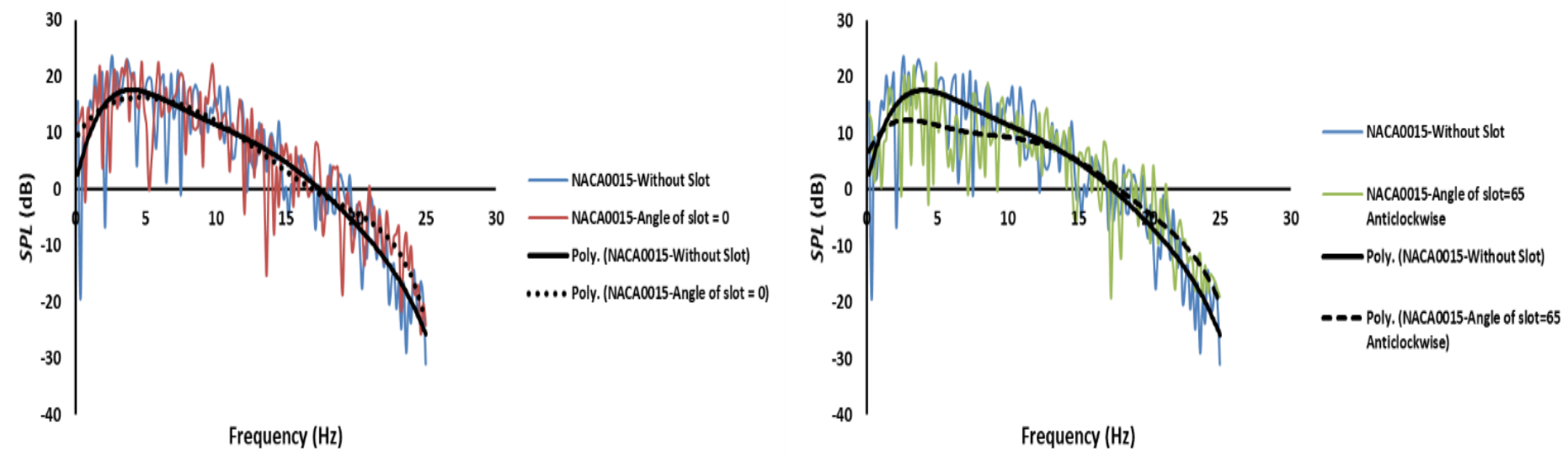

c)

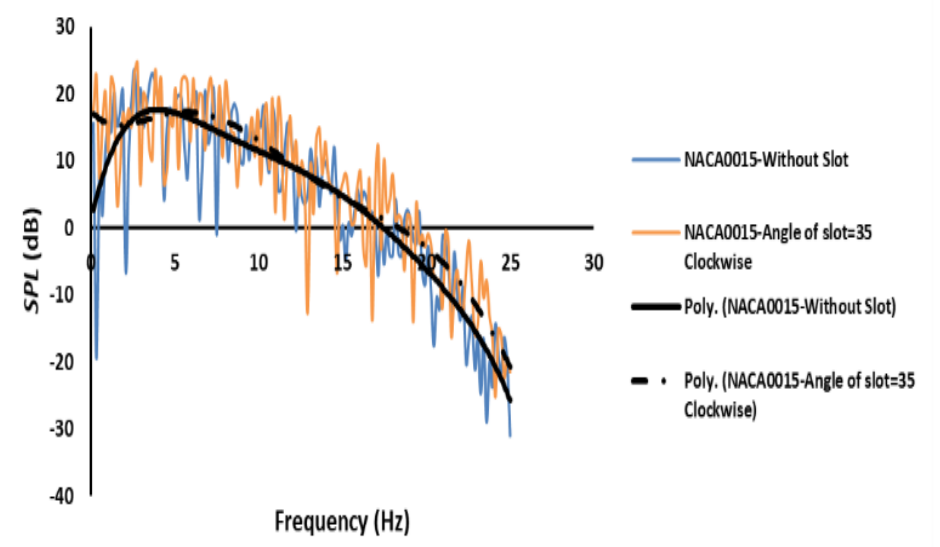

Figure 15 The Sound pressure level in dB for NACA0015 under non-oscillating velocity at a far field receiver located at 35 chord with different slot angle and different angles of attack A) 11.3 degrees B) 12.3 degrees C) 14.4 degrees 

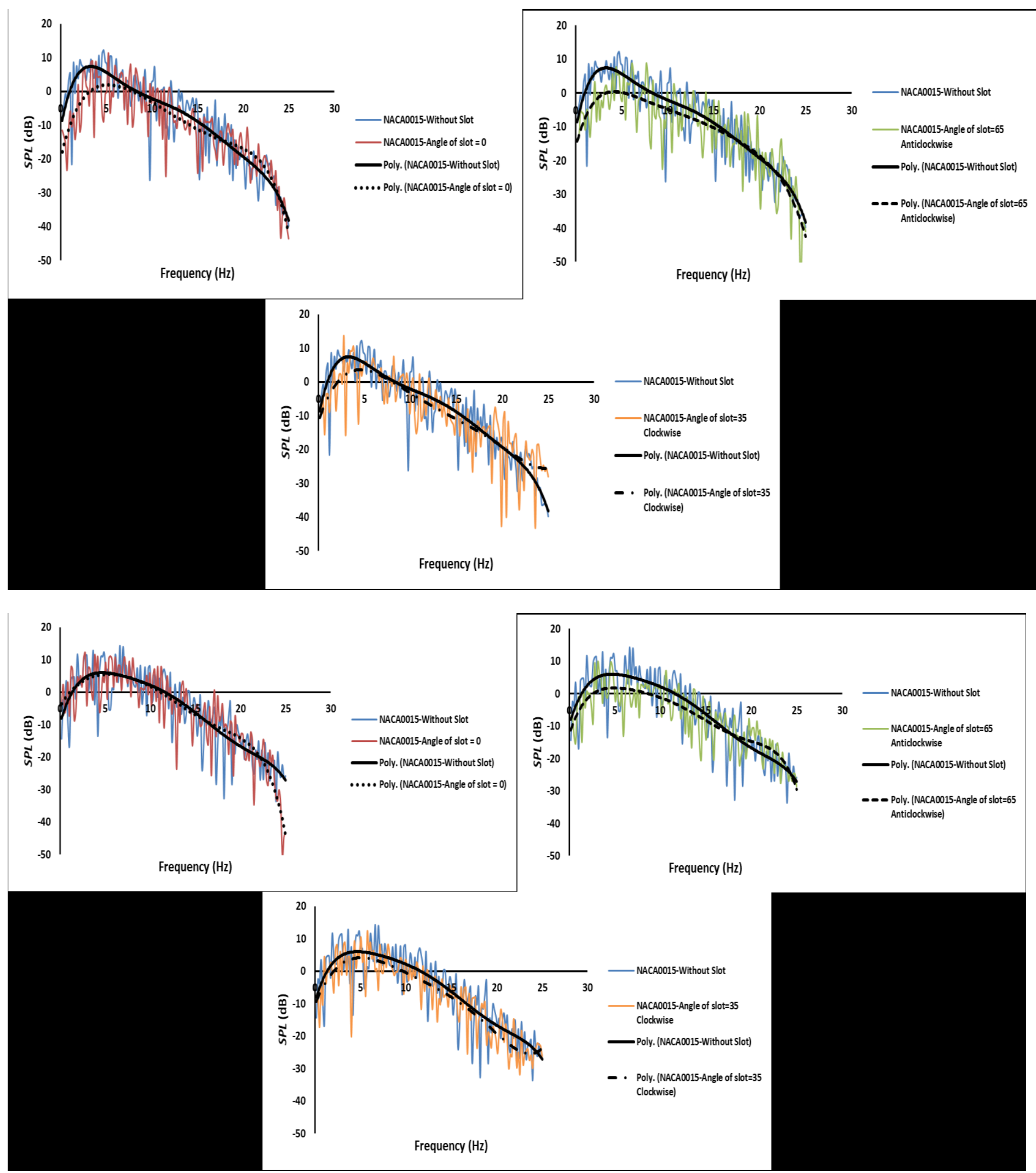

Figure 16 The Sound pressure level in dB for NACA0015 under non-oscillating velocity at a far field receiver located at 128 chord with different slot angle and different angles of attack $A$ ) 11.7 degrees

B) 13.6 degrees 


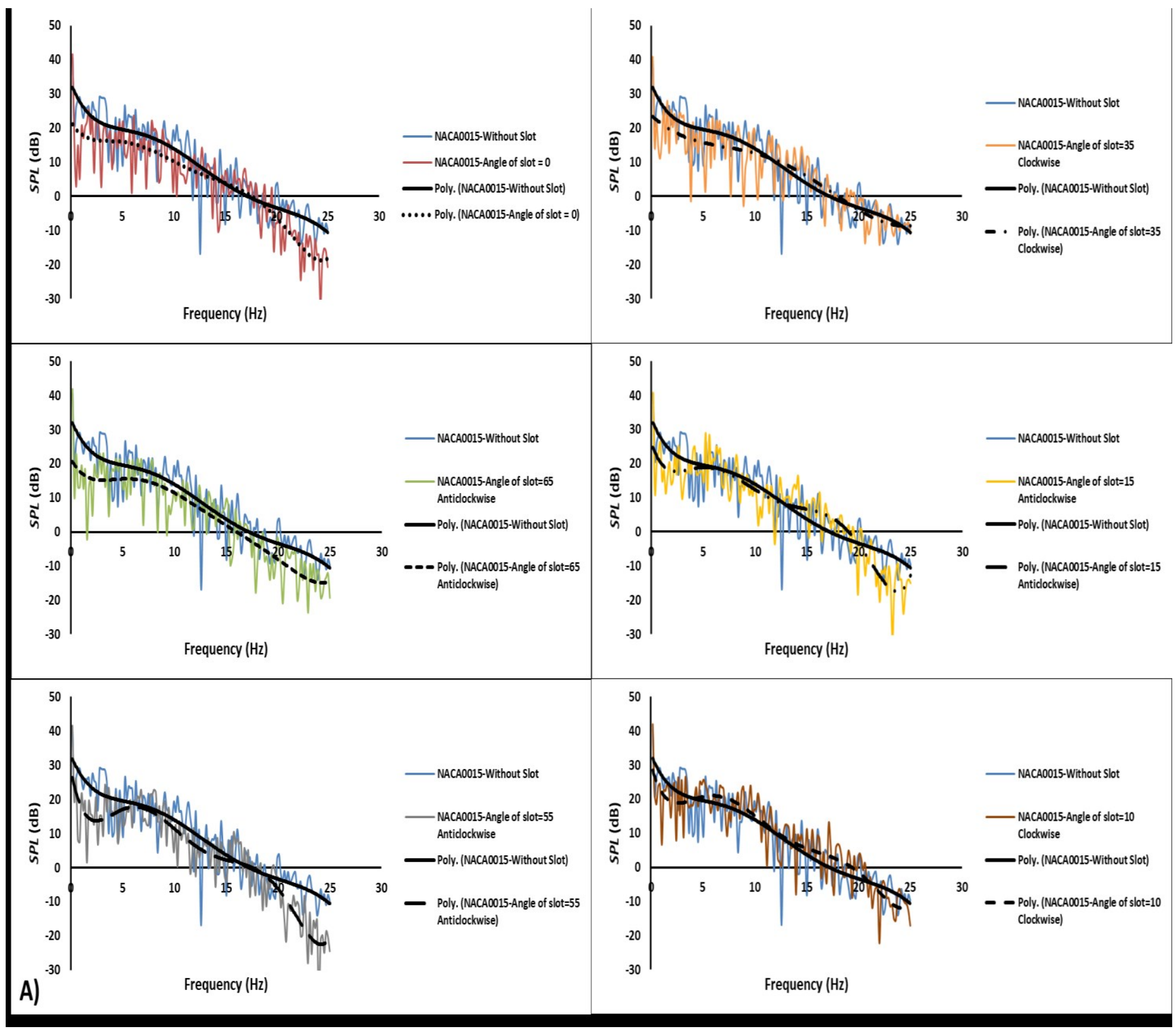




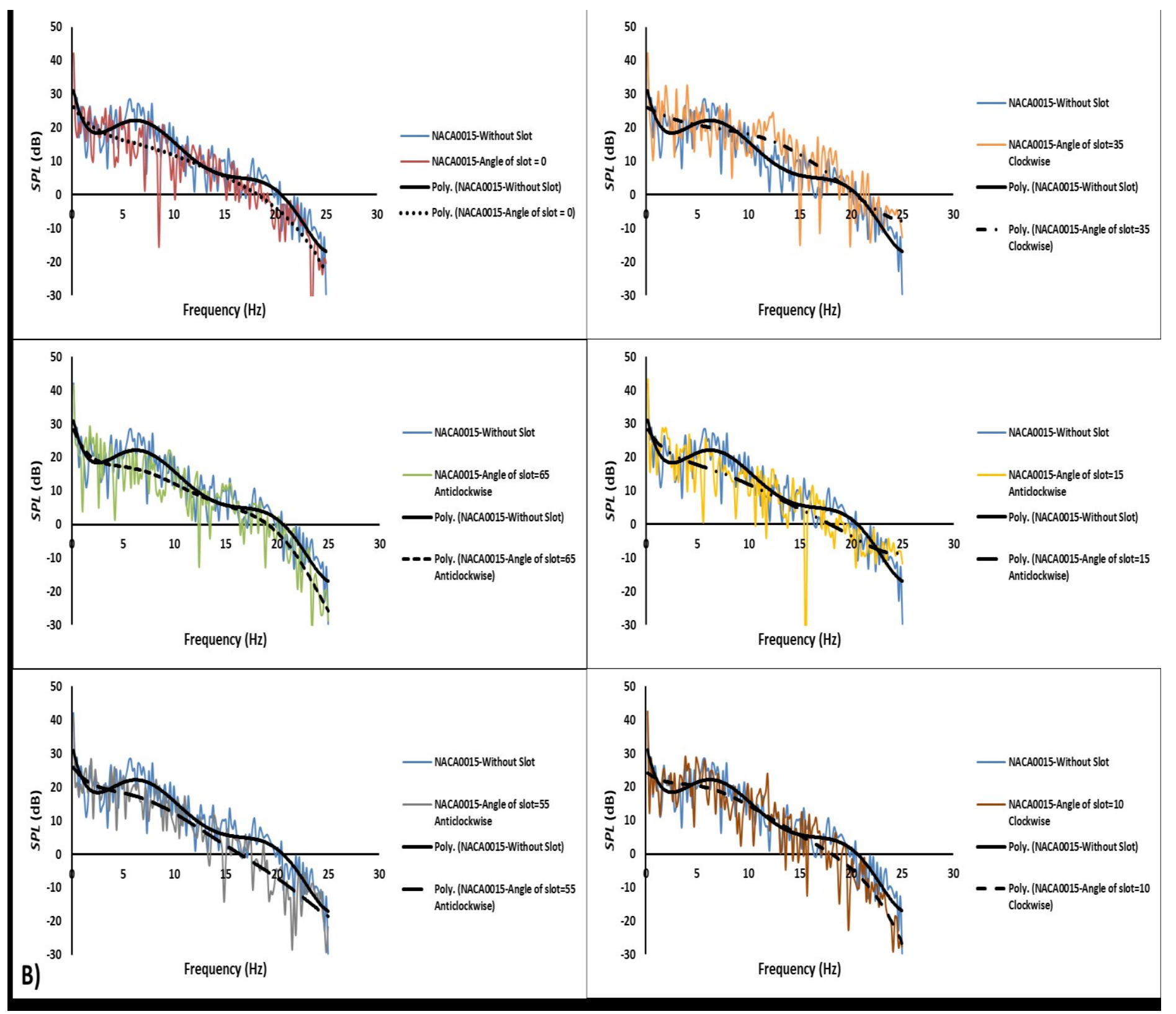




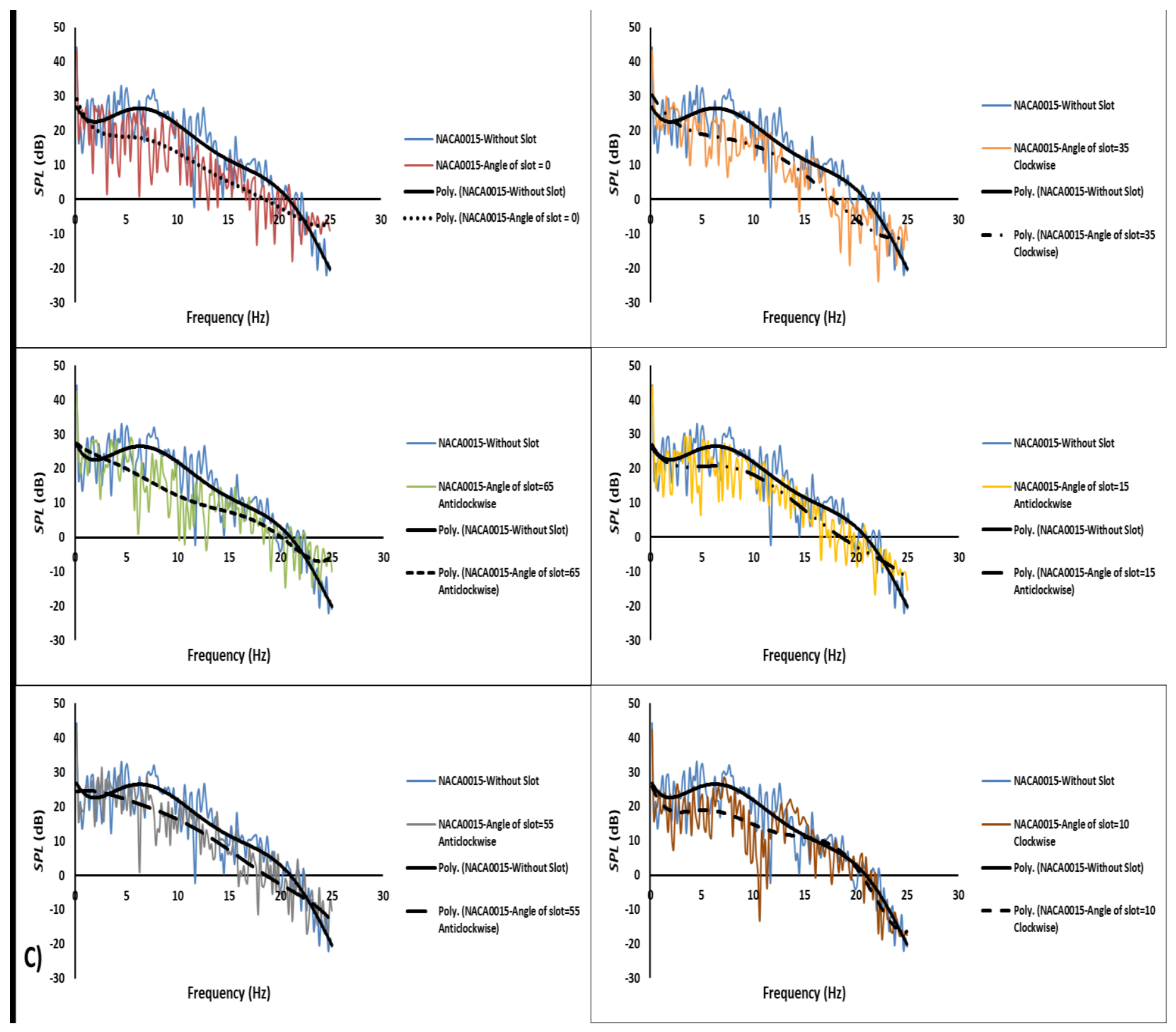

Figure 17 The Sound pressure level in $\mathrm{dB}$ for NACA0015 under oscillating velocity at a far field receiver located at 35 chord with different slot angle and different angles of attack A) 11.3 degrees B)

12.3 degrees C) 13.6 degrees 


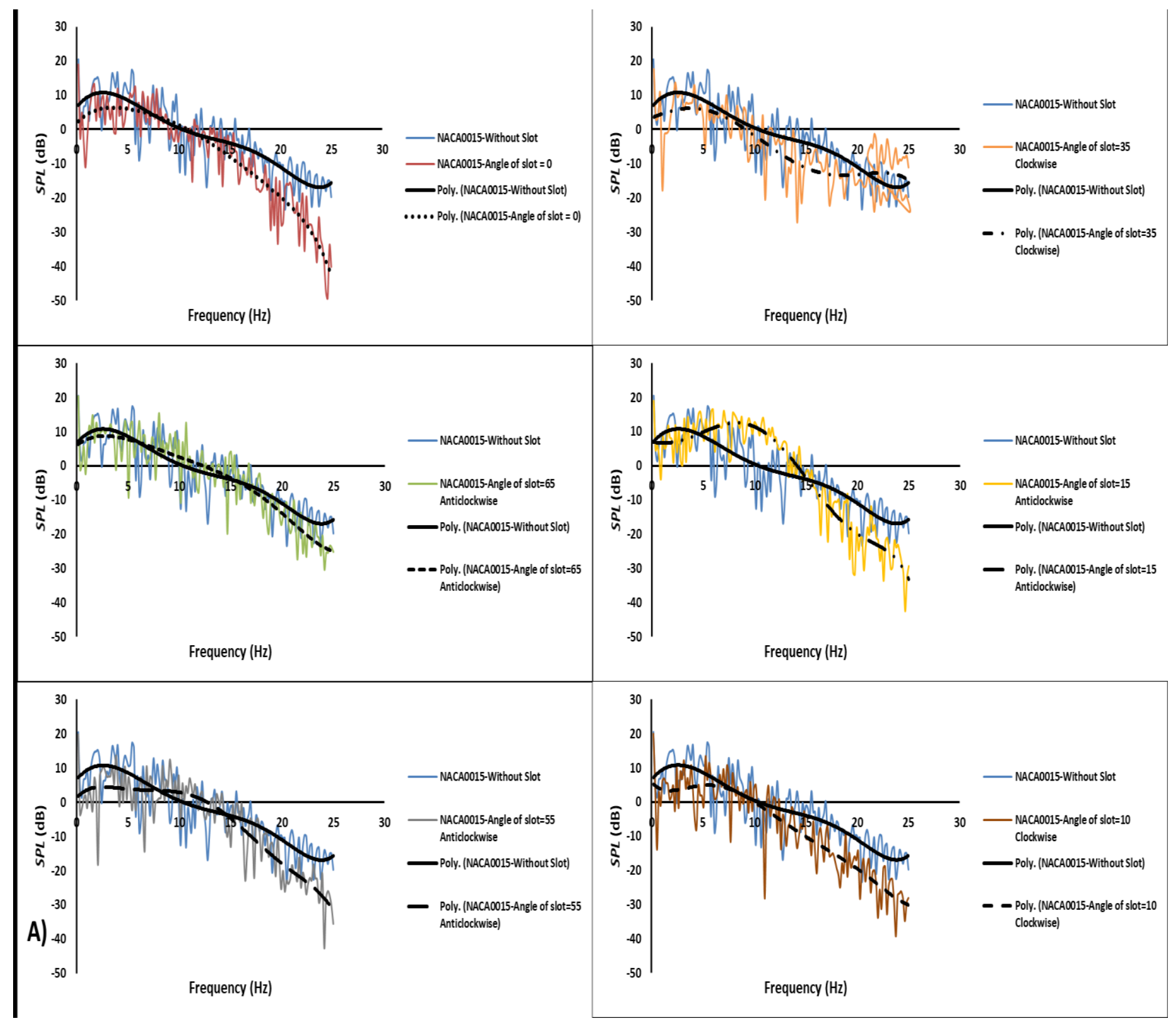




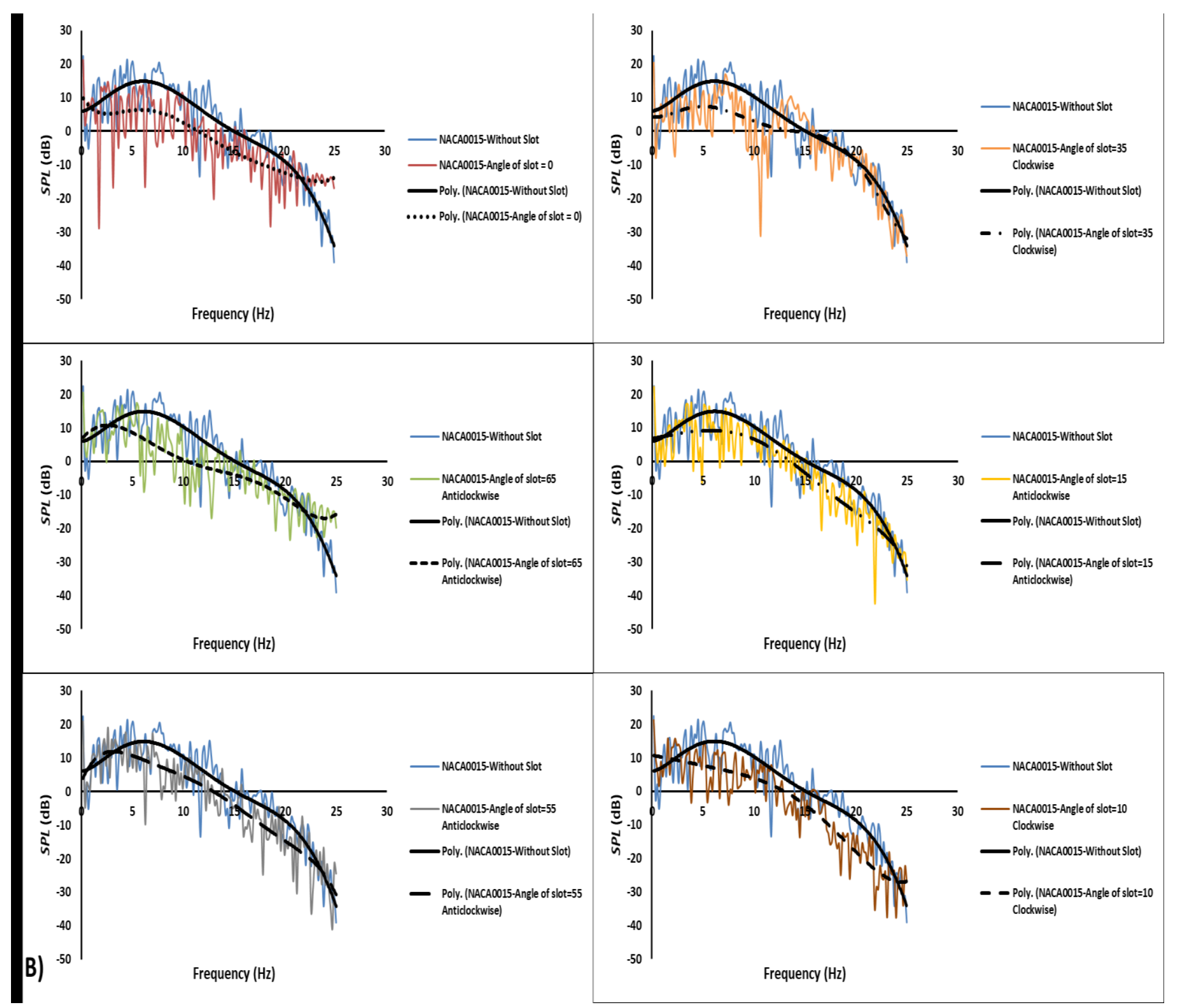




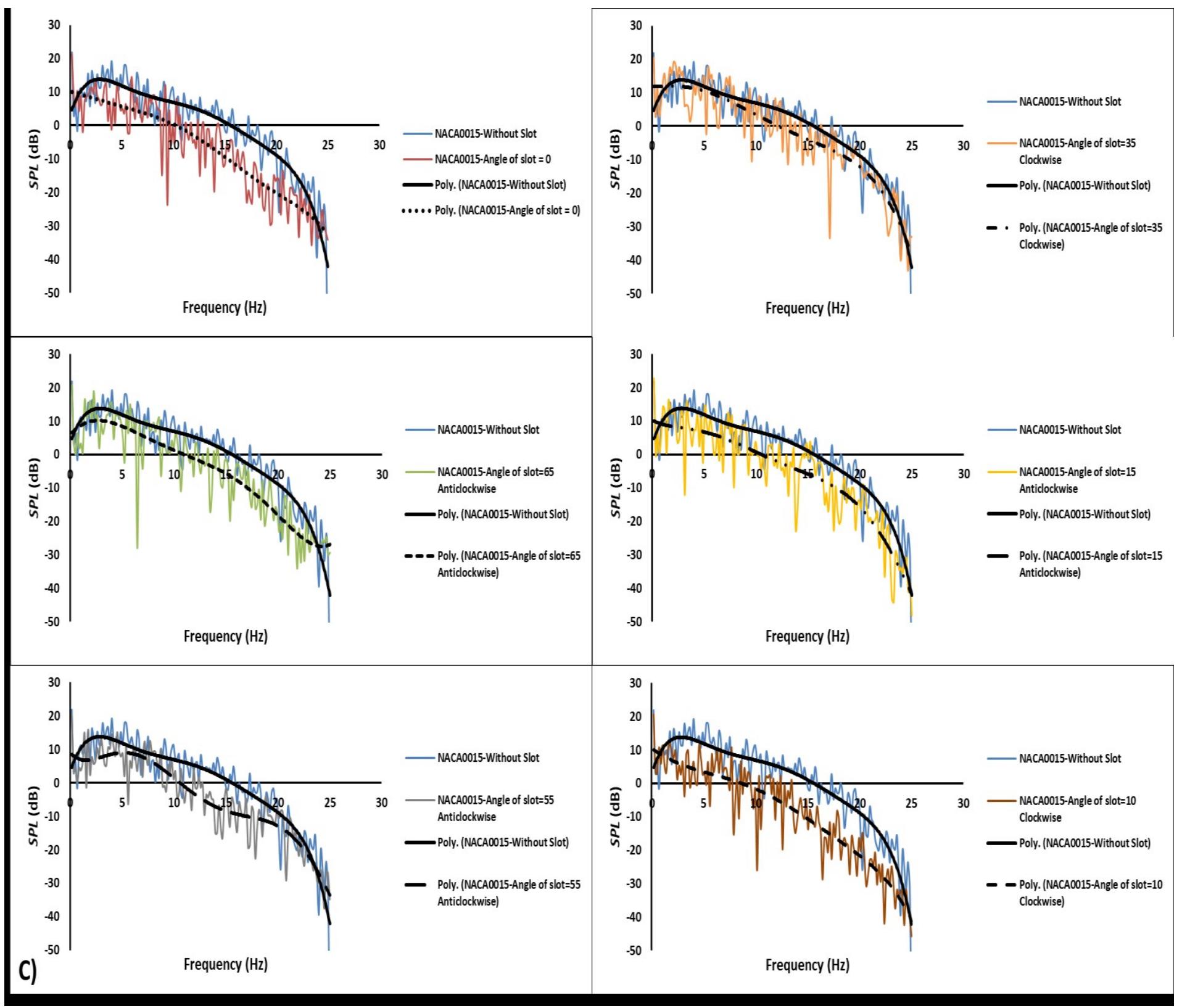

Figure 18 The Sound pressure level in dB for NACA0015 under oscillating velocity at a far field receiver located at 128 chord with different slot angle and different angles of attack $A) 11.7$ degrees

B) 13.6 degrees C) 14.4 degrees 

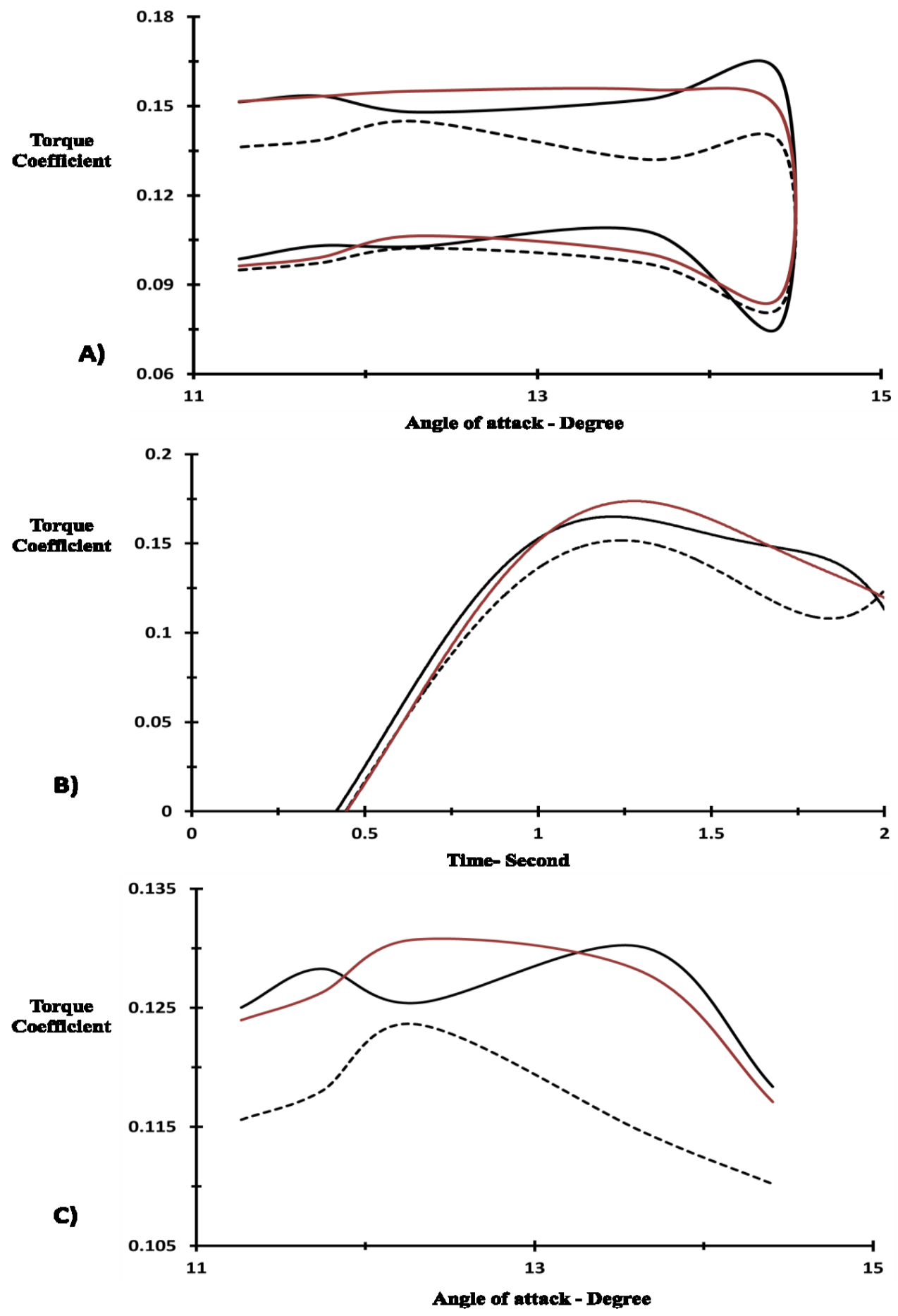

Figure 19 The NACA0015 without and with suction slot at optimum angle under sinusoidal wave with time period 4 second $(0.25 \mathrm{~Hz})$ "---without suction slot $-\alpha_{S S}=0$ degree" " $-\alpha_{S S}=10$ degrees clockwise $A$ ) The hysteretic behavior $B$ ) The instantaneous torque coefficient $C$ ) The average torque coefficient 

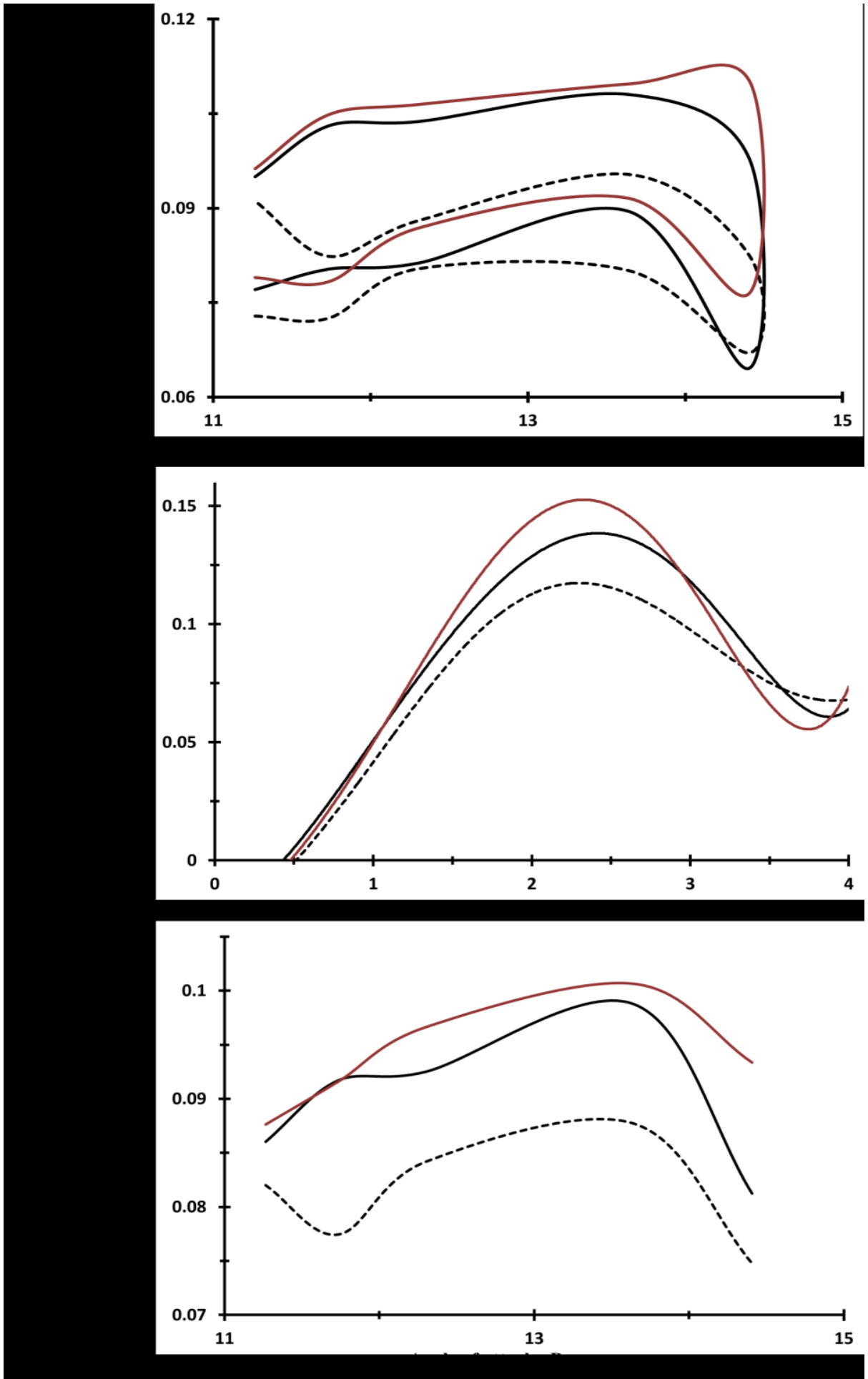

Figure 20 The NACA0015 without and with suction slot at optimum angle under sinusoidal wave with time period 8 second $(0.125 \mathrm{~Hz})$ " $=--$ without suction slot $-\alpha_{S S}=0$ degree", $-\alpha_{S S}=10$ degrees clockwise A) The hysteretic behavior B) The instantaneous torque coefficient C) The average torque coefficient 

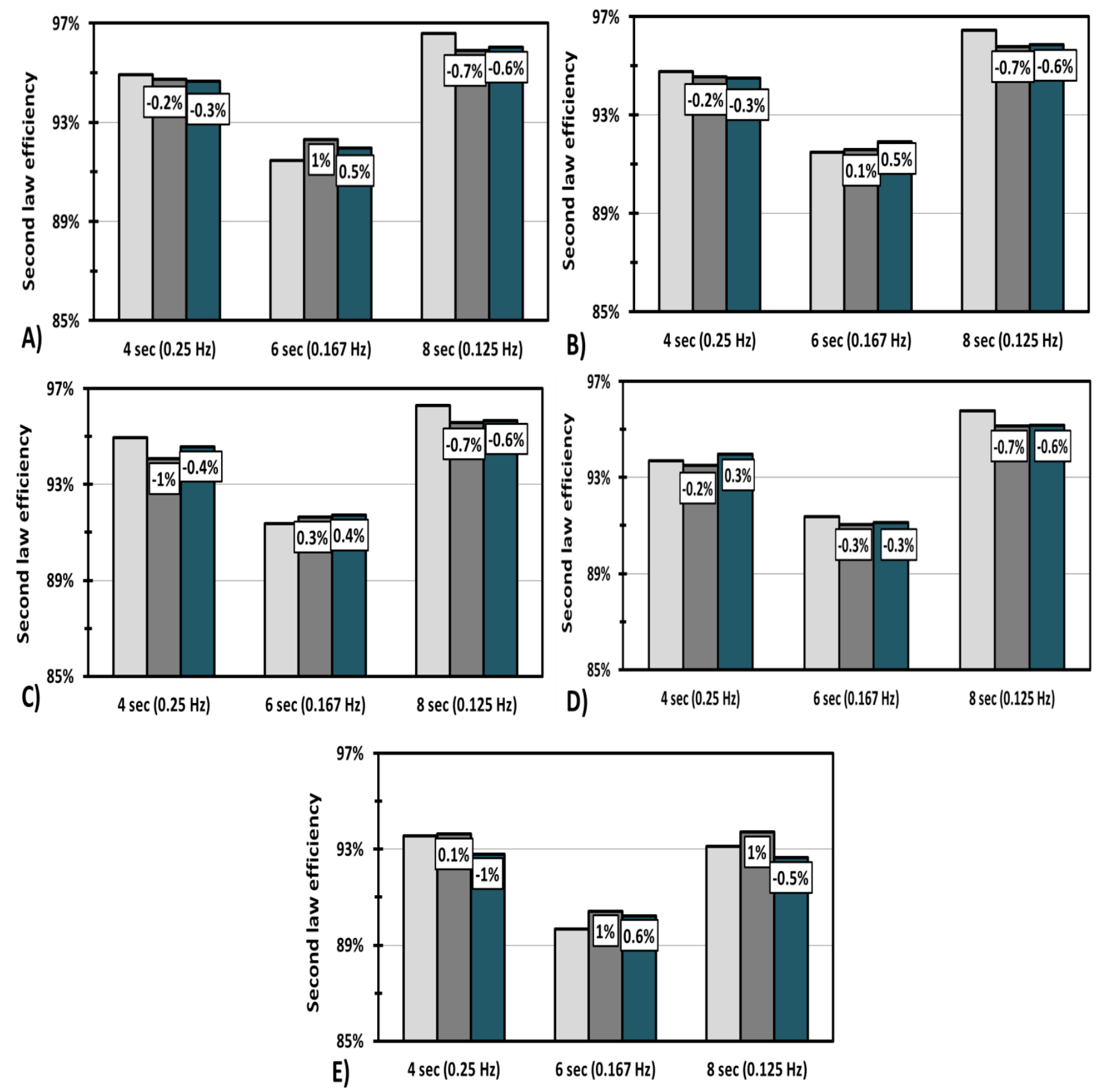

Figure 21 The second law efficiency at the compression cycle for the NACA0015 without and with suction slot at optimum angle with sinusoidal velocity and $t_{\sin }$ equal to $4 \sec (0.25 \mathrm{~Hz}), 6 \sec (0.167 \mathrm{~Hz})$, $8 \sec (0.125 \mathrm{~Hz})$ " $\square$ without suction slot $\square \alpha_{S S}=0$ degree", $\square \alpha_{s S}=10$ degrees clockwise A) 11.3. B) 11.7. C) 12.3. D) 13.6. E) 14.4. 


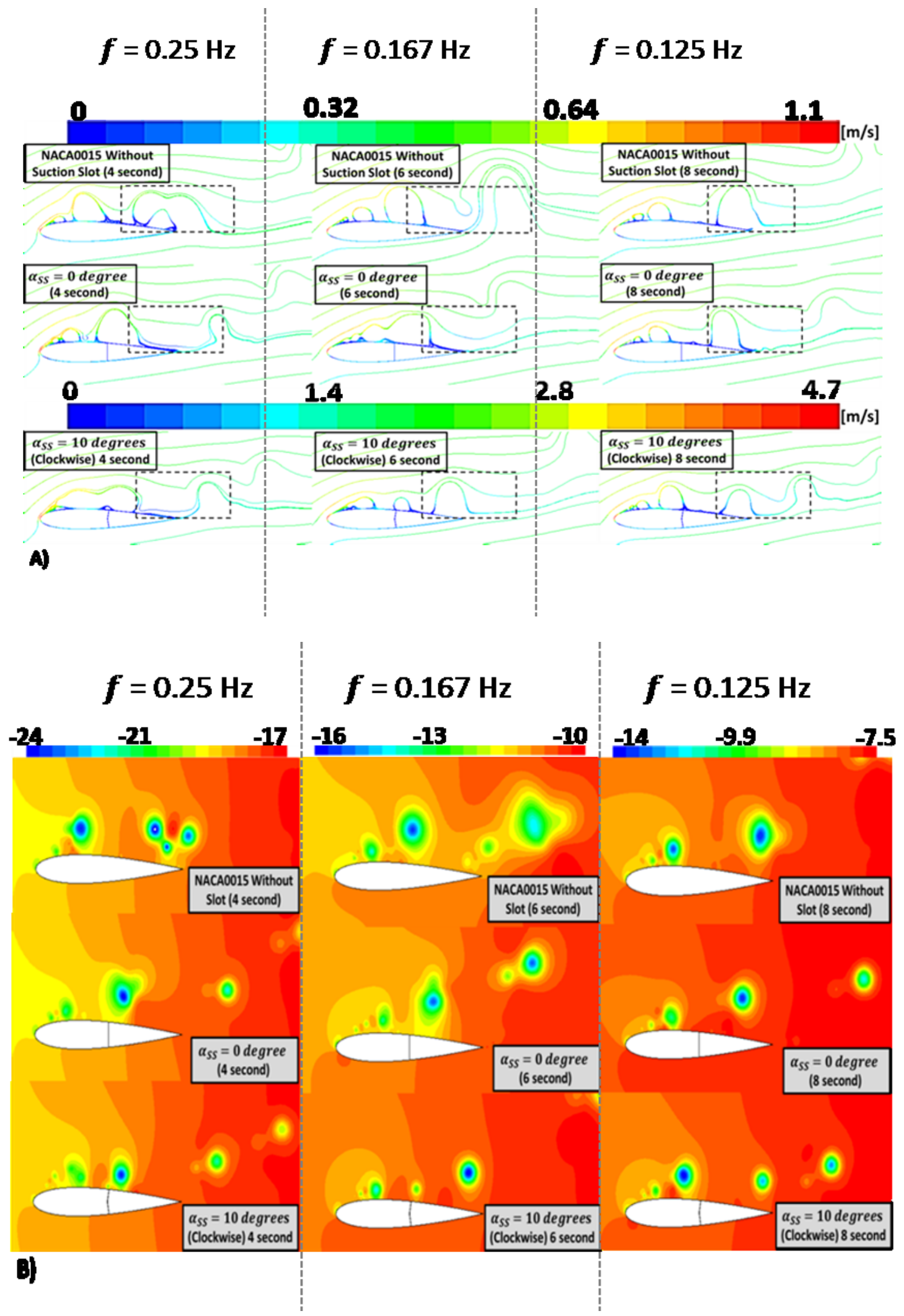




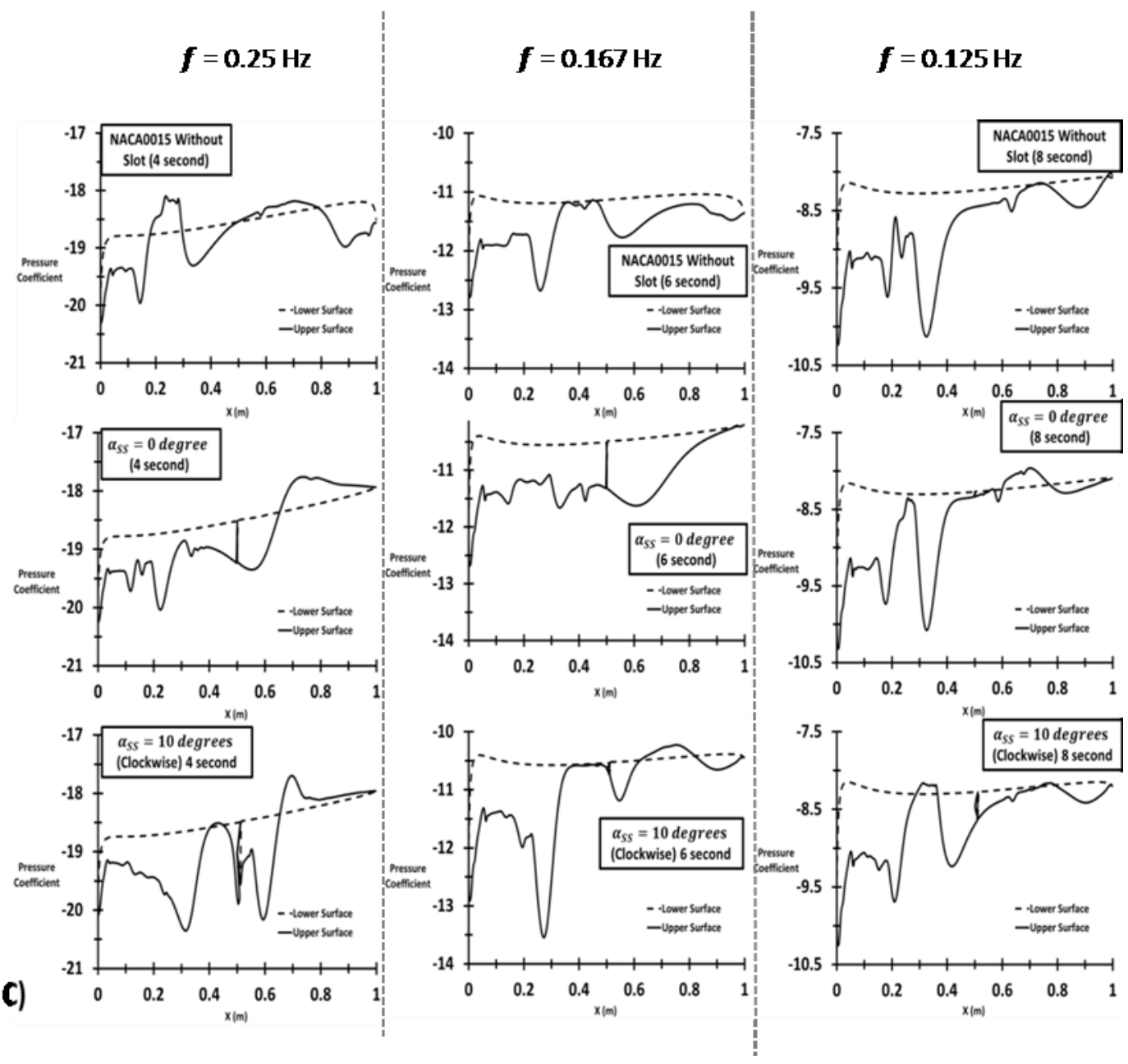

Figure 22 Flow structure around the NACA0015 and $t_{\text {sin }}$ equal to $4 \sec (0.25 \mathrm{~Hz}), 6 \sec (0.167 \mathrm{~Hz}), 8 \sec$ $(0.125 \mathrm{~Hz}) \mathrm{A})$ Path-line coloured by mean velocity magnitude B) Contour of pressure coefficient $C$ ) pressure distribution at upper and lower surface 


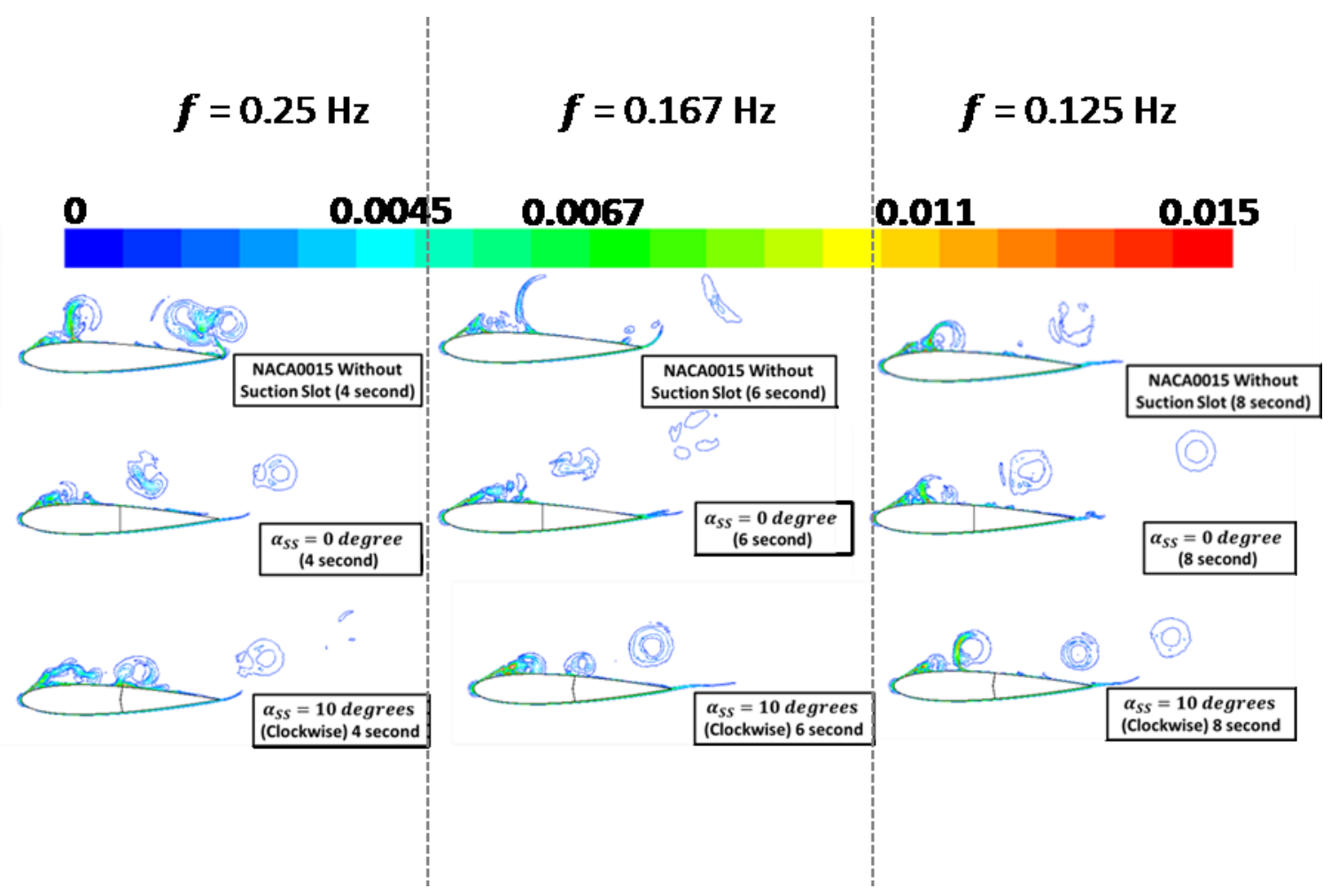

Figure 23 The sinusoidal flow around NACA0015 without slot and with the optimum angle of suction slot at decelerating flow and $t_{\text {sin }}$ equal to $\left.4 \sec (0.25 \mathrm{~Hz}), 6 \sec (0.167 \mathrm{~Hz}), 8 \sec (0.125 \mathrm{~Hz}) \mathrm{A}\right)$ Path-line coloured by mean velocity magnitude $B)$ Contour of global entropy generation rate 